\title{
HOW TEACHERS PERCEIVE THE ONGOING INFLUENCE OF A PORTFOLIO ON REFLECTION: \\ A CASE STUDY
}

By

My Binh Nguyen

\begin{abstract}
A thesis
submitted to the Victoria University of Wellington in partial fulfilment of the requirements for the degree of Master of Education
\end{abstract}




\begin{abstract}
This case study investigated the long-term influences of compiling a portfolio on resource teachers' (RTLB) reflection on practice. The findings provide a detailed analysis of the reflection that is stimulated by the portfolio process and the extent to which this has been ongoing in the RTLBs' practice. Compiling the portfolio stimulated the RTLBs' reflection on practice in a number of aspects, from selecting cases and evidence to writing, reading, collegial support, and professional supervision. It also promoted a more critical understanding of what it means to be a reflective practitioner. Among these, the writing involved in the portfolio process appears to be one of the most important factors in promoting reflection. However, reflective writing has not been maintained in the participants' current practice, whereas other aspects of reflection have, to some extent, continued. The overall quality of reflection has thus become more technical, albeit less deep, as it grows to cater for participants' professional needs. Much emphasis is put on formal/professional supervision and collegial support as important vehicles in maintaining the post-portfolio reflection. The former is deemed highly valuable because of the professional guidance and the sense of direction that a professional supervisor can offer as he/she triggers the RTLB's reflection, while the latter provides them with opportunities to share with their colleagues the things that they find useful, discuss the issues that they have in common, have their practice challenged and critiqued, and look at better practice. The establishment of communities of practice particularly stands out as an effective vehicle for sustaining reflection. The study includes recommendations for maintaining reflection in the post-portfolio phase, as well as for sustained portfolio use. Suggestions are also made for the application of portfolio assessment in the Vietnamese higher education system. Further research is recommended to expand the scope and scale of this study, as is collecting empirical evidence that would validate the findings in a Vietnamese context. A more thorough investigation into the Vietnamese higher education system and its cultural, social and political features is also recommended in order to generate a more detailed proposal for the application of portfolio assessment in Vietnam.
\end{abstract}




\section{ACKNOWLEDGEMENTS}

This thesis would not have been possible without the guidance and the help of several individuals who in one way or another contributed and extended their valuable assistance in the preparation and completion of this study.

First and foremost, my utmost gratitude goes to my supervisor, Dr. Liz Jones, whose guidance and encouragement I will never forget. Liz has given me invaluable input through her broad base of knowledge and her professional perceptiveness. I especially appreciate her taking the time to read and give me timely feedback despite her busy schedule. She has been my inspiration as I hurdle over all the obstacles in the completion of this research. She was not merely a teacher of a body of knowledge but also a role model in supervising, motivating and encouraging my independence.

I also would like to thank Dr. Don Brown and Dr. Lottie Thomson, who have helped me with selecting and contacting the participants for my research. Their kind support means a lot to me. I am also thankful to my participants for the valuable support and insights that they have offered. Without them, this study would not have been completed.

I am especially grateful to New Zealand Ministry of Foreign Affairs and Trade who granted me an NZAID scholarship for me to pursue my studies in New Zealand. I am thankful for their financial and spiritual support throughout my two years here. I also would like to express my sincere thanks to Ms. Le Thi Tuyet Ngoc, M.A. Dean of Faculty of Foreign Languages; Ms. Nguyen Thi Dieu Linh, M.A. - Head of 
the Department of English Language and Translation; and the board of directors of Hanoi University of Science and Technology for supporting my academic pursuit and granting me study leave.

To my family, I owe a special word of thanks for their ongoing support and love. My husband has been a most patient and supportive partner, who has in many ways put his own ambitions aside so that I could accomplish mine. My little son has been a delightful motivation for me throughout the journey. Finally, I dedicate this thesis to my loving parents who have always believed in me and encouraged me to pursue my academic dreams. 


\section{ABBREVIATIONS}

LOs Learning outcomes

RTLB Resource teacher/s; learning and behaviour

PDP Professional development programme 


\section{TABLE OF CONTENTS}

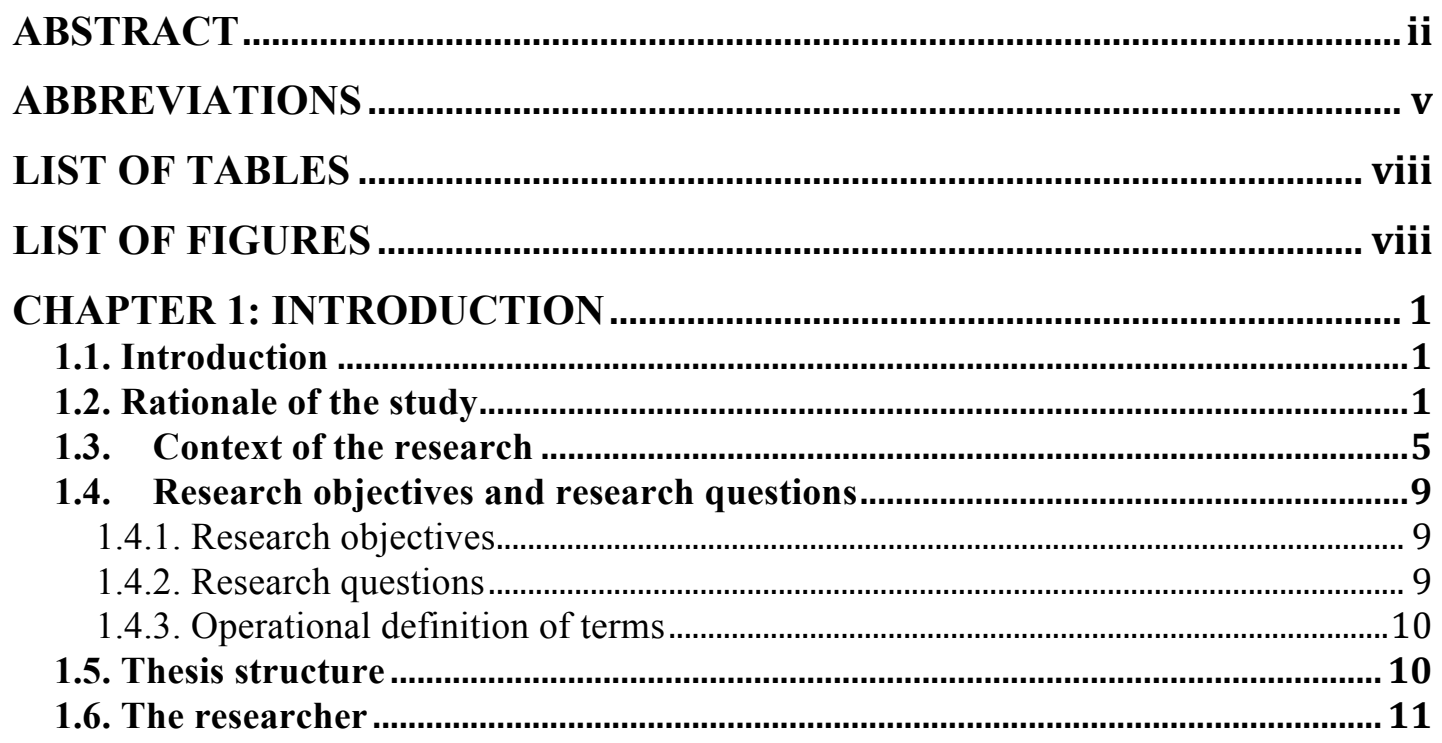

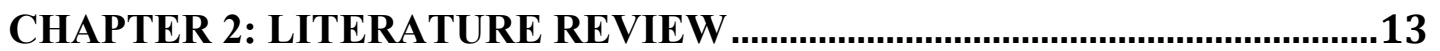

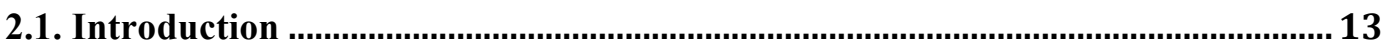

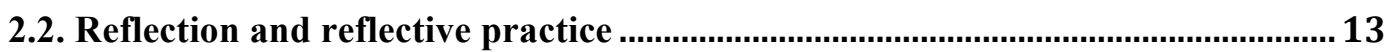

2.2.1. The conceptualization of reflection and reflective practice.....................................13

2.2.2. Definition of reflection and reflective practice............................................................22

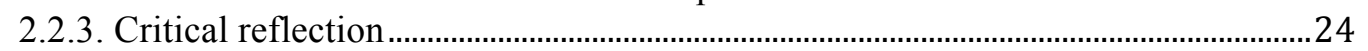

2.2.2. Benefits of reflective practice..................................................................................27

2.3. The role of portfolio assessment in promoting reflective practice ........................30

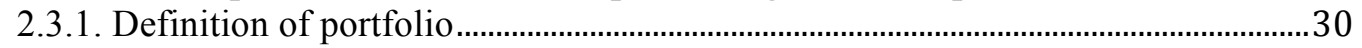

2.3.2. Portfolios as an assessment tool ............................................................................ 32

2.3.3. The relationship between portfolio assessment and reflection.................................37

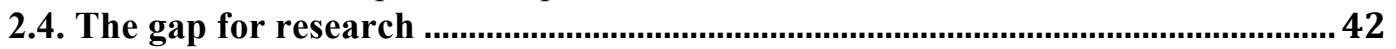

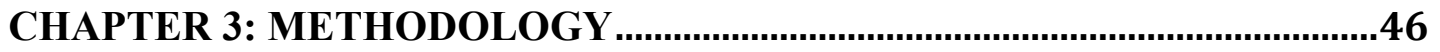

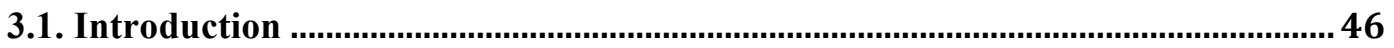

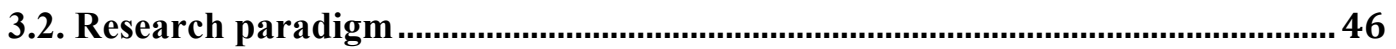

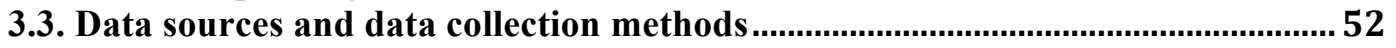

3.3.1. Participants .......................................................................................................... 52

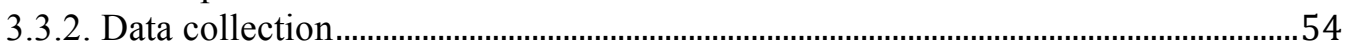

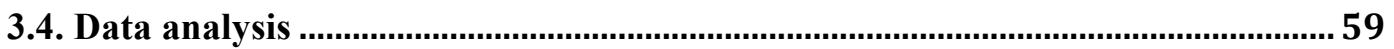

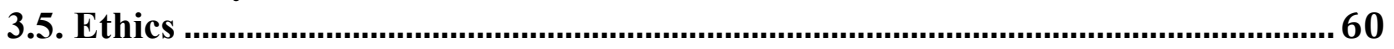

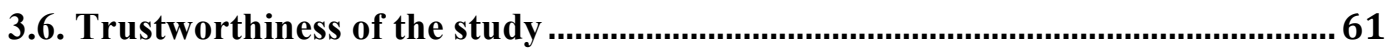

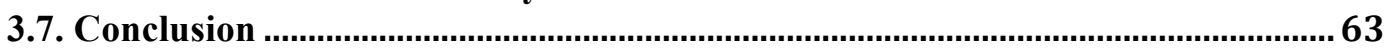

CHAPTER 4: TEACHERS' PERCEPTION OF THEIR OWN REFLECTION

DURING THE PORTFOLIO PROCESS........................................................64

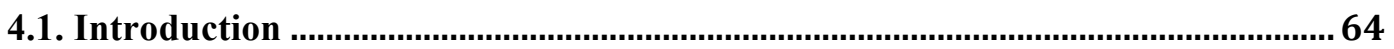

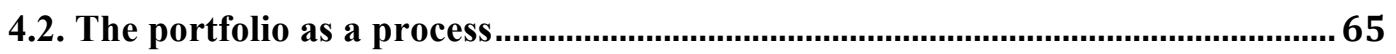

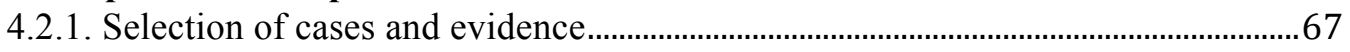

4.2.2. Annotating and writing ........................................................................................ 69 
4.3. Reading and theoretical literature ....................................................................... 71

4.4. Collegial support and professional supervision...................................................... 72

4.5. Developing a more critical understanding of the term "reflective practitioner"

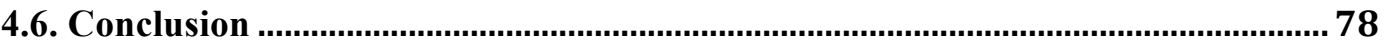

\section{CHAPTER 5: ON-GOING INFLUENCES OF COMPILING THE} PORTFOLIO ON TEACHERS' REFLECTION ON PRACTICE .....................80

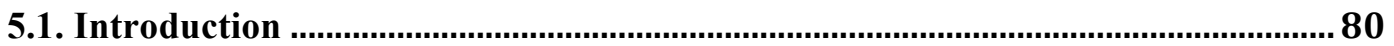

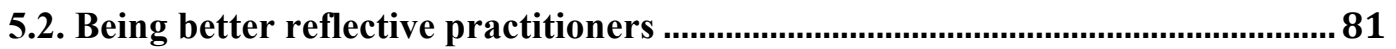

5. 3. Ongoing reflection on the learning outcomes of the programme and setting them as standards for practice ....................................................................................... 85

5.4. Being research-based practitioners......................................................................... 89

5.5. Ongoing influences on the collection, management and presentation of data.... 93

5.6. Conclusion

CHAPTER 6: MAINTAINING THE INFLUENCES OF THE PORTFOLIO

ON TEACHERS' ONGOING REFLECTION ON PRACTICE ...................... 100

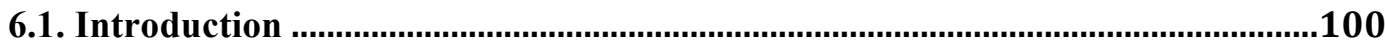

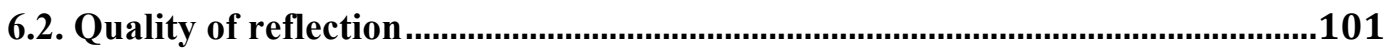

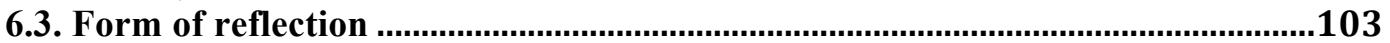

6.4. Maintaining the reflection: Formal supervision ................................................107

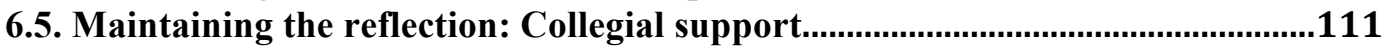

6. 5.1. Collegial support within cluster....................................................................... 112

6.5.2. Collegial support across clusters/ Community of practice .................................... 115

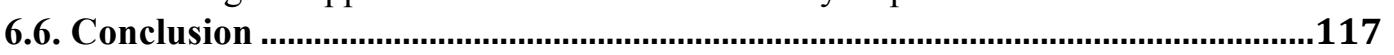

CHAPTER 7: DISCUSSION, IMPLICATIONS AND CONCLUSION.......... 119

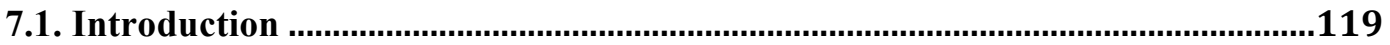

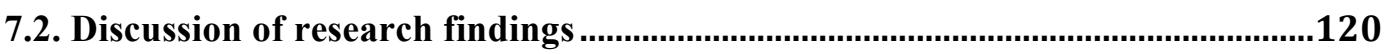

7.2.1. Reflection promoted by the portfolio process......................................................... 120

7.2.2. Sustained aspects of reflection after the portfolio experience ................................ 122

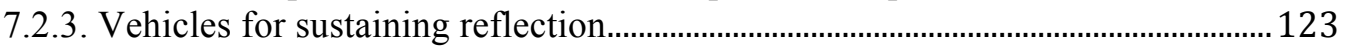

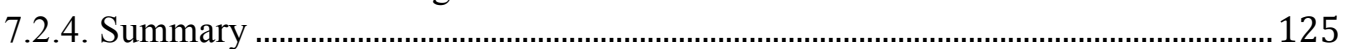

7.3. Implications for practice ...................................................................................128

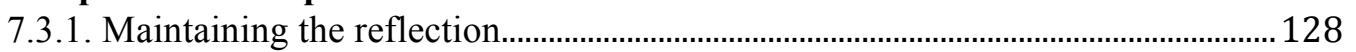

7.3.2. Sustained portfolio use ............................................................................................... 130

7.3.3. Implications for portfolio use in the Vietnamese education context................... 131

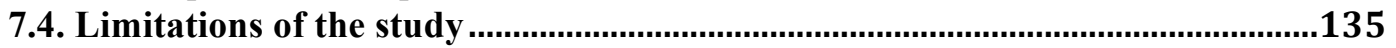

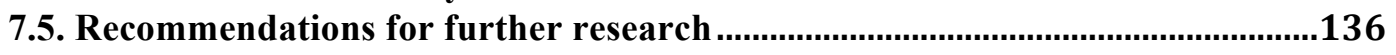

7.6. Conclusion ......................................................................................................................137

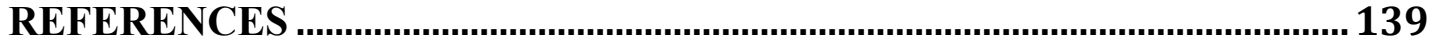

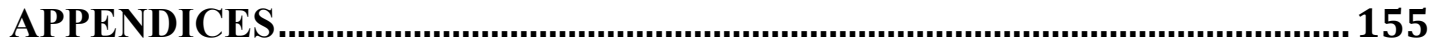

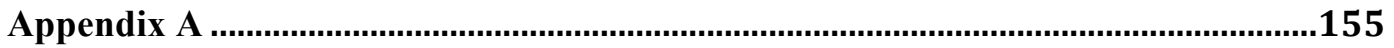

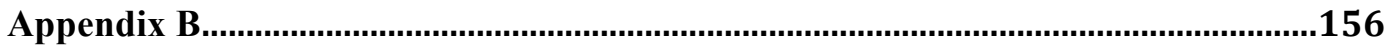

Appendix C ..............................................................................................................................157

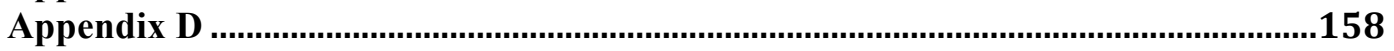

Appendix E..............................................................................................................................159

Appendix F ......................................................................................................................161 


\section{LIST OF TABLES}

Table 2.1: Overview of reflective authors' views about reflection (Dimova \& Loughran, 2009, p. 213)

Table 3.1: Comparison of general research traditions (Hancock \&Algozzine, 2006, p. 10)

Table 3.2: Characteristics of participants

Table 3.3: Summary of relative merits of interview versus questionnaire

(Tuckman, 1972, as cited by Cohen et al., 2007, p. 352)

\section{LIST OF FIGURES}

Figure 2.1: The critical reflection process (Laurie Peterman, as cited in Brookfield, 1995, p. 30)

Figure 2.2: Conceptual framework for reflection (Jones, 2007, p. 55. Adapted and expanded from LaBoskey, 1993)

Figure 2.3: Matrix of portfolio uses related to various forms of assessment (Smith \& Tillema, 2001, p. 185)

Figure 2.4: Routes in sustained use of portfolios (Smith \& Tillema, 2001, p. 200)

Figure 3.1: A graphical illustration of the research process adopted in this study

Figure 7.1. Conceptual framework for ongoing influences of the portfolio process on teachers' reflection on practice 


\section{CHAPTER 1: INTRODUCTION}

\subsection{Introduction}

This thesis investigates portfolio assessment as a formative process and its long-term influences on teachers' reflection on practice. More specifically, it seeks to reveal the participants' perceptions of their own reflection during and after the portfolio process, as well as the ways in which this reflection has been maintained in their practice after the portfolio experience ended.

This chapter sets the scene by presenting the rationale of the study, followed by a description of the research context. The research objectives and research questions of the study will also be addressed. Then, a description of the thesis structure will highlight the main points in each chapter. A biographical sketch of the researcher will conclude this chapter.

\subsection{Rationale of the study}

Over the past two decades, concern over the quality of education and training in the Vietnamese higher education system has been increasing remarkably. Since the implementation of the economic reform policy in 1986, the country has gone through major transformations that have affected every aspect of economic and social life, including education. The nation has come to recognize the importance of a "knowledge society" in which the quality of teachers plays a key role, as demonstrated in Vietnam's Education Law in 1998 (Article 14) and 2005 (Article 15). More recently, the country's accession to the World Trade Organization in 2007 has put even more pressure on the higher education system by introducing the concept of "world-class universities", which has been more and more emphasized as 
the goal for which to strive. More than ever, the improvement of the quality of teaching and learning has become a national priority.

However, in reality, the Vietnamese education system in general, and its higher education system in particular, is facing many problems, one of which is the loose control over the quality of teaching. This is partly due to a teacher-centered approach, in which teachers are unreflective and maintain their roles in transmitting unproblematic knowledge to passive students (Hua, 1998; Nguyen, 2003; Sloper \& Le, 1995). Furthermore, teachers are particularly respected in Vietnamese social and spiritual life (Hua, 1998; Nguyen, 2003), which has, to some extent, hindered the assessment of their teaching performance (Tran, 2004; Vu, 2004).

The form of assessment that has been used so far in the Vietnamese education context is summative assessment, for which the criteria that have been used are subjective and not scientifically reliable, thus negatively affecting the outcomes of the assessment (Tran, 2006). In that sense, this summative assessment often serves only the most basic purposes of assessment without addressing its wider and deeper intents (Le, 2008). It aims at evaluating lecturers' performance rather than encouraging improved practice or the elevation of students' achievements. Furthermore, the assessment process is mostly conducted internally, where colleagues openly comment on one another's performance. Such a method appears to be ineffective because it neither reflects teachers' quality accurately nor encourages them to improve themselves professionally. On the other hand, formative assessment to enhance the professional skills of teachers (Danielson, 1996; Griffin, 1995) has been limited.

Such a context presents an apparent need for the introduction of other forms of teacher assessment into the Vietnamese higher education system. Given the 
government's priority for improving the quality of teachers, it is necessary to look for tools for formative assessment that encourage teachers to reflect on their teaching practice and continue to grow professionally. My postgraduate learning experience at Victoria University of Wellington introduced me to the concept of portfolio assessment, and I am convinced that this may serve as one possible solution to our problems. Over the past two decades, the use of portfolios in teacher education has been widely embraced by many countries in the world as an effective tool for teacher assessment and professional development. A considerable amount of literature has addressed the benefits of portfolio assessment in promoting quality learning (e.g., Ashford \& Deering, 2003; Jones, 2009; Smith \& Tillema, 1998; Strijbos, Meeus, \& Libotton, 2007; Wade \& Yarbrough, 1996; Woodward, 1998, 2000). The process of compiling the portfolio, which involves collecting evidence and reflecting on this evidence, is believed to not only encourage trainee teachers to take responsibility for their own learning, but also allow them to connect their personal theories with practice (Davies \& LeMahieu, 2003; Shulman, 1998). A large body of research also claims the benefits of a portfolio in promoting reflective practice (Antonek, McCormick, \& Donato, 1997; Biggs, 1998; Borko, Michalec, Timmons, \& Siddle, 1997; Jones, 2010a; Mokhtari, Yellin, Bull, \& Montgomery, 1996; Setteducati, 1995; Winsor, Butt, \& Reeves, 1999). The portfolio is thus regarded as an important tool for formative assessment in teacher education (Zeichner \& Wray, 2001).

The fact that portfolio assessment still remains an approach that has not been adopted in Vietnam, despite its worldwide-acknowledged benefits, opens up a wide door for research. Given the nation's existing problems in quality control and assessment of teachers, an introduction to the concept of portfolio assessment could be of great value in the reform of the Vietnamese education system. Vietnamese 
educational authorities have been open to new concepts, philosophies and practices from other parts of the world, as demonstrated by the increasing adoption of modern (Western) teaching and learning approaches in Vietnam (Pham, 2008). Examples of such approaches include student-centered learning, team work, and cooperative learning. In that light, the researcher intends to make use of the New Zealand educational experience to gain a practical insight into the concept of portfolio assessment so as to be able to introduce it to the higher education community in Vietnam. Due to the limited scope of the research, I have chosen to focus on the aspect of portfolio assessment that promotes reflection among teachers, since it directly addresses the problems in the Vietnamese higher education context as described above. The purpose of this qualitative study is therefore to investigate portfolio assessment as a formative process and the quality of the reflection that it facilitates among teachers. More specifically, this research seeks to reveal teachers' perceptions of the ongoing influence of the portfolio experience on their reflection on practice.

It is believed that the purpose of this study particularly aligns with the Vietnamese government's strategic plans for educational reform, and that it will have practical implications for applying portfolio assessment in Vietnam. As pointed out by Pham (2008), the adoption of a foreign philosophy or practice must go hand-in-hand with a thorough understanding of the concept and how it works, so that necessary modifications can be made when it is implemented in this new context. In that light, even though the study is not set in Vietnam, the lessons learnt from the implementation of portfolio assessment in the New Zealand context can provide valuable knowledge that may serve as a foundation for future empirical research in the Vietnamese education context. 


\subsection{Context of the research}

The study is conducted within the context of EPSY 564, a postgraduate paper taught as part of a professional development programme (PDP) that was designed and delivered by a consortium of three New Zealand universities to provide training for Resource Teachers: Learning and Behaviour (RTLB) in New Zealand. The role of the RTLB is to support students who have been identified by their teachers as being at risk of not achieving or have special educational needs. RTLB are also expected to work as a collaborative problem-solver to develop and implement strategies to address those needs. In order to fulfill this role, RTLB need to support teachers to make changes so that the New Zealand curriculum is accessible to all students. They also need to support structural change in schools and classrooms so that the students' special needs are met in regular classrooms (Jones, 2007). There are thus seven intended learning outcomes (LOs) of the PDP:

An RTLB will:

1. Work to a high professional and ethical standard

2. Work to improve learning and behavioural outcomes for Māori students

3. Work to ensure equitable educational opportunity for all learners

4. Follow an educational/ecological model

5. Work to a collaborative problem solving model

6. Be skilled practitioners and promoters of effective teaching skills

7. Be reflective practitioners.

(EPSY 564, 2010) 
There are four papers in the PDP, the first three of which focus on the student contexts, classroom contexts, and school and community contexts respectively. The fourth paper (EPSY 564), which is the main research context of this study, focuses on the development and refinement of quality RTLB professional practice. It requires the RTLB to compile a portfolio of cases and projects from their authentic work that demonstrate that they have met the seven LOs of the PDP.

The paper is delivered in a seminar format with cooperative learning methodology, discussion of practice, and supervision of practical assignments. Assessment is conducted based on the presentation of a portfolio. The definition of a portfolio for the purposes of this paper is as follows:

A portfolio is a selective collection of teacher work gathered across diverse contexts over time, framed by reflection and enriched through collaboration that has as its aim the advancement of teacher learning (EPSY 564: Paper Four Course Outline, 2010, p. 1).

The portfolio aims at the following goals:

- To enhance the understanding of the work of the RTLB

- To enable RTLB to select evidence from their authentic work that they consider is most appropriate and explicit to demonstrate their effective practice

- To enable RTLB to make direct links from the theory that informs their work to their practice

- To encourage RTLB to work collegially to document their practice, critically analyse it, select evidence that clearly demonstrates effective practice 
- To critique their own practice against best practice, outcomes of the programme and their own personal philosophy

- To report on their work in a coherent and professional manner.

(EPSY 564, 2010)

The portfolio consists of three parts, all of which are presented in a portfolio format.

\section{Portfolio: Part One (10\%)}

The purpose of this task is to provide RTLB with the opportunity to receive feedback to ensure that they have a good understanding of the requirements of a portfolio before they complete the next two parts of the portfolio. This assessment task requires RTLB to submit a case to demonstrate their achievement of their understanding and application of the collaborative problem-solving process and ecological assessment. The standard of professional and ethical practice demonstrated is also assessed. The LOs assessed in this assignment are 1, 3, 4, 5 and 7.

\section{Portfolio: Part Two: Māori portfolio (25\%)}

The purpose of this task is to provide RTLB with the opportunity to submit one case to ensure they have a good understanding of the Māori cultural perspectives and issues of their work. The goal is to have them select material that represents their efforts in working with teachers and whanau to enhance learning opportunities and to improve behavioural directions for Māori children. RTLB demonstrate their achievement of LO number 2 in any of three contexts (i.e. individual, classroom and school/community). The standard of professional and ethical practice demonstrated is also assessed. RTLB are also required to include a reflective statement to provide evidence of LO 7. 


\section{Portfolio: Part Three (65\%)}

This consists of three cases/projects demonstrating effective practice across the three contexts (i.e., individual, classroom and school/community). The standard of professional and ethical practice demonstrated is also assessed. RTLB are required to include a reflective statement for each case and a concluding statement for the whole portfolio. The LOs assessed in this assignment are 1, 3, 4, 5 and 7.

The presentation of cases/projects consists of a brief outline of what RTLB did and the outcomes of these actions. In order to demonstrate how these actions are examples of quality practice, RTLB have to provide supporting documentation, which can be in a variety of forms such as records of meeting, observations, interviews, case notes, planning forms, transcripts of interviews, photographs and case reports. The RTLB must also provide commentaries on their actions and documentation to explain how what they did was effective, grounded in recognised good practice, and demonstrated the LOs of the PDP. Finally, the reflective statements that conclude each case/project require RTLB to consider and comment on certain issues, such as how consistent their actions were with their intentions, their personal theory, established practice and the wider socio-political and ethical issues of their practice.

By presenting the cases, RTLB are expected to demonstrate that their practice is competent; that they work within their limits of competence; that they recognize issues of confidentiality, duty of care and conflict of interest, and that their practice can be shown to be valid educationally. They must also demonstrate that they work effectively across the three contexts (i.e., individual, classroom and school/community). This means that they must have one case in each context. Finally, RTLB are expected to demonstrate reflection by including a concluding 
statement that draws all the elements of the portfolio together. (EPSY 564: Paper Four Course Outline, 2010, pp. 3-8)

\subsection{Research objectives and research questions}

\subsubsection{Research objectives}

The research seeks to reveal the perceptions of RTLB on ongoing influences of the portfolio experience on their reflection on practice. In particular, the three objectives of this study are:

1. To explore the participants' engagement in reflection during the portfolio process.

2. To investigate which aspects of reflection that were stimulated by compiling the portfolio have been maintained in the participants' practice since the portfolio experience ended.

3. To examine the conditions under which the reflection has been maintained in the participants' practice since the portfolio experience ended.

\subsubsection{Research questions}

The specific research question being addressed by this research is: What are the perceptions of on-going influences of compiling a portfolio on teachers' reflection on practice?

The following are sub-questions:

1. How do teachers perceive their reflection during the portfolio experience?

2. What aspects of reflection on practice that were stimulated by the portfolio process have continued after the portfolio experience ended? 
3. How have these aspects been maintained after the portfolio experience ended?

\subsubsection{Operational definition of terms}

Reflection: A process of critically examining one's present and past practice as a means of building one's knowledge and understanding in order to improve practice (Jones, 2007).

A portfolio: a selective collection of teacher work gathered across diverse contexts over time, framed by reflection and enriched through collaboration that has as its aim the advancement of teacher learning (EPSY 564, 2010).

Portfolio experience: The process of compiling the portfolio during participants' enrolment in the fourth paper of EPSY 564 (Professional Practice: The Portfolio).

\subsection{Thesis structure}

This thesis includes seven chapters. This chapter, which serves as an introduction to the thesis, sets the scene by presenting the rationale of the research, as well as the research objectives and research questions.

Chapter Two sets up a theoretical background for this study through a review of relevant literature. It discusses the literature specifically related to the study: reflection and reflective practice, the role of reflection in teachers' professional development and assessment, the portfolio and its role in promoting reflection on practice. A gap in research will also be highlighted, thus validating the significance of the study.

Chapter Three describes the methodological approach of this study. In this chapter, the choice of a qualitative approach and the selection of the case study are presented and explained. A detailed description of the data collection and analysis processes 
will be provided. The trustworthiness of the study will also be discussed in this chapter.

Chapter Four addresses the first research question, which seeks to reveal the participants' perception on their own reflection during the process of compiling the portfolio. It aims to examine the different aspects of reflection that were stimulated by compiling the portfolio.

Chapter Five addresses the second research question, which seeks to investigate the ongoing influences of the portfolio on teachers' reflection on practice. In particular, it aims at finding out which particular aspects of reflection that were stimulated by compiling the portfolio have been maintained since the portfolio experience ended.

Chapter Six investigates the way in which teachers' reflection on practice has been maintained since they completed the portfolio. It discusses the vehicles that have assisted the sustenance of participants' reflection in their current practice.

Chapter Seven summarizes and ties together some of the main issues addressed under each of the three research questions. This is followed by a discussion of the implications for practice based on the findings from the study. Recommendations for future research will also be presented in this chapter, as well as limitations of the study.

\subsection{The researcher}

I have been working as a teacher of English at Hanoi University of Technology (Vietnam) since 2005. Before that, I was trained to become either a teacher or a translator/interpreter and had a Bachelor's degree in English as a Foreign Language. For the four years that I taught at Hanoi University of Technology before I came to New Zealand, I was always interested in professional development for teachers. This 
is partly due to the fact that despite my four years of experience, I am still considered a novice in this highly demanding profession. I am thus intrinsically motivated to improve my practice and become a better teacher. Another reason for my interest in teachers' professional development (PD) is the lack of PD programs at my work place, despite it being one of the top universities in the country. From what I have observed, the loose control over teachers' quality assessment in Vietnam has not stimulated the need for improved practice, and thus limited the chance for PD programs. This poses a big challenge for young teachers like me who want to improve but lack the necessary support to do so. Most importantly, the lack of reflection in Vietnamese teachers' practice manifests itself as a major issue to me. I personally believe that teaching and learning are complex processes that require teachers to constantly reflect on their past and current practice in order to meet students' needs. My study in New Zealand has opened up an opportunity for me to look further into this area of interest and learn about new concepts that may allow me to make a difference when I go back home. It is my dream to lend a hand in promoting sustained professional development among teachers in Vietnam. This is the driving force behind my journey so far and will continue to be a driving force in the future. 


\section{CHAPTER 2: LITERATURE REVIEW}

\subsection{Introduction}

The previous chapter outlined the three main objectives of this study, which are to explore the participants' engagement in reflection during the portfolio process, to investigate which aspects of reflection that were stimulated by compiling the portfolio have been maintained in the participants' practice since the portfolio experience ended, and to examine the conditions under which the reflection has been maintained in the participants' current practice. In order to achieve these aims, an understanding of the theoretical background of the study is needed before providing a description of an appropriate methodology.

This chapter reviews the body of literature that is relevant to the research objectives. Since the main focus of the study is on reflection and reflective practice, it is important to define these terms and address the studies that have been conducted so far in the area of interest. Literature regarding the portfolio and its use in teachers' assessment and professional development, especially in promoting reflection, will also be reviewed.

\subsection{Reflection and reflective practice}

\subsubsection{The conceptualization of reflection and reflective practice}

Over the past two decades, reflection and reflective practice have been regarded as an approach to practice towards which teachers and teacher educators must strive (Gore \& Zeichner, 1991; LaBoskey, 1993; Rodgers, 2002). The origin of the notion 
of reflection dates back to early twentieth century, when psychologist and educationalist John Dewey introduced reflective thinking as a distinctive form of thinking in that it involves "(1) a state of doubt, hesitation, perplexity, mental difficulty, in which thinking originates, and (2) an act of searching, hunting, inquiring, to find material that will resolve the doubt, settle and dispose of the perplexity" (Dewey, 1933, p. 12). In his argument, Dewey highlights the need for reflective practitioners to not only question their experience but also to apply their reflective thinking to practice. Dewey asserts that this depends on the practitioner's attitudes of open-mindedness, whole-heartedness, and responsibility. A reflective practitioner is thereby characterized as someone who is open to new ideas and findings, and willing to listen to opinions different from their own; engage wholeheartedly in the process of thinking and reflection; and is responsible for the consequences of their actions.

According to Dewey, there are five overlapping phases in the process of reflection. The first phase is identifying the problem, understanding its causes and its complexity. The second phase involves the generation of suggestions as one is faced with the identified problem. In the third phase, hypotheses are built by considering ways that such suggestions can be applied in practice. The fourth phase ensures the appropriateness of the hypotheses by drawing from relevant materials that assist with the justification of the choice being made and its development into something applicable. The final stage puts the chosen hypotheses to the test, which is bound to produce either positive or negative results. In Dewey's argument, negative results do 
not manifest themselves as obstacles or failures; on the contrary, they tend to promote learning and reflection.

Van Manen (1977) contributes to the conception of reflection by identifying three distinctive levels of reflections, the first of which focuses on the technical side of teaching, (i.e., treating teaching episodes as isolated events). The second level appears to be more advanced, since it puts into consideration the theory and rationale for the current practice. The highest level incorporates the ethical, social and political aspects of one's practice into their reflection. In van Manen's argument, this level is the most important because it leads the practitioners towards more informed understandings of their practice $(1977,1991)$. Van Manen addressed this level by the term "critical reflection", the notion of which will be further discussed later in this chapter. It should be noted that although many researchers advocate the hierarchical nature of van Manen's levels of reflection, others (e.g., LaBoskey, 1993) assert that these ought to be treated as foci of reflection rather than levels. In other words, none of these levels are necessarily "higher" or more sophisticated than the others as different situations may involve reflection on different issues within those foci.

Another writer whose work has greatly influenced the conceptual development of reflective practice is Donald Schön $(1983,1987)$, who introduced the concept of reflective practice; this involves thoughtful considerations of one's own experiences in applying knowledge to practice. Schön thus sees reflective practice as a critical process that allows novice practitioners to draw from others' experience in order to refine their own skills and professionalism. Schön also emphasizes the "complexity, 
uncertainty, instability, uniqueness, and value-conflict" (1983, p. 39) in regard to professional practice. His viewpoint thereby challenges the traditional positivist view of professionalism as a decision-making process that is solely based on the expertise obtained from previous training. In Schön's argument, a reflective practitioner must combine textbook expertise and field knowledge to define the important issues and the contexts in which these issues should be positioned. Accordingly, a reflective practitioner must be able to deal flexibly with a changing environment by asking himself/herself questions about the basis of his judgment, as well as the influences and considerations that impact his choices. This point of view is further supported by Lyons (1998) who asserts that reflective thinking requires linking together experiences to make conscious the teacher's knowledge and understanding of practice. Accordingly, a reflective practitioner must learn not only the subject knowledge, but also the way to engage in dynamic professional relationships and to establish meaningful connections between theory and practice in order to provide a rationale for their actions.

Schön $(1983,1987)$ also took the initiative in introducing the concepts of reflectionin-action and reflection-on-action. Reflection-in-action, as defined by Schön, is the reflection that occurs somewhat consciously while a professional is addressing a problem in the so-called "action-present." It challenges the professional's assumptions that are based on previous experience, and causes him to "restructure strategies of action, understandings of phenomena, or ways of framing problems" (1987, p. 28). Reflection-on-action, on the other hand, occurs consciously after the action and may involve documentation. 
Schön's ideas have been widely applied to teacher education and teacher development programmes, despite the number of critiques that his work received (Jones, 2007). As the concept became more and more popular, some researchers have expressed concerns about the way Schön's concept of reflective practice is being used in teacher education and claim that the application of the concept is moving beyond its original intent (Boud \& Walker, 1998; Clift, Houston, \& Pugach, 1990). According to these writers, the problem lies in the use of reflection as a purely instrumental process that not only lacks the support of conceptual frameworks but also fails to encourage students to challenge teaching practices. Furthermore, the emphasis on individual disclosure is also identified as a weakness that manifests itself in the common use of reflective practice in teacher education. A contextual approach to the concept of reflective practice is therefore recommended in which the situational aspects of teaching are combined with the process advocated by Schön. This viewpoint is further supported by Boud, Cressey, and Docherty (2006), who suggest that the aforementioned issues can be addressed if the coaches create an environment of trust and develop a context for reflection that is unique for each and every learning situation. Boud et al. thus introduce the concept of productive reflection that looks at reflection and reflective practice from a collective perspective rather than the traditional individual approach. Key features of productive reflection are described as follows:

- An organizational rather than an individual intent and a collective rather than individual orientation. 
- Reflection is necessarily contextualized within work; it connects learning and work.

- It involves multiple stakeholders and connects players.

- It has a generative rather than instrumental focus.

- It has a developmental character.

- Reflection is an open, unpredictable process; it is dynamic and changes over time.

(Boud, Cressey, \& Docherty, 2006)

Developing on these key features of productive reflection, Boud (2010) asserts that reflection can be relocated in the professional practice context that is characterized by contextualization, transdisciplinarity, embodiment, and co-production. Contextualization here refers to the idea that a process of reflection may work well in one context but does not necessarily transfer as well to another, thus emphasizing the need for tailoring the reflection to fit particular contexts. Transdisciplinarity, on the other hand, points to the fact that the notion of reflection and reflective practice is likely to differ from one member to another in a group, depending on their backgrounds, cultures or disciplines. While it is challenging to establish a common ground among such diverse individuals, it also brings benefits in that members of the groups have the opportunity to view things from others' different perspectives and, at the same time, draw on their own traditions and assumptions. The third characteristic - embodiment - puts emphasis on the notion of emotional engagement, which implies that practitioners reflect better when they do it voluntarily and can 
connect to the task at a deep, personal level. This manifests itself as a challenge to the use of reflection as a component of formal assessment. Finally, Boud draws attention to the co-productive relationships in which there exist differences in skills and knowledge, as well as imbalances in power. Boud summarizes the challenge from practice that professionals have to face as follows:

As we move beyond the individual towards the social context then these [sociologically oriented traditions, related ideas associated with the practice turn, engagement with notions of reflexivity from a post-structural perspective] need also to be brought into the repertoire. We need to find ways of rehabilitating some key aspects of reflection that have been eroded through unthinking use, while moving further to deal with these new issues. (Boud, 2010, p. 36)

Apart from the major influences above, a large body of research has also addressed the conceptualisation of reflection and reflective practice. In order to obtain a bigpicture understanding of reflection in pedagogical practice, in 2009 Dimova and Loughran conducted a comprehensive review of literature in the area, the findings of which are summarized in Table 2.1. By comparing the views on reflection of the most eminent authors of the twentieth century, such as Dewey, Schön, Vygotsky, Lefebvre and Shchedrovitsky, Dimova and Loughran arrived at the conclusion that reflection can be seen as a multi-faceted mental phenomenon that manifests itself in various difficult situations of human practice, mostly in activities and communication. It allows practitioners to gain conscious understanding of 
themselves as individuals and also of people around them. Dimova and Loughran summarize the nature of reflection in practice settings well:

As practice settings become pressured by increasing bureaucratic and political demands of accountability, practice itself tends to suffer. The desire to develop check-lists of competencies proliferates as the push toward capturing and measuring skills serves to respond to accountability in ways that minimizes (or ignores) the qualities and expertise of the reflective practitioner. If reflective practice is to genuinely be encouraged in the workplace, trust and support must be seen as hand-in-hand with responsibility. It is more likely than not, that by developing deeper understandings of reflection in workplace settings that practitioners' learning about their professional knowledge of practice will be enhanced. When considered in this way, the complex nature of reflection can be embraced and offer a new and different framework for enhancing practice. In practice settings, teaching and learning are inextricably linked and, as such, reflection is clearly a central pedagogic imperative. (Dimova \& Loughran, 2009, p. 216) 


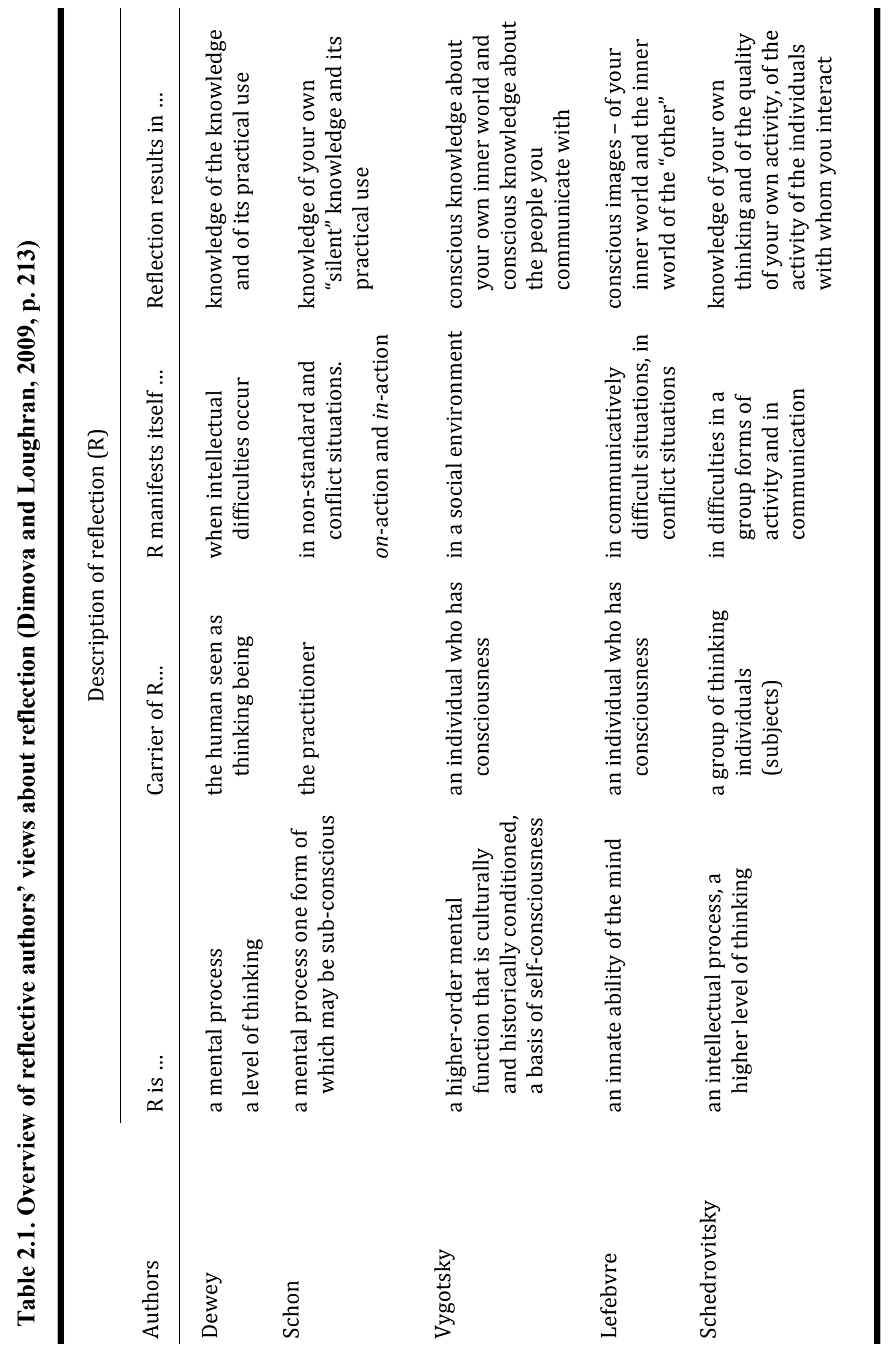




\subsubsection{Definition of reflection and reflective practice}

The terms "reflection" and "reflective practice" have been used interchangeably, although there is a basic difference between them. As concisely stated by Jones (2007), "reflection is a thinking process, while reflective practice is practice that is informed by such thinking” (p. 51). In an effort to define reflection, Atkins and Murphy (1993) conducted a review of the relevant literature and pointed out a common point in different theorists' definitions of the term. It is the description of reflection as a process in which an awareness of uncomfortable feelings and thoughts is followed by a critical analysis of feelings and knowledge, leading to the development of a new perspective. Reflection, therefore, involves the self and must lead to a change in perspective. Atkins and Murphy further cite Boyd and Fales (1983), who define reflection as a "process of internally examining and exploring an issue of concern, triggered by an experience, which creates and clarifies meaning in terms of self, and which results in a changed conceptual perspective," (p. 1189) and Boud, Keogh, and Walker (1985), who claim that "reflection in the context of learning is a generic term for those intellectual and affective activities in which individuals engage to explore their experiences in order to lead to new understandings and appreciations" (p. 1189)

With the focus on reflection in practice settings, reflection can be defined as a process in which the practitioner critically examines his or her past and present practice in order to gain knowledge and understanding, thus improving practice (Buysse, Sparkman, \& Wesley, 2003). According to Mezirow (1990), it involves critically questioning the content, process, and premise underlying the experience in 
an attempt to make sense of or better understand the experience. Content reflection involves identifying and analyzing the problem or situation from the perspectives of all the people who are involved in the situation. Process reflection requires practitioners to consider appropriate strategies to solve the identified problem and justify the strategy that is chosen in the end. Finally, premise reflection requires the practitioner to question his own beliefs and assumptions. In Merizow's argument, this is the hardest part of reflection. As assumptions are what we instinctively believe in, recognizing and questioning them can understandably be a challenging task.

This point of view is supported by Brookfield (1995), who claims that the most distinctive feature of the reflective process is the focus on "hunting assumptions." Hunting assumptions, as defined by Brookfield, means examining what has generally been thought to be true (common sense assumptions) in order to obtain a more reliable guide to action. A reflective teacher therefore ought to be someone who is constantly on the hunt for assumptions.

Brookfield identifies three categories of assumptions:

- Paradigmatic: Assumptions of the teachers' paradigmatic approach to the profession. Examples include assumptions such as adults are self-directed learners; critical thinking is an intellectual function characteristic of adult life; good adult educational processes are inherently democratic; and education always has a political dimension. 
- Prescriptive: Assumptions of what is believed to be the best practice. Examples include what should be done in certain situations, or what constitutes a good educational process.

- Causal: Assumptions of the causal relationship between practice and outcomes. Brookfield claims that this type of assumption is the easiest to uncover and closest to reflective practice.

Brookfield argues that while these assumptions are valid in certain situations, it is also worthwhile to examine them from different angles. Only by doing so can teachers reach a critical level of reflection, which will be discussed in the following section.

\subsubsection{Critical reflection}

Fook (2010) articulates critical reflection as involving the "ability to understand the social dimensions and political functions of experience and meaning making, and the ability to apply this understanding in working in social contexts" (p. 50). In Fook's argument, critical reflection incorporates a more complex understanding of (1) the importance of personal experience to provide a meaningful framework for disparate assumptions, (2) the remaking of power as personal, (3) emotion as part of experience, and (4) how personal and social experiences are integrated and necessary for meaningful action in the collective realm.

According to Brookfield (1995), critical reflection serves two distinctive purposes: firstly, "to understand how considerations of power undergird, frame and distort educational processes and interactions", and secondly, "to question assumptions and 
practices that seem to make our teaching lives easier but actually work against our own best long-term interests" (p. 8).

Brookfield asserts that critical reflection is important for a number of reasons. Firstly, it allows teachers to take informed actions that can be explained and justified to themselves and others. Secondly, it enables teachers to provide a rationale for their practice that can help improve their credibility with students. Thirdly, it helps teachers avoid taking the responsibility for everything that happens in their classroom, whether it is good or bad. Fourthly, it keeps teachers emotionally grounded. Fifthly, it makes the classroom challenging, interesting and stimulating for students. Finally, it increases democratic trust, thus allowing students to learn democratic behavior and a moral tone. Brookfield concludes that "critical reflection urges us to create conditions under which each person is respected, valued, and heard. In pedagogic terms, this means the creation of democratic classrooms. In terms of professional development, it means an engagement in critical conversations" (1995, p. 27).

In order to become critically reflective, Brookfield asserts that the teacher must use four critically reflective lenses:

- The teacher's unique autobiography as a teacher and learner, which involves self-reflection to further understand one's own paradigmatic assumptions and instinctive reasonings. It also provides insight into what the students are experiencing. 
- The students' lens, which involves the teacher learning from students' perspectives.

- Colleagues' experiences, which involves seeking input from colleagues in the form of observations, feedback, or critical dialogues.

- The theoretical literature, which allows the interpretation of situations in different ways or from different angles.

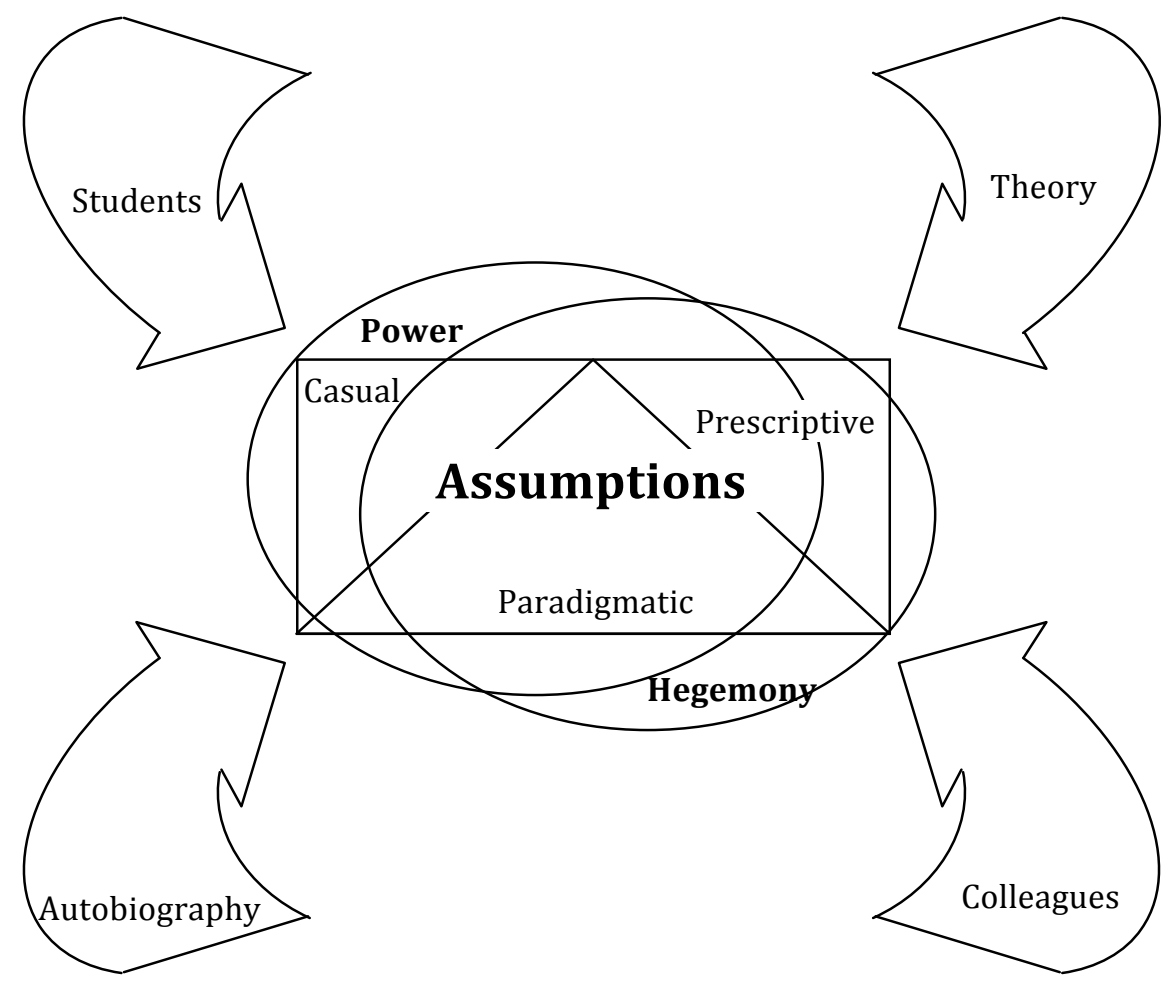

Figure 2.1: The critical reflection process (Laurie Peterman, as cited in Brookfield, 1995, p. 30).

Figure 2.1 illustrates the critical reflection process that is recommended by Brookfield. He particularly draws attention to the role of critical dialogues and theoretical literature in promoting teachers' critical reflection. Brookfield asserts that the engagement in critical dialogues with colleagues, if carefully structured and 
guided, could be of great value to critical reflection. He also believes that by delving into theoretical literature on critical pedagogy, reflective practice, and adult learning and education, teachers can enhance their understanding and define their own assumptions. It also gives them the opportunity to learn from the practices and lessons of others.

\subsubsection{Benefits of reflective practice}

It is claimed that the overall benefit of reflective practice is that it will enrich, systematize and construct professional knowledge (Carr \& Kemmis, 1988; CochranSmith \& Zeichner, 2005; Elliot, 1991; Kemmis \& McTaggart, 1988). In the context of teacher education, reflection is believed to help teachers gain a deeper understanding of their own practice on an on-going basis, including an understanding about the assumptions and knowledge upon which their practice is based, as well as their aims, values and beliefs (Buysse, Sparkman, \& Wesley, 2003; Loughran, 1995; Mclntyre, 1993; Zeichner, 1996).

Loughran (2002) also emphasizes the influence of reflection on the practitioner's understanding and claims that "reflection is effective when it leads a teacher to make sense of a situation in ways that enhance understanding so that she or he comes to see and understand the practice setting from a variety of viewpoints" (p. 36). Enhanced understanding hereby refers to a significant transformation in understanding, a deeper understanding, or a confirmation of one's existing understanding (Mezirow, 1991). 
Many studies have also credited reflection for confronting and subsequently changing practice (e.g., Francis, 1997; Taylor, 1997). Because the reflection process involves self-assessment and justification of practice, the practitioner gradually develops new theories that change and improve their practice (Korthagen, 2001; Lester, 1995). Other benefits include the validation of a teacher's ideals, the recognition of teaching as artistry, and respect for diversity in applying theory to classroom practice (Ferraro, 2000).

Jones (2007) further asserts that reflection played the role of an important "ingredient" in the development of capability, which can be linked to long-term professional development. However, Jones points out that while reflection does enhance practice, that impact relies on the practitioner's ability to build an adequate knowledge base for them to reflect on, as well as the skills to take effective action. She also puts emphasis on the reflection process as a means of informing and improving practice rather than a deliberative problem framing and solving process. This concept is illustrated in Figure 2.2. 


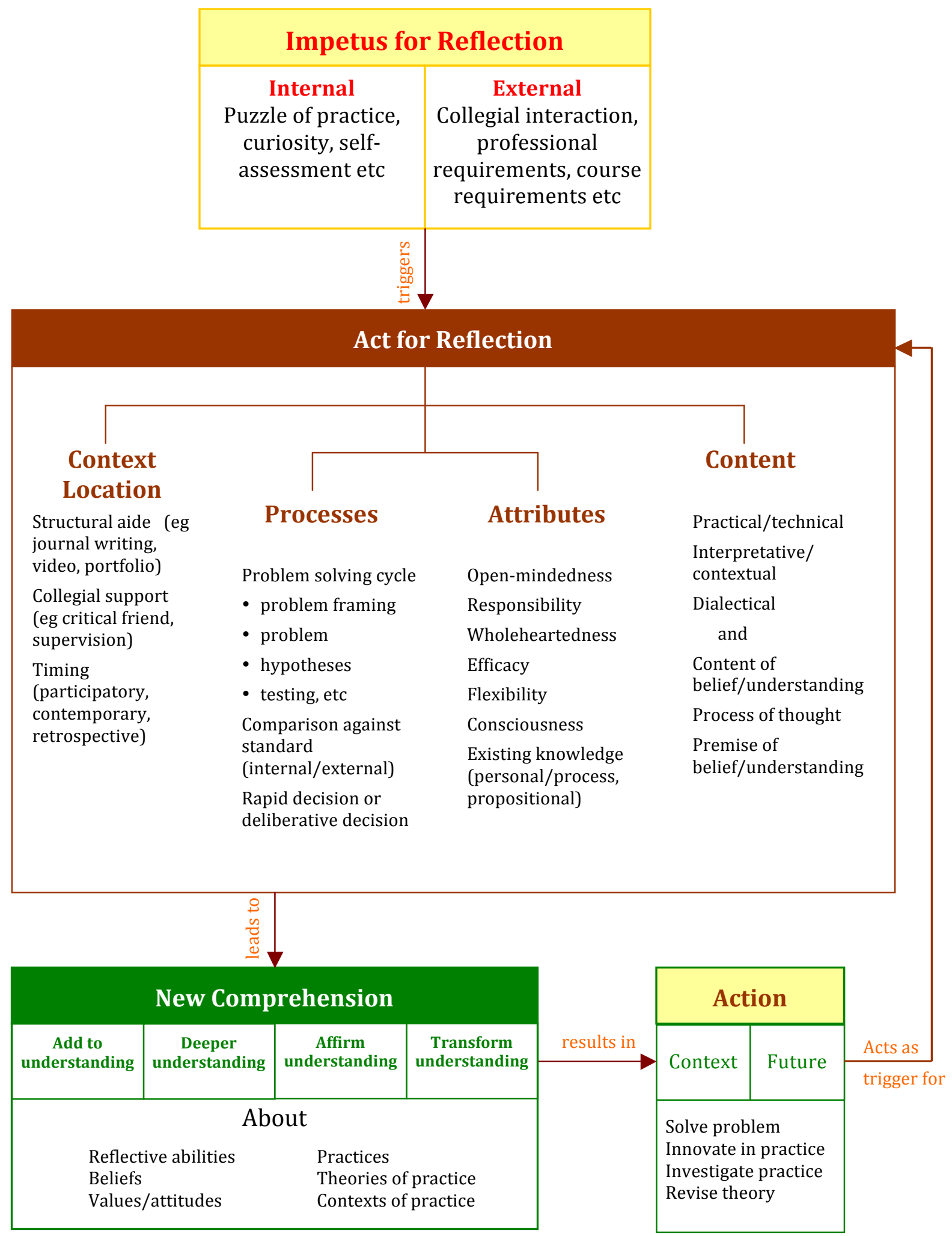

Figure 2.2: Conceptual framework for reflection (Jones, 2007, p. 55. Adapted

and expanded from LaBoskey, 1993). 
In summary, reflection can be defined as a process in which the practitioner critically examines his or her past and present practice in order to gain knowledge and understanding, thus improving practice. It involves critically questioning the content, process, and premise underlying the experience in an attempt to make sense of or better understand the experience. Reflection allows practitioners to become more professionally capable in that they develop a good knowledge base to reflect on and acquire the skills to improve their own practice. Reflection can be enhanced by being relocated in the professional practice context that is characterized by contextualization, transdisciplinarity, embodiment, and co-production.

\subsection{The role of portfolio assessment in promoting reflective practice}

\subsubsection{Definition of portfolio}

To enhance reflective practice, the educational literature has focused on the medium of writing (diaries, journals and portfolios) as potential approaches. In that context, portfolios, in particular, have been embraced as an effective tool for teacher assessment and the improvement of reflective practice. According to Lyons (1998), portfolio assessment has the potential to foster "collaborative, interpretive communities of teacher learners who can interrogate critically their practice and uncover and make public what counts as effective teaching in today's complex world of schools and learners" (p. 20).

Smith (1997) defines the portfolio as a purposeful collection of examples of work collected over a period of time that provides tangible and detailed evidence of one's competence. The portfolio can be in a variety of forms, from a student's writing 
folder to a scrapbook of personal items, and may include a range of casually to carefully chosen evidence to prove one's competence (Graves \& Sunstein, 1992). A portfolio can be comprised of student's work in one subject area over a few months, or even work produced over many years from a student's entire academic program (Wade \& Yarbrough, 1996).

There are many diverse interpretations of the portfolio that makes it difficult to arrive at one universal definition of the term (Smith \& Tillema, 2003; Wade \& Yarbrough, 1996; Zeichner \& Wray, 2001). However, Wade and Yarbrough (1996) provide a list of some generally accepted notions about portfolios as follows:

1. Portfolios demonstrate student growth and learning over a certain period of time and they should include more than one or two items.

2. Portfolios are a tool for students to document and reflect on their learning while at the same time serve as a means of assessment that allows teachers to evaluate students' growth and achievement.

3. Portfolios allow students to make their own choices regarding the items to be included and the organization of their portfolios. They also have the opportunity to voice their opinion regarding what parts of the portfolio are to be evaluated and what criteria are to be used.

4. Portfolios allow authenticity in students' work which cannot be revealed through tests.

5. Portfolios provide evidence of self-reflection as students examine their own work and reflect on it to set further goals. The documentation allows them to 
follow the changes that they make along the way, thus facilitating learning and reflection.

(Wade \& Yarbrough, 1996, p. 65)

Citing Barton and Collins (1993), Jones (2007) discussed the seven features of an effective portfolio. Firstly, the purpose of the portfolio, be it formative/diagnostic or summative, has to be explicit to both teachers and students. Secondly, the portfolio must promote integration by linking the coursework and the students' practical fieldwork experience. Thirdly, portfolios are multi-sourced, (i.e., they manifest a wide range of materials from various settings in order to create a big picture of the student as a skilled practitioner). Fourthly, portfolios are authentic, thus ensuring ecological validity. The fifth feature of an effective portfolio is the dynamic assessment that enables students to demonstrate growth and change over a sustained period of time. Portfolios also promote ownership among students by serving as a unique expression of their understanding and skills, thus fostering personal and professional growth throughout the process. Finally, portfolios are multipurpose since they are deemed to be beneficial for both students and teachers, and are generally seen as information-rich assessments. Apart from these seven features, Jones also draws attention to the role of collegial dialogue in both the development and evaluation of the portfolio.

\subsubsection{Portfolios as an assessment tool}

From a life-long learning perspective, Meeus, Van Petegem, and Van Looy (2006) identified four different modes of portfolio implementation: (1) as admission to 
higher education (assessment of competencies required), (2) during higher education courses, (3) on entrance into the profession (as part of a job application), and (4) as part of professional life (documenting continuing professional development). Smith and Tillema $(2001,2003)$, as seen in Figure 2.2, base their classification on the identification of two major dimensions: (1) the purpose of the portfolio (selection or promotion oriented or learning or developmentally oriented); (2) the setting of use (mandated by external requirements or self-directed or voluntary) (Smith \& Tillema, 2003). Based on these dimensions, they classify the portfolio into four types: the dossier portfolio, the training portfolio, the reflective portfolio and the personal development portfolio.

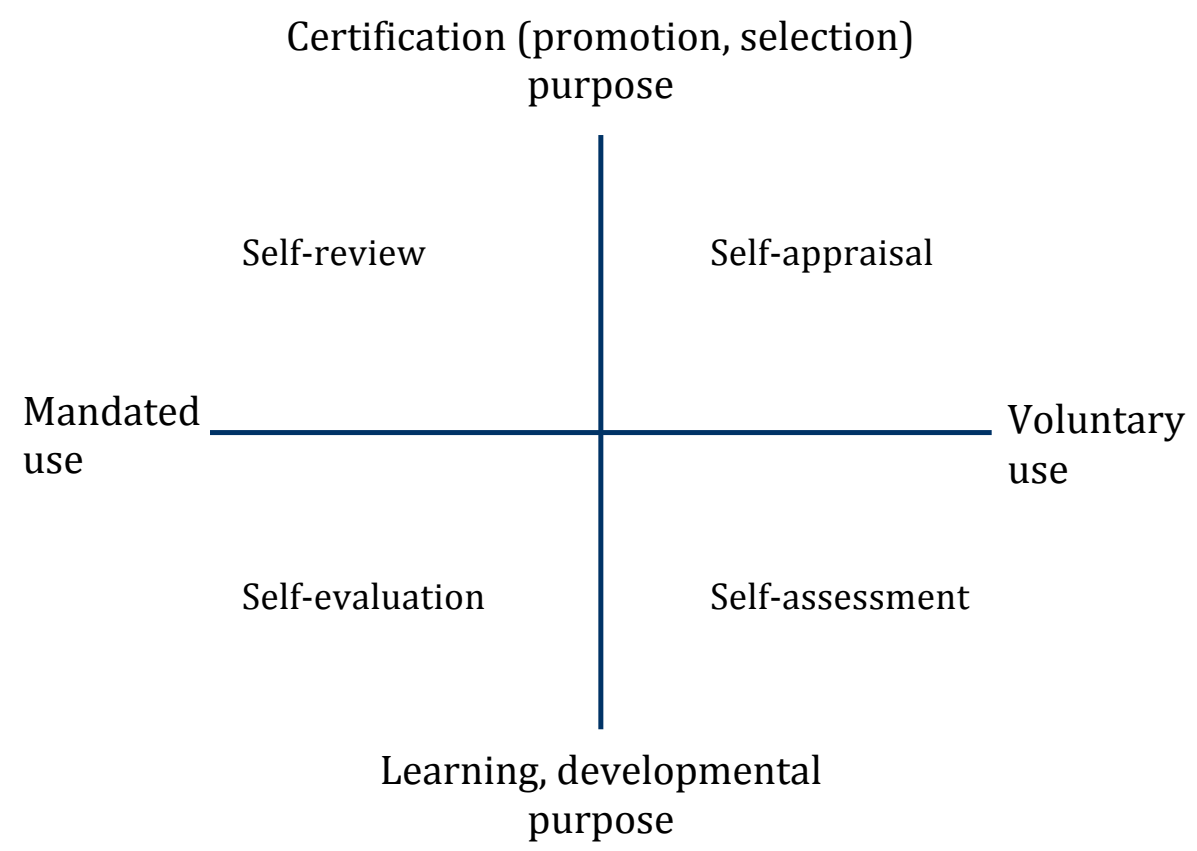

Figure 2.3: Matrix of portfolio uses related to various forms of assessment

(Smith and Tillema, 2001, p. 185) 
Wade and Yarbrough (1996) point out that educators may view portfolios largely as a form of alternative assessment or as a strategy for enhancing reflective thinking. This point of view is supported by Jones (2007), who asserts:

Portfolios have the potential to meet the requirements of assessment tasks that promote quality learning: promoting deep rather than surface learning, engaging with authentic problems, promoting reflection, transformative learning and autonomy, focusing on both the process of learning and the product, and doing double duty for both formative and summative assessment. (p. 101)

The use of portfolios as an assessment tool has been widely advocated because of the learning that it promotes (Loughran \& Corrigan, 1995; Paulson, Paulson, \& Meyer, 1991; Woodward, 1998). The process of compiling the portfolio generates different learning outcomes from other traditional forms of assessment and contributes to the increased responsibility among students for their own learning. This increased responsibility (Davies \& LeMahieu, 2003; Winsor et al., 1999) is triggered by the construction of a portfolio that allows them to articulate and demonstrate what they are learning about themselves as teachers. It also encourages student teachers to selfassess the learning that they have gained, the goals that they have set, and the extent to which they have achieved those goals. As pointed out by Jarvinen and Kohonen (1995), this self-assessment process helps novice teachers develop a professional identity and skills.

According to Smith and Tillema (2001), the most important advantage of the portfolios is "the way they capture achievements under realistic circumstances and 
record them using authentic evidence and tangible products" (p. 184). They also highlight the portfolio's ability to document strengths and weaknesses in performance, to develop awareness of competence, and to resolve discrepancies between standards and achieved performance. Other benefits of the portfolio as an assessment tool include the way it encourages teachers to integrate theory and practice (Antonek et al., 1997; Barton \& Collins, 1993; Ladbrook \& Middleton, 1997; Winsor et al., 1999), allows students to articulate and express their beliefs, and promotes transformative learning (Freidus, 1998). Finally, the preparation of a portfolio has been widely acknowledged for promoting reflection (e.g., Antonek et al., 1997; Biggs, 1998; Borko et al., 1997; Mokhtari et al., 1996; Setteducati, 1995; Winsor et al., 1999). This aspect of portfolio assessment will be discussed in more depth later in this chapter.

Because of its role as a form of assessment, it is also important to consider the validity and reliability of the portfolio in order to deem it trustworthy. Meeus, Petegem and Engels (2009), in a study that addresses the issue of validity and reliability of portfolio assessment for pre-service teachers, argue that the validity of portfolio assessment for teaching and partnership competencies is low while the validity for learning competencies can be high. Therefore, portfolios are more suitable for the assessment of students' capacity to execute a self-regulated learning process, whereas when it comes to assessing teaching competencies, they should be used as a complement to other tools. 
A number of threats to the portfolio's validity has been identified, one of which is the limited understanding of its purpose and values among both students and teachers, given the fact that it is a rather unconventional form of assessment (e.g., Freidus, 1998; Krause, 1996; Ladbrook \& Middleton, 1997; Loughran \& Corrigan, 1995; Lyons, 1998; Wade \& Yarbrough, 1996). In many cases, students' lack of understanding about the requirements and process negatively impacts their motivation to perform the task. It is therefore recommended that proper mentoring on these issues is provided to students in order to improve the portfolio's validity in this aspect (Freidus, 1998).

Another threat to validity is the fact that constructing a portfolio is a very time consuming process, which to some extent affects the assessment of students' work (Winsor et al., 1999). Furthermore, there are aspects of practice that can be quite difficult to demonstrate in the form of a portfolio entry (Wade \& Yarbrough, 1996). The fact that the portfolio is done as an assessment task also manifests itself as a threat because it involves the use of models and therefore may make the process too instructional (Baume, Yorke, \& Coffey, 2004; Daro, 1996). Finally, concerns about grades may hinder the sharing of certain information on the students' part during mentoring and supervision (Boud \& Walker, 1998).

Regarding the reliability of portfolio assessment, Meeus et al. (2009) assert that portfolios are "incapable of fulfilling the classic psychometric requirement of reliability" (p. 411) since portfolios and standardization are essentially incompatible. However, they suggest that the reliability of portfolio assessment, despite being 
problematic, can still be brought to an acceptable level if the following measures are taken:

- using a common assessment protocol (prior moderation);

- using a common checklist of assessment criteria;

- holistic marking;

- adequate training of assessors; and

- use of various assessors (retrospective moderation).

(Meeus et al., 2009, p. 411)

However, it should be noted that this study is not directly concerned with the reliability of portfolio assessment. It is interested in the consequential and predictive validity to some extent in that it seeks to investigate whether the process encourages ongoing reflection and those who have been assessed as reflective continue to be so after the event.

\subsubsection{The relationship between portfolio assessment and reflection}

A large body of research has explored the relationship between portfolios assessment and reflection. Throughout the 1990s, researchers generally embraced the benefits of portfolios in promoting learning and reflective practice (e.g., Antonek et al., 1997; Biggs, 1998; Borko et al., 1997; Mokhtari et al., 1996; Setteducati, 1995; Winsor et al., 1999). Particularly, the study by Borko et al. in 1997 reported that an impressive majority of participants ( $71 \%$ in written statements, $100 \%$ in interviews) explicitly mentioned reflection as a benefit of the portfolio process. According to Huba and Freed (2000), reflection occurs at three stages of the portfolio process: selection of 
evidence, annotation of evidence for presentation in the portfolio, and during conversations with peers, faculty advisors and others about their portfolio entries. Gupta, Ecclestone, and Greaves (2001) further assert that the portfolio encourages learners to write down reflection on their own experiences, thus improving the quality of reflections and avoiding "single loop reflection" (p. 3). Single loop learning refers to the search for another strategy that will address and work within the governing variables when a problem occurs, as opposed to double loop learning which subjects those variables to critical scrutiny (Argyris \& Schön, 1974). Dialogues with others throughout the process also contribute to reflection in two aspects: critical conversations that question portfolio entries and their significance, and collaborative inquiry (Lyons, 1998).

Many researchers have raised questions about a number of aspects of portfolio assessment (i.e., feedback delivery from assessors, the lack of research on validity and long-term influence of portfolios). In 2001, Smith and Tillema addressed the sustained use of a portfolio as an instrument to support long-term professional development and found out that portfolios are mainly used for documentation but have a high potential as mirrors of competence when used as instruments for selfevaluation and self-assessment among professionals (Smith \& Tillema, 2001). In a later study, Smith and Tillema (2003) pointed out that each type of portfolio may influence learning and reflection in different ways and at different levels. They also put emphasis on the voluntary portfolio (for selection purposes) as a more reflective type of portfolio, which requires a certain level of professional maturity. This point of view is further supported by a study by Rijdt, Tiquet, Dochy and Devolder in 
2006. Examining the use of portfolio assessment in higher education contexts, Rijdt et al. suggest that while the portfolio experience does bring about certain positive effects, it may not be the ideal assessment instrument for all teachers in that it does not encourage some teachers to reflect on their practice as much as other forms of assessment do. This conclusion aligns with the discussion in an article by Meeus et al. (2006), which puts emphasis on the need for a classificatory framework for portfolio use in the higher education context. In this article, Meeus et al. also point out the limited added value of portfolios aimed at profession-specific competencies, as well as the questionable reliability of the reflections in such types of portfolios. They then argue that portfolios aimed at learning competencies, on the other hand, can be of great value in building a capability for life-long learning. However, these findings contradict a study by Jones in 2007 which revealed that the portfolio does enhance professionalism. Jones points out that compiling the portfolio influences practitioners to undertake new practices, improve existing practice, and become more planned and systematic in their work.

A number of other studies have also been conducted over the past decade on the multi-facets of portfolio use that influences learning and reflection. A quasiexperimental research project by Meeus, Petegem, and Meijer (2008) reveals that the learning portfolio can significantly increases students' capacity for autonomous learning, given that supervisors give them enough autonomy to do so. On a different note, a comparative study was specifically designed and carried out by Groom and Maunonen-Eskelinen (2006) to explore the impact of the portfolio on reflective practice in different ecological settings. The findings suggest that portfolios can have 
an impact on the development of reflective practice of student teachers and the way they perceive their roles in the classroom. Different contexts, national priorities, approaches and policies cannot be overemphasized as significant factors in how portfolios are perceived and used for critical reflection of their practice. OrlandBarak (2005), on the other hand, takes a different approach in search for "untold" evidence of reflective practice in portfolios. The study suggests that the quality of reflection resides less in the use of different types of portfolios to address different purposes, and more in the collaborative process of participation in constructing a group portfolio. Orland-Barak also points out the absence of critical reflection in portfolios as evidenced by the predominance of descriptive reflective language, indicating reflection at technical level only. This finding aligns with those made by Nagle (2009), who links this phenomenon to pre-service teachers' beliefs about teaching and learning.

A study by Jones (2007) further explores the portfolio's role in fulfilling important formative functions for Resource Teachers: Learning and Behavior (RTLB). The study analyzes the relationship between the design and teaching of portfolio practice, and the learning and professional practice of RTLB in the context of a PDP that prepares experienced teachers for their role as RTLB in New Zealand. The study takes the form of an action research project and extends over a period of four years. Jones' findings suggest that the engagement in the portfolio process can enhance professionalism and improve practice. The portfolio experience reportedly stimulates a change in teachers' understanding of the terms "reflection" and "reflective practice". The engagement in the portfolio process makes the RTLB understand that 
reflection goes beyond simply relating what they do to the outcomes of the situation; the term is now linked to aspects like personal theory, good practice as identified in literature and research, or the wider ethical or socio-political issues related to the case. Thanks to the enhanced understanding that they have gained during the portfolio process, participants become more confident in their role as RTLB. The findings also indicate that due to the influence of the portfolio, the RTLB's practice becomes more planned and thoughtful, which results in better outcomes. Moreover, there is evidence of new practices being adopted, as well as the RTLB's engagement in searching for new knowledge and skills. Finally, the portfolio encourages RTLB to pay attention to the link between theory and practice, thus inspiring them to keep their practice research-based.

Another important point in Jones' findings was the link between the portfolio and promoted reflection. The process of compiling the portfolio reportedly stimulated reflection among RTLB in a number of stages. Firstly, by choosing pieces of evidence to include in the portfolio, teachers reflect on (1) that particular practice in relation to the learning outcome, and (2) the quality of the evidence. As they continue to the annotation process, a further process of reflection occurs as they reconsider the quality of the evidence and its relation to the learning outcome. The next stage, writing reflective statements, encourages RTLB to reflect beyond the outcomes of their cases and deeply on their practice as a whole. Finally, the writing of the theory statements is also seen as a major contributor to enhanced reflection because it requires RTLB to articulate their own beliefs, thus allowing them to be more aware of the content and the link between their theory and their practice. 
However, the findings also reveal some shortcomings of the portfolio in regard to reflection. Because the nature of the portfolio is to showcase teachers' best work, it can be difficult for teachers to reflect on successful cases, i.e. reflection may occur more consciously when casework is less successful. Furthermore, the high stakes of the portfolio as a form of assessment are likely to influence the way RTLB address the weaknesses in their practice. Jones therefore suggests that although reflection is more likely to be promoted when the portfolio is mandatory, careful considerations must be made regarding the influences of the requirements on the extent and nature of the reflection.

\subsection{The gap for research}

Despite the large body of literature addressing multiple aspects of portfolio assessment, there still remains the need for further research to better understand the role of portfolios in promoting professional development and the quality of the reflection that they stimulate (e.g., Borko et al., 1997; Jones, 2009; Smith \& Tillema, 2003). One particular aspect of portfolio assessment that has not received proper attention is the long-term influence of portfolios on professional development. Very few studies have been conducted on this specific area of interest. The only notable research undertaken so far is Smith and Tillema's (2001) investigation into the sustained use of a portfolio as an instrument to support professional development in the long term. In particular, it seeks to reveal why and how professionals continue to maintain their portfolio. The study focuses on four main issues: documentation of 
professional competence and development, systematic self-reflection, maintaining a reflective dialogue with peers, and learning from mistakes by analytic reflection.

As the findings suggest, documentation of evidence is seen as the most profound incentive for sustained portfolio use, followed by reflection and improved awareness, the chance for collegial dialogues on professional performance, and lastly development and learning. The main reasons for discontinued portfolio use, on the other hand, are because it is time consuming, not mandatory, and not helpful in short-term professional development. Smith and Tillema also point out that while voluntary use of the portfolio is better in enhancing professional development, it is more likely to be sustained if it is mandatory (see Figure 2.3). They therefore suggest that a balance can be reached by the inclusion of a coach in the assessment context who provides instructions for the compilation of the portfolio and at the same time offers professional and personal support in a non-threatening way.

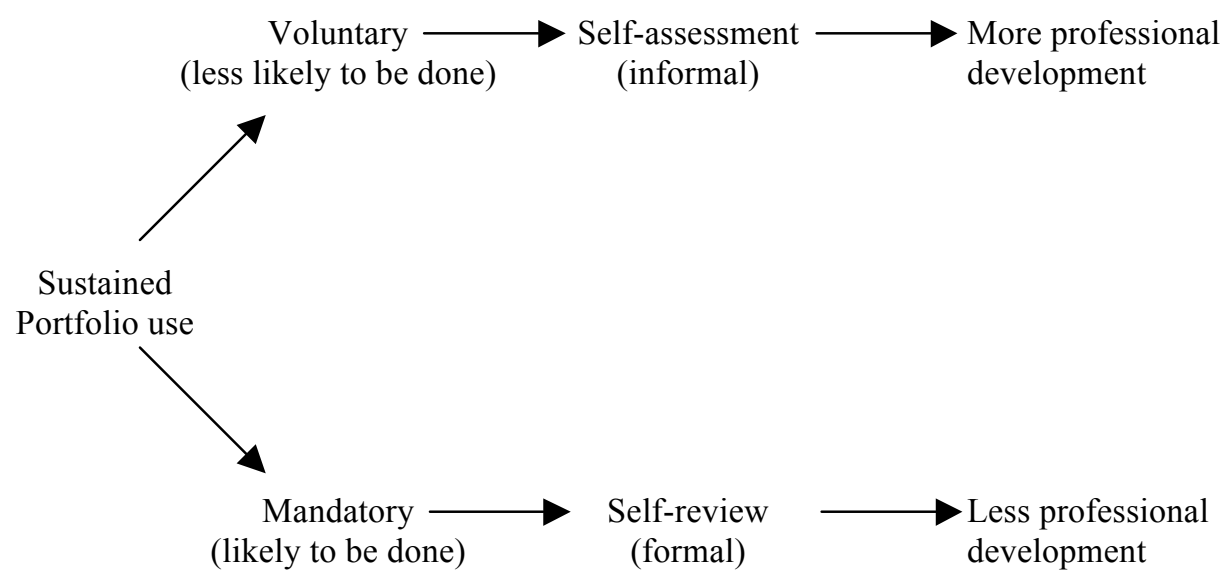

Figure 2.4: Routes in sustained use of portfolios (Smith and Tillema, 2001, p. 
In this study, Smith and Tillema also identify of the long-term effects of the portfolio on professionals. These effects include increased self-awareness and flexibility, and greater openness in discussing problems with colleagues. It is also affirmed that the portfolio encouraged systematic reflection which continues to occur in their practice after the portfolio experience ends. However, given the study's main focus on the sustained use of the portfolio, Smith and Tillema do not delve deeper into reflection on practice as an ongoing influence of the portfolio. This poses itself as a gap in research that can be filled by thorough investigation into how that systematic reflection was sustained in the professionals' practice after the portfolio experience.

In that context, Jones (2007) emphasizes the need for more research into the sustainability of reflection after the portfolio experience is completed and calls for a follow-up study to verify whether the reflection is maintained on an on-going basis.

One of the reasons that portfolios are used as assessment tools is that they may foster sustainable assessment. While the evidence for this study supports this, a follow-up study of RTLB in subsequent years of practice is needed to verify that the ongoing self-assessment, reflection on practice, and interrogation of research and theoretical literature were sustained once the professional development programme was concluded. (p. 284)

Based on the foundation that has been laid out in Jones' study, this research seeks to reveal the long-term influences of compiling a portfolio on ongoing reflective practice and therefore serves as a follow-up to Jones' study. In order to gain in-depth knowledge on this particular topic, the study firstly explores the participants' 
engagement in reflection during the portfolio process. Next, it seeks to shed light on the aspects of reflection that have been sustained in the participants' practice since the portfolio experience ended. Finally, it examines the conditions under which the reflection has been maintained in the participants' current practice. It is therefore expected that this research will provide valuable insights into the area of interest, based on which recommendations can be made for portfolio use in practice.

The following chapter will describe the research methodology that is employed in this study in order to achieve the intended goals. 


\section{CHAPTER 3: METHODOLOGY}

\subsection{Introduction}

This study had three main objectives: to explore participants' engagement in reflection during the portfolio process; to investigate which aspects of reflection that were stimulated by compiling the portfolio have been maintained in the participants' practice since the portfolio experience ended; and to examine the conditions under which the reflection has been maintained in the participants' current practice.

This chapter describes the methodological approach of this study in order to meet these three objectives. In this chapter, the choice of the qualitative approach and the selection of the case study are presented and explained. A detailed description of the process of data collection and data analysis will be provided. The trustworthiness of the study will also be discussed.

\subsection{Research paradigm}

The study is based on the interpretative research paradigm that treats reality as a complex matter with various underlying layers in which one single phenomenon can be interpreted in multiple ways. Accordingly, anti-positivist researchers are interested in exploring the multiple facets of a phenomenon that have not been touched upon, instead of establishing specific relationships among the components as a positivist researcher would (Cohen, Manion, \& Morrison, 2007).

The study employed a qualitative approach, in the form of a case study, to explore teachers' perceptions of the long-term influence of the portfolio experience on their ongoing reflection. Qualitative research allows researchers to gain complex contextual insights into how people experience a certain research issue. It focuses on 
the "human" side of an issue and aims at obtaining a rich and complex understanding of a particular phenomenon (Denzin \& Lincoln, 2000). This approach therefore appeared to be appropriate for this study, given its goal to gain deeper insights into the ongoing influences of the portfolio process on teachers' reflection on practice.

One of the strengths of the qualitative research approach lies in the flexibility in its research methods and choice of theories (Flick, 2009; Seale, 1999; Seale, Gobo, Gubrium, \& Silverman, 2004), which allows researchers to make comparisons and discover variations and diversity in social actors' perceptions and behaviour (Flick, 1992). Hence, the qualitative approach, in many cases, has more explanatory power than quantitative measures. In addition, qualitative researchers are more capable of capturing the perspectives of the subjects under study, as they can get closer to these individuals through interviews and observations (Flick, 2009; Hammersley, 1992). In this study, the choice of the qualitative approach allowed the researcher to gain deeper insight into participants' perceptions of the portfolio's influences on their reflection on practice.

The case study method was chosen for this study because it provides richer and deeper insight into the research topic by detailed account and analysis of one or more cases, thus enabling a holistic understanding of the case as a bounded system and its internal workings (Johnson \& Christensen, 2008). Yin (2003) defines the case study method as an empirical inquiry that investigates a contemporary phenomenon within its real-life context; when the boundaries between phenomenon and context are not clearly evident; and in which multiple sources of evidence are used. Yin also points out that the case study approach enables the answering of the questions of "how" and "why" about a particular phenomenon, while a wide statistical sampling method of quantitative research is more appropriate to find out "whether" a particular 
phenomenon exists. Table 3.1 compares research traditions in quantitative, qualitative, and case studies. 
Table 3.1. Comparison of general research traditions

\begin{tabular}{|c|c|c|}
\hline Quantitative Studies & Qualitative Studies & Case Studies \\
\hline $\begin{array}{l}\text { Researcher identifies topic or } \\
\text { question(s) of interest and } \\
\text { selects participants and } \\
\text { arranges procedures that } \\
\text { provide answers that are } \\
\text { accepted with } \\
\text { predetermined degree of } \\
\text { confidence; research } \\
\text { questions are often stated in } \\
\text { hypotheses that are } \\
\text { accepted or rejected using } \\
\text { statistical tests and } \\
\text { analyses. }\end{array}$ & $\begin{array}{l}\text { Researcher identifies topic } \\
\text { or question(s) of interest; } \\
\text { collects information from a } \\
\text { variety of sources, often as } \\
\text { a participant observer; and } \\
\text { accepts the analytical task } \\
\text { as one of discovering } \\
\text { answers that emerge from } \\
\text { information that is } \\
\text { available as a result of the } \\
\text { study. }\end{array}$ & $\begin{array}{l}\text { Researcher identifies topic } \\
\text { or question(s) of interest; } \\
\text { determines appropriate unit } \\
\text { to represent it, and defines } \\
\text { what is known based on } \\
\text { careful analysis of multiple } \\
\text { sources of information } \\
\text { about the "case." }\end{array}$ \\
\hline $\begin{array}{l}\text { Research process may vary } \\
\text { greatly from context being } \\
\text { investigated (e.g., survey of } \\
\text { how principals spend their } \\
\text { time) or appropriately } \\
\text { reflect it (e.g., observation } \\
\text { of how principals spend } \\
\text { their time). }\end{array}$ & $\begin{array}{l}\text { Research process is designed } \\
\text { to reflect, as much as } \\
\text { possible, the natural, } \\
\text { ongoing context being } \\
\text { investigated; information is } \\
\text { often gathered by } \\
\text { participant observers } \\
\text { (individuals actively } \\
\text { engaged, immersed, or } \\
\text { involved in the information } \\
\text { collection setting or } \\
\text { activity). }\end{array}$ & $\begin{array}{l}\text { Research process is defined } \\
\text { by systematic series of } \\
\text { steps designed to provide } \\
\text { careful analysis of the case. }\end{array}$ \\
\hline $\begin{array}{l}\text { Information collection may } \\
\text { last a few hours or a few } \\
\text { days, but generally is of } \\
\text { short-term duration using } \\
\text { carefully constructed } \\
\text { measures designed } \\
\text { specifically to generate } \\
\text { valid and reliable } \\
\text { information under the } \\
\text { conditions of the study. }\end{array}$ & $\begin{array}{l}\text { Information collection may } \\
\text { last a few months or as } \\
\text { long as it takes for an } \\
\text { adequate answer to } \\
\text { emerge; the time frame for } \\
\text { the study is often not } \\
\text { defined at the time the } \\
\text { research is undertaken. }\end{array}$ & $\begin{array}{l}\text { Information collection may } \\
\text { last a few hours, a few } \\
\text { days, a few months, or as } \\
\text { long as is necessary to } \\
\text { adequately "define" the } \\
\text { case. }\end{array}$ \\
\hline $\begin{array}{l}\text { Report of the outcomes of } \\
\text { the process is generally } \\
\text { expository, consisting of a } \\
\text { series of statistical answers } \\
\text { to questions under } \\
\text { investigation. }\end{array}$ & $\begin{array}{l}\text { Report of outcomes of the } \\
\text { process is generally } \\
\text { narrative, consisting of a } \\
\text { series of "papers to the } \\
\text { story" or "chapters to the } \\
\text { book." }\end{array}$ & $\begin{array}{l}\text { Report of outcomes of the } \\
\text { process is generally } \\
\text { narrative in nature, } \\
\text { consisting of a series of } \\
\text { illustrative descriptions of } \\
\text { key aspects of the case. }\end{array}$ \\
\hline
\end{tabular}

(Source: Hancock \& Algozzine, 2006, p. 10) 
By adopting the case study method, this study therefore aims at focusing intensively on a small sample (case) in order to gain an in-depth understanding of the phenomenon, (i.e., the long-term influences on teachers of their compiling a reflective portfolio). This case study is bounded to the participants who enrolled in the same training course with the same requirements for their portfolios, thus having the same idea of the portfolio process. The units of analysis in this case are therefore individual participants. Figure 1 provides an overview of the research process employed in this study. 

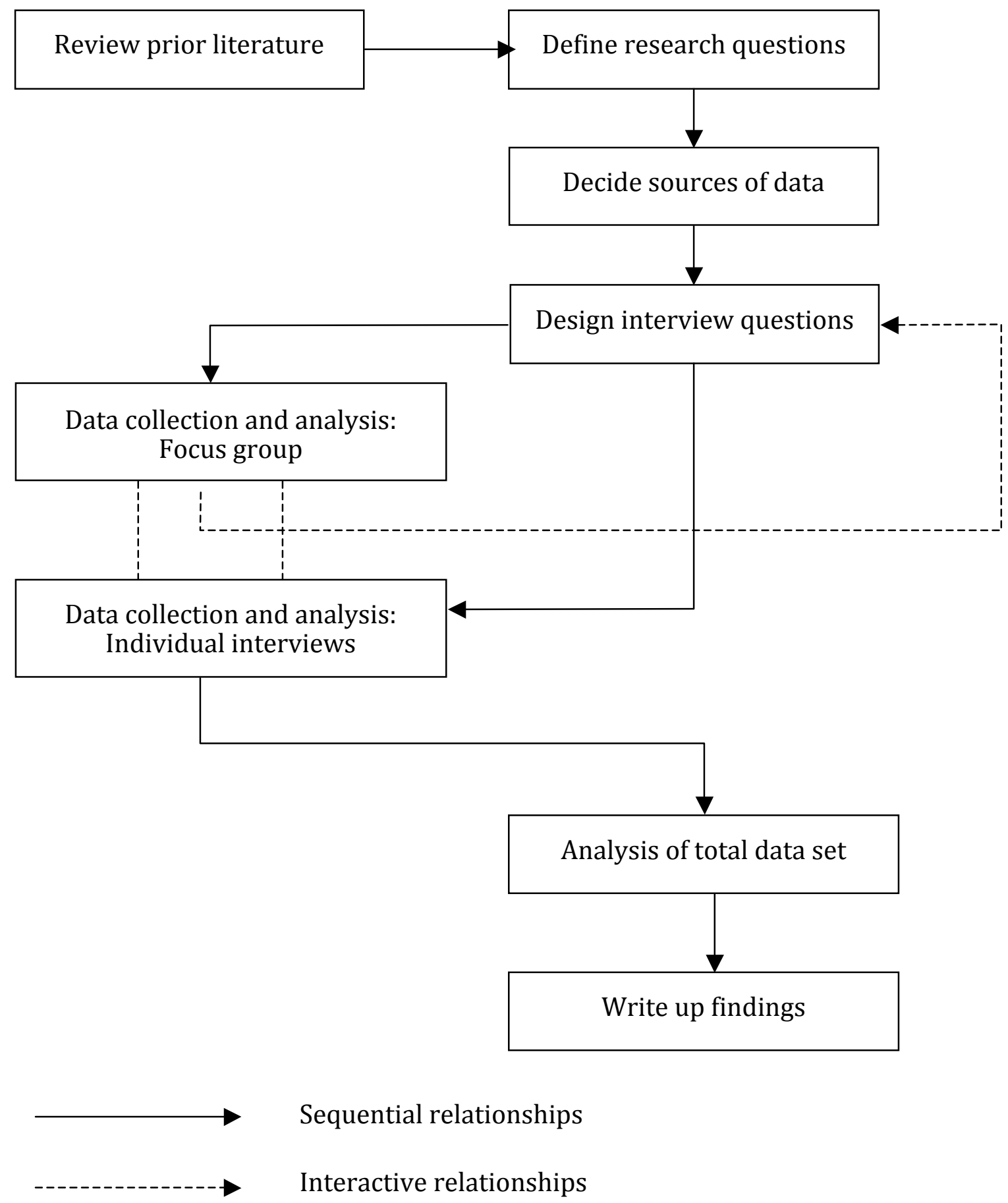

Figure 3.1: A graphical illustration of research process adopted in this study 


\subsection{Data sources and data collection methods}

\subsubsection{Participants}

A sample of nine participants was drawn from RTLB who enrolled in a course on the portfolio as a professional practice, which was the fourth component of EPSY 564 a PDP for resource teachers conducted by the School of Educational Psychology and Pedagogy (Victoria University of Wellington) during the years 2007, 2008 and 2009. Participants were of different age ranges and had different background experience with teaching in general and with working in special education in particular. Table 3.2 summarizes the characteristics of the participants in this study.

Table 3.2: Characteristics of participants

\begin{tabular}{|c|c|c|}
\hline Description & Range & $\begin{array}{l}\text { Number of } \\
\text { participants }\end{array}$ \\
\hline \multirow{3}{*}{ Age range } & $31-40$ & 2 \\
\hline & $41-50$ & 2 \\
\hline & $51+$ & 5 \\
\hline \multirow{3}{*}{ Completed in } & 2007 & 3 \\
\hline & 2008 & 3 \\
\hline & 2009 & 3 \\
\hline \multirow{2}{*}{$\begin{array}{c}\text { Highest } \\
\text { qualification }\end{array}$} & MEd & 2 \\
\hline & $\begin{array}{c}\text { Post Graduate } \\
\text { Diploma }\end{array}$ & 7 \\
\hline \multirow{3}{*}{$\begin{array}{l}\text { Teaching } \\
\text { experience }\end{array}$} & $<15$ & 3 \\
\hline & $15-25$ & 3 \\
\hline & $25+$ & 3 \\
\hline \multirow{2}{*}{$\begin{array}{c}\text { Special } \\
\text { Education } \\
\text { experience }\end{array}$} & $<5$ & 3 \\
\hline & $5+$ & 6 \\
\hline \multirow{2}{*}{$\begin{array}{c}\text { Portfolio } \\
\text { experience prior } \\
\text { to training }\end{array}$} & No & 8 \\
\hline & Yes & 1 \\
\hline
\end{tabular}


Because of the emphasis on the long-term impact of portfolio assessment on ongoing reflection, the research targeted participants who had already completed the programme two or three years ago to see whether the reflection has been maintained. The study also intended to select participants who were successful with the portfolio assessment and have shown a high level of reflection in their portfolios. Therefore, the sample was purposefully selected by the course coordinator based on their final grades; only graduates with top grades, (i.e., within the A- to A+ range) were invited to participate in this study. Although it can be argued that such successful teachers are already reflective, the study aimed to look at the "added value" (i.e., how the portfolio experience helped them become more reflective than they already were). Given the limited scope of the study, selecting RTLB who were more successful with the portfolio assessment helped meet the purpose of the study and yet keep it manageable.

Purposeful sampling was used to select participants for this study because it helps develop a deeper understanding of the phenomena being studied by selecting cases that were likely to be "information-rich" with respect to the purposes of the study (Gall, Borg, \& Gall, 1996). The goal is to achieve an in-depth understanding of those selected individuals rather than selecting a sample that would accurately represent a defined population (Gall, et al. 1996). Additionally, purposeful sampling provides the widest possible range of data to include into the thick description of the phenomenon (Denzin \& Lincoln, 2000).

For the sample of this study, a list of potential participants was initially identified by the course coordinator based on the grades from 2007, 2008 and 2009. For the focus group, potential participants were selected from those who were based in the Wellington region so that they could be easily assembled for the focus group. For 
individual interviews, the course coordinator identified participants from different regions in New Zealand. Recruitment was conducted initially by informal invitations being made to potential participants by the course coordinator. Upon receiving participants' approval, their contact details were forwarded to me, and I then sent out a formal invitation to interested participants and provided more information regarding the study and myself (see Appendix A, B). RTLB who indicated their willingness to participate in the study were asked to complete an informed consent form to participate in a focus group or in-depth interviews (See Appendix C, D). In total, three people participated in the focus group and six others participated in individual interviews.

\subsubsection{Data collection}

Qualitative data for the study were collected from participants by way of a focus group and semi-structured interviews. The data collection process began with a focus group that served as a source of qualitative data that provided background information about the topic of interest (Johnson \& Christensen, 2008). In examining its position in the educational research contexts, Wilson (1997) asserts that the focus group is a useful qualitative method in educational research because of the "face validity" of the data that it provides. Its strength lies in the interaction among participants and the researcher, which fosters empathy for the "stories" that are shared within the group. Wilson therefore advocates the use of focus group in the educational research context by pointing out that focus groups:

- Encourage more open discussion of sensitive issues for both respondents and researchers;

- Allow researchers to probe for meaning where they might have been more reluctant to do so in individual interviews; 
- Demonstrate a greater variety of discourse than is available in other methods with the exception of observation; and

- Let researchers experience being in a group with their respondents and hearing them talking with their peers.

(Wilson, 1997)

The focus group method can be employed at the initial stage of the study to form a basis for the development of further investigations (Bellenger, Bernhardt, \& Goldstucker, 1976; Flores and Alonso, 1995). In this particular study, the use of the focus group was intended to obtain access to the participants' viewpoints in a broader sense, thus identifying themes and/or problematic areas that needed to be further addressed in the next stage of the research - the individual interviews. The combination of the focus group with other qualitative techniques such as in-depth interviews is also believed to allow researchers to arrive at more meaningful conclusions (Cohen \& Engelberg, 1989; Morgan, 1988).

The focus group lasted one and a half hours and involved the participation of three RTLB, with me as the facilitator. At the beginning of the session, participants were allowed five minutes to read through a set of questions that had been prepared by me (See Appendix E) and record their immediate responses. This was intended to help participants prepare themselves for the discussion, as well as disclose information that they may not want to share in public, if any. (These sheets were collected at the conclusion of the interview.) I then facilitated the focus group by introducing questions, asking participants to elaborate where necessary, encouraging equal participation from all members by directing the discussion to those who had not voiced their opinion, and summarizing main points. A flip chart was used to record and summarise the main points in the discussion. The focus group was tape recorded, 
transcribed and analyzed for major themes by content analysis. The findings of the focus group were then used as a basis for the refinement of interview questions for the later phase of the study.

The next stage of data collection in this study involved in-depth interviews with individual participants. The research interview is defined as "a two-person conversation initiated by the interviewer for the specific purpose of obtaining research-relevant information, and focused by him on content specified by research objectives of systematic description, prediction, or explanation" (Cohen \& Manion, 1994, p. 271). The interview is therefore widely acknowledged as a flexible tool for data collection that allows researchers to address issues of more complexity and depth (Cohen et al., 2007). Because of its common features with the selfadministered questionnaire, comparison has been inevitable. While questionnaires tend to be more reliable and encourage more honesty, the interview, on the other hand, offers the opportunity for the interviewer to clarify any misunderstandings or questions that may arise along the process (Cohen et al., 2007). This direct interaction allows the interviewer to collect data at greater depth; however, its disadvantage lies in the potential subjectivity and bias that may influence the interviewer (Borg, 1963, as cited in Cohen et al., 2007). Table 3.3 summarizes the main points of comparison between the interview and the questionnaire. 
Table 3.3. Summary of relative merits of interview versus questionnaire

\begin{tabular}{|c|c|c|}
\hline Consideration & Interview & Questionnaire \\
\hline $\begin{array}{l}\text { Personal need to collect } \\
\text { data }\end{array}$ & Requires interviewers & Requires a secretary \\
\hline Major expense & Payment to interviewers & Postage and printing \\
\hline $\begin{array}{l}\text { Opportunities for } \\
\text { response-keying } \\
\text { (personalization) }\end{array}$ & Extensive & Limited \\
\hline Opportunities for asking & Extensive & Limited \\
\hline Opportunities to probing & Possible & Difficult \\
\hline $\begin{array}{l}\text { Relative magnitude of data } \\
\text { reduction }\end{array}$ & Great (because of coding) & $\begin{array}{l}\text { Mainly limited to } \\
\text { rostering }\end{array}$ \\
\hline $\begin{array}{l}\text { Typically, the number of } \\
\text { respondents who can be } \\
\text { reached }\end{array}$ & Limited & Extensive \\
\hline Rate of return & Good & Poor \\
\hline Sources of error & $\begin{array}{l}\text { Interviewer, instrument, } \\
\text { coding, sample }\end{array}$ & $\begin{array}{l}\text { Limited to instrument and } \\
\text { sample }\end{array}$ \\
\hline Overall reliability & Quite limited & Fair \\
\hline Emphasis on writing skill & Limited & Extensive \\
\hline
\end{tabular}

(Source: Tuckman, 1972, as cited by Cohen et al., 2007, p. 352)

By considering the interview's higher participant involvement and motivation, which enable richer data to be collected, I opted for this method and employed in-depth interviews instead of questionnaires. The purpose of in-depth interviews is to understand the lived experience of people and the meaning that they associate with that experience (Van Manen, 1990). It puts emphasis on the conversation and interaction between humans and the knowledge that it generates, instead of treating humans as manipulable objects that do not have any connection with the data (Kvale, 1996).

The interviews in this study were conducted with a semi-structured method (Denzin, 2009; May, 1997; Yin, 1994). Similar to structured interviews, semi-structured 
interviews are also developed based on specific questions; however, a major difference is that the interviewee is free to elaborate beyond the answers to reflect on their own experiences and perceptions of particular issues or incidences in the past that are relevant to the questions being asked in the interview. A semi-structured interview method therefore allows interviewees to participate more on their own terms instead of the restricted standardized terms that structured interviews permit (May, 1997). It also provides the interviewer the chance to understand the context of the interviewee, which is an important source of information in itself to explain the statements and views made by the interviewee (May, 1997).

Following the semi-structured format, I developed a set of questions to be asked in each interview (see Appendix F) and prompted the interviewees to clarify or elaborate on their responses where necessary. All of the questions in the interview were open-ended, which allowed flexibility and follow-up in case the interviewee's response was limited or vague (Cohen et al., 2007). I also followed up on unexpected answers and points that were raised by the interviewees and treated them as contributors to new levels of understanding.

The interviews in this study were conducted in an informal manner and the interviewees were given opportunities to focus on issues that interested them the most, rather than being pressured to comment on every single item. A list of semistructured and open-ended questions was sent to the interviewee at least two days before the interview to allow time for preparation and thus more comprehensive answers (see Appendix F). Participants were also encouraged to bring along the portfolios that they compiled for the course and use them as a prompt for their comments. I also took notes during and after the interviews in order to keep a summative reflection of my perception of the interview and the interviewee. These 
notes also served as an alternative source of information that could complement the information recorded from the interview transcript.

The average length of the interviews was one hour each; all the interviews were conducted in the town in which the RTLB worked, mostly in their office. The time of the interviews was determined at the interviewee's convenience. All the interviews were tape recorded with the permission of the interviewees and transcribed afterwards. Interviewees had the option to review interview transcripts and request amendments where relevant; however, no amendments were requested.

\subsection{Data analysis}

After being transcribed, the data was then analyzed for themes and commonalities using content analysis, which examines data for recurrent patterns based on key words, phrases or units. These patterns were systematically identified across the data set and grouped by a coding system. The coding process followed the inductive approach in which codes were generated by directly examining the data (Johnson \& Christensen, 2008). The process was facilitated by NVivo 8 - a specialized software for qualitative data analysis. The use of computer software in qualitative data analysis is recommended for qualitative researchers because it serves to facilitate an accurate and transparent data analysis process while also providing a quick and simple way of counting who said what and when, which in turn provides a reliable, general picture of the data (Johnson \& Christensen, 2008; Morrison \& Moir, 1998; Richards \& Richards, 1994).

The coding of data into relevant nodes was based on the themes that emerged from the interview and focus group transcripts. Such themes were identified by key words/ phrases and interpretation of the underlying meanings of particular chunks of 
information from the transcripts. These themes were mostly identified in relation to the three research questions of the study. In most cases, there were sub-themes emerging from larger, overarching themes. During the process of coding, the researcher also established additional codes in the form of tree nodes (nodes that include sub-themes) or free nodes (nodes that stand independently and do not include sub-themes). A coding tree that included these themes was then built inside NVivo 8.

Unlike quantitative research where the findings are summarised in terms of representative numbers, qualitative research in the form of interviews reports the findings by way of quotations from interviewees. In this study, information from the interviews and documentation was synthesized and compared in order to validate and provide depth for the findings. Then, the findings were reported by using illustrative quotes from both the focus group and the interviews.

\subsection{Ethics}

This research has been assessed by Victoria University Faculty of Education Ethics Committee and was approved on August $9^{\text {th }}, 2010$, prior to the commencement of the data collection process.

The research was conducted as part of the requirements for the completion of the Master of Education degree and did not involve any conflicts of interest. The research was conducted on a confidential but non-anonymous basis and informed consent was obtained through a signed consent form (see Appendix C, D). At no time when reporting on the findings of this study were the participants' identities disclosed. Each participant was assigned a code number that was attached to all the 
information that they provided. Attribution of information in this study was therefore done anonymously.

During the data collection process, participants did not encounter any hazards or inconvenience. Because all the participants completed the course two or three years ago, their selection by the course coordinator and participation in this study should not put any pressure on them. Participants had the option to withdraw from the study at any time before the data collection process began.

All the data were kept at a secure location, and was only available to my supervisor and myself. Participants had the option to review interview notes, which were all stored securely and will be destroyed two years after the completion of the thesis.

\subsection{Trustworthiness of the study}

In order to enhance the trustworthiness of the research, triangulation has been employed in this study in a number of ways. According to Bloor and Wood (2006), triangulation is "the systematic comparison of findings on the same research topic generated by different research methods. Such comparisons are often portrayed as a procedure of validation by replication, but the portrayal is misleading" (p. 170). Flick, Kardorff and Steinke (2004), on the other hand, broadly defined triangulation as "observation of research from (at least) two different points" (p. 178). There are different types of triangulation - by data, research methods, researcher, theory (Miles \& Huberman, 1994), and members' check (Denzin, 1997) - which helps ensure validity in qualitative research in different ways. For example, methodological triangulation allows researchers to avoid the biases and flaws that they may have to encounter when using a single method approach (Webb, Cambell, Schwartz, \& Sechrest, 1996). Additionally, it provides a more holistic and contextual 
view of the units under study (Jick, 1979). Overall, triangulation not only enhances the validity of the findings but also allows the researchers to gain insights of greater depth and detail (Jick, 1979; Denzin, 2009).

In this study, data triangulation was operationalized by drawing upon multiple sources of data. The sources of data to be collected included participants who were different lengths of time away from completing the portfolio, with three people completing the portfolio in 2007 , three in 2008 , and three in 2009 . The data were also triangulated between the transcript of the tape recorded focus group session and the participants' written responses to the set of questions that was distributed at the beginning of the focus group. In addition to this, triangulation of methods was also employed via individual interviews and the focus group, as they involved different groups of participants. The focus group was conducted in the initial phase of data collection and thus served as a basis for the refinement of interview questions in the later phase of the study. Furthermore, where relevant, within each interview, the interviewee was asked to comment or elaborate on the perceptions and opinions of earlier interviewees. This allowed direct triangulation and cross-validation between the interviewees themselves without the intervention of the researcher.

Triangulation by theory was employed in this study through the literature review, which informed the research design and the interpretation of findings.

Triangulation by members' check was also obtained by the option for interviewees to check interview transcripts for accuracy in interpretation and expression. For the focus group, this was done by the use of a flip chart that allowed participants to review field notes on the spot and suggest correction where relevant. 


\subsection{Conclusion}

This chapter described the methodological approach to this study in which it takes the form of a case study. Data were collected through a focus group and six individual, semi-structured interviews. The recruitment of participants along with the process of data collection and analysis were described, and ethical issues were addressed. Triangulation and the trustworthiness of the study were also discussed in this chapter.

The following three chapters will present the findings that have been drawn from the three research questions of this study. Chapter 4 in particular will address the first research question, which seeks to reveal the participants' perception of their own reflection during the process of compiling the portfolio. 


\section{CHAPTER 4: TEACHERS' PERCEPTION OF THEIR OWN REFLECTION DURING THE PORTFOLIO PROCESS}

\subsection{Introduction}

The following three chapters will present the findings that have been drawn from the three research questions. This chapter will address the first research question, investigates the participants' perception of their own reflection during the process of compiling the portfolio.

As described in the previous chapter, the portfolio was the main assessment tool for the fourth component of the PDP under study (EPSY 564). The paper, "Professional Practice: The Portfolio", emphasized the development and refinement of quality RTLB professional practice. The RTLB were required to compile a portfolio of cases and projects from their authentic work that demonstrated that they have met the seven LOs of the PDP. The LOs were intended to enable the RLTB to:

1. Work to a high professional and ethical standard

2. Work to improve learning and behavioural outcomes for Māori students

3. Work to ensure equitable educational opportunity for all learners

4. Follow an educational/ecological model

5. Work to a collaborative problem solving model

6. Be skilled practitioners and promoters of effective teaching skills

7. Be reflective practitioners.

The portfolio process aimed at encouraging RTLB to critically analyse their own practice, enhancing their understanding of the work of the RTLB, and making direct 
links from theories to practice. A detailed description of the portfolio process and its requirements has been provided in chapter 1 .

This chapter reports on the impact of this process on the RTLBs' reflection on practice. In order to examine this, the participants were asked to describe how they reflected while they were compiling the portfolio. The data collected from the focus group and the interviews were then analysed to identify themes. The findings showed that the reflection happened in a number of ways, such as case selection, evidence annotation, data collection and presentation, and awareness regarding theoretical literature, all of which resulted in a more in-depth understanding of the term "reflective practitioner." Each of these aspects will be discussed in the following sections.

\subsection{The portfolio as a process}

Firstly, it should be noted that a common theme in participants' responses was the emphasis on the portfolio as a process, not a finished product, in promoting their reflection. All participants found the process valuable in helping them become better practitioners, even though they also perceived the experience as a lot of hard work and stress over an extended period of time. Because of the considerable amount of time and effort invested in compiling the portfolio, the process was deemed a "painful" one, especially in the context of its being a summative assessment task. Some participants found it particularly difficult in the initial stage where they were unfamiliar with a number of new concepts and the way in which the portfolio assessment worked. An RTLB explained:

It was really hard to get our heads around what we had to do and it was difficult to understand the annotation and what they meant by annotation and reflection. At the beginning it was really hard. And it was a very short time 
frame to find cases that fitted all along.

Despite the hard work that they invested into the process, most participants found it valuable in fostering learning and stimulating their reflection. Through the process of identifying cases, selecting evidence to demonstrate the learning outcomes, and annotating the evidence, the RTLB had the opportunity to look back at their practice and reflect on what it meant for them personally. The process also allowed them to reflect on why they had chosen certain artefacts to illustrate their practice and why those were important to them. Participants also pointed out that this reflection was further enhanced in later stages of the process in which they had to use relevant literature to support what they did and why they thought it was valuable. Lastly, the final stage which required them to reflect on the case as a whole and identify what could have been done better, was one in which reflection naturally occurred. There was clearly a considerable amount of reflection going on throughout the process. As some participants said,

The whole process is about reflection. It's about being specific and choosing pathways into ways of explicitly showing how you're doing your job. If you do that, you can reflect all the way through it. So I think the portfolio has been really good for that because you couldn't help but reflect. It's one of those things that you have to do; otherwise you're not being explicit enough.

The portfolio process was big, but the reflection you got from it was huge. I think that the process was as important as the end result. I don't think you can really learn everything without going through that process.

There's always a balancing act between trying to meet many current demands and being true to the model and delivering in the sort of depth that 
one ought to. In other words, not taking shortcuts. I think the portfolio laid down the principles pretty well there and the reflective process probably helped to reinforce my own thinking, these are good things to do, it's not just doing it to show in a portfolio but these are worthwhile and meaningful actions.

The requirement for RTLB to go through the whole process, from selecting cases and evidence to annotating and reflecting, allowed them to consolidate the learning and theories that informed their work. Although claiming that it was overall a challenging task, the participants generally acknowledged the benefits of the portfolio process in enhancing reflection by having them critically analyse their practice instead of just taking a cursory look at what worked and what did not work. In their opinion, the selection of cases and evidence, along with annotating and writing, were parts of the process in which most of their reflection occurred.

\subsubsection{Selection of cases and evidence}

Most of the participants explained that most of their reflection occurred during the stage of drawing together cases and selecting evidence from their authentic work to match the learning outcomes. This process gave them the opportunity to question what they were doing, why they were doing it and then back it up with documentations, annotations, discussions, and reflection. This reflection could occur at the beginning, during or at the end of the process. In most cases, it occurred at the beginning as the RTLB worked through their documentation to select the best case to match the desired learning outcome. This process allowed them to reflect on the quality of the evidence and how well it could serve as proof that they had achieved a certain learning outcome (LO). An RTLB explained: 
outcomes and what we did.

There were also cases in which the reflection reportedly happened at the end of the process. In such cases, as the RTLB revisited the evidence, they became aware of the shortcomings in their own practice that otherwise they would not have noticed. This could be demonstrated by the following examples.

It wasn't until I finished the case and initially I reflected that I felt it actually went quite well. But then when I revisited it and had everything down on paper when summarising it, I realised that as a matter of fact I put way too many strategies in ... So my reflection was that I overwhelmed the teacher with too many strategies, and that is something to be mindful of in the future.

Because sometimes you feel like you're dealing with a whole lot of bits of a puzzle and when I started putting all the data and compiling that, I started to reflect on, oh we need to go backwards here and have another look at our goal.

The process also encouraged RTLB to reflect on the type of data that they need to collect for the portfolio (and ultimately, for their job), as well as how to collect and present them. Although this aspect was generally acknowledged by participants as one of the RTLBs' weaker areas, most participants agreed that through the portfolio, they became more aware of how important it was to have good pre and post data, and how to collect this. To quote some participants,

Compiling the portfolio I guess kept me true to that process where there might be temptation to cut corners and so on, make shortcuts. I guess as I was working through that case, I was aware of what sort of data I needed to 
gather in order to demonstrate that I was delivering good practice.

I think that if I hadn't gone through the portfolio, I possibly wouldn't have realised how important that process is, to get the pre-data and the end data.

Other people seem to just have a bank [of forms] which they just photocopy as they need to go. But for me, it [the portfolio] has made me more aware of being creative in data collection and the types of forms that you require. One form does not fit all.

This kind of reflection encouraged the RTLB to be more thorough in data collection, not only to get good data out of it, but also to ensure that they did not miss out on any pieces of data that may later affect their intervention. Most participants believed that this has set them on a course of good practice and caused them to aspire to maintain the reflection as they moved on with their job. This statement by an RTLB illustrates:

I guess if I hadn't been as thorough in my observation before the intervention, I would have missed out that sort of insight and that was crucial to my understanding of what was going to be useful later on. In my current practice, that's a very important message for me to hold on to and I need to remember that the observation of the ecology of the classroom is really important and to try to understand what is working for kids and observing them in different situations. That's the reflection that stays with me and is particularly useful.

\subsubsection{Annotating and writing}

The fact that RTLB were required to annotate, (i.e., to make commentaries on the evidence) was also seen as a contributor to the reflection that occurred in the process. 
According to most participants, the annotation offered an opportunity for RTLB to critically analyse the artefacts that they had chosen, thus identifying their strengths and weaknesses, and how they could be linked to the intended learning outcomes. By making comments on these, the RTLB gained a clearer view of the reason behind their choice of artefacts and how they could demonstrate their proficiency. The following statements illustrate:

Because I had to actually write it down so I had a clearer sense of where I'm heading and why I'm heading there.

Writing those commentaries helped to strengthen my evidence by showing my thinking behind it and also by showing that it has met all those criteria.

The process of writing up the whole portfolio was also identified as an important stage in which the reflection occurred. In particular, the writing of reflective statements offered an opportunity for RTLB to critically think about who they were, what they did and why. This enabled them to enhance the reflection that was stimulated in the earlier stages by further consolidating their personal beliefs, theories and values. Through writing and rewriting those statements, participants acknowledged their reflection being triggered and enhanced.

Most of my reflection comes in as I start to write things up, just taking that out on paper and piecing things together.

I must have rewritten my portfolio three or four times. I think I rewrote it because I was reflecting while I was writing it, so that's why the rewriting occurred. 


\subsection{Reading and theoretical literature}

Another frequently mentioned contributor to reflection during the portfolio process was the course readings that the RTLB were required to do during the PDP. Participants specifically valued the reading list that they had been provided with and have reportedly come back to those readings from time to time in their current practice. Reflecting on those readings gave them the opportunity to gain a thorough understanding of the literature, of being a reflective practitioner, and of their professional work as an RTLB. For them, it was part of the portfolio that built up the practice of what to read, and how to read and interpret it. Many participants reported that they were amazed at how they could quote different researchers and theorists in their daily work, and know exactly what research to refer to in order to support their choices in practice.

If you hadn't compiled the portfolio, you wouldn't necessarily have such an in-depth knowledge of those theorists and how their theories relate to practice.

And being able to bring in a lot of research on what we're doing and link it to our practice was very valuable for me.

The reflection that was stimulated by those readings helped the RTLB to become aware of the role of theoretical literature and the importance of keeping their practice current and research-based. They went beyond the course readings and did their own search for relevant literature that supported their work. The following statements illustrate:

It [the portfolio] opened up the whole literature base as well. My own reflection wasn't just within my own understanding but it has perhaps led me 
to a better understanding that I didn't have [before] because I've had to search the literature and reflect on the basis of what the literature has to say. I think finding literature that appears to be robust and useful was a really important part of that.

So that's one of the awareness that I had from my portfolio, that my research and what I'm asking the teachers to do has to be current, and it has to be research based.

By reflecting on this aspect, not only did the RTLB establish the practice of using research-based evidence to support their work, but they also challenged themselves to look at theoretical literature in a balanced way by asking questions, such as: "Is this what all the research is showing or is this what the research that I want to look at is saying?" Or, "there is a lot of research that says this but does it really fit in the system where we are? How does it fit with my personal philosophy? Is it relevant?" Such questions allowed them to reflect on who and what they are with respect to the literature, and then work forward in their own practice.

\subsection{Collegial support and professional supervision}

Most participants claimed that a considerable part of their reflection occurred when they were having critical dialogues with colleagues. They generally found it helpful to share with colleagues and have their thoughts and ideas reflected back to them. This was attributed to the part of the portfolio process where they were exposed to a safe environment in which they could be honest and open to share their understanding and experience.

I'm better at reflecting by talking things through with other people so part of my reflection was bouncing off my colleagues. I think I'm better at putting it 
into words, spoken words with someone and that may not necessarily feedback ideas. It's just that I'm blurting stuff out when I'm going. And that's what self-reflection is to me too, looking at the good and the bad part of it.

So through talking and all that, the portfolio has taught us to dig deeper and reflect all the time.

Since an important component of the portfolio dealt with following a collaborative model, reflection was bound to occur when RTLB were involved with teams or when they worked on collaborative projects. Many participants reportedly reflected on the differences between being a classroom teacher and an RTLB, with the former working independently while the latter's work often involved collaboration. This kind of reflection made them become mindful of other people's thoughts and feelings, and try to make sure that they were not imposing their own thoughts on others right from the start. It also prompted their awareness of obstacles that may hinder their work as a collaborative RTLB, especially in the secondary context where the system was rather balkanised (Hargreaves, 1994). Such a balkanised state, in which teachers worked in separated departmental units with little chance for crossover, forced the RTLB to reflect on their skills in order to get people interacting with one another without taking over, thus identifying areas that they could acquire more knowledge, experience, and skills. The following quotations demonstrate this:

When you look at problem analysis, you have to be able to reflect on your teachers and listen to what they're saying, so you're internalising your own reflection. It's a reciprocal process going on here.

So I guess my reflection has extended to the thinking, putting myself into others' shoes and think how they feel in the situation they're in with me. 
You're working in what you think is a collaborative way with the teacher and then the next time you come in and they're veered off from what you're doing. The next minute, they're throwing something out and it becomes a whole new problem or case. So in my reflection, it's trying to stay on track with what we're actually here for.

In many cases, participants took part in peer supervision/mentoring as part of the portfolio process and they found it particularly helpful in enhancing their reflection. There were participants who were on the receiving end of the process, being a novice RTLB and getting supervision from more experienced RTLB in their cluster. There were also others who acted as mentors for a group of colleagues. They all found this experience rewarding because as they helped other teachers reflect, they themselves reflected.

Finally, most participants stated that having professional supervision also enhanced their reflection during the portfolio process. They generally valued the input of supervisors in triggering their own reflection, merely by asking questions or by assuring that they were doing the right thing. It helped develop the RTLB's sense of who they were and how they wanted to be.

I found her [my supervisor] a really good sounding board to make sure I was on the right track when I was thinking things through.

Additionally, some participants pointed out that the professional supervision that they had within the portfolio made them secure in the expectation that they could be confident in sharing where they were at without feeling like they were going to be "torn to shreds." An RTLB explained,

It's the opportunity to sit down with somebody who really knew this stuff and 
play out in the sort of way that lays out your heart, this is what I've done with the best of intentions for these families, these kids, these teachers, and this is me. And then have them very tenderly and gently challenge you and encourage you to improve on that.

It is worth noting that a large part of the participants' reflection in this aspect could be attributed to the respect that they had for the lecturers, whom many referred to as important catalysts for their reflection. Because they could really see that the lecturers did what they said, and modelled exactly what they wanted to be done, the RTLB began to value those things and were encouraged to critically reflect on their own practice. As an RTLB put it,

If it was sort of normal lecturers who would just say that and you can't see the link into how they actually operate that themselves and develop that respect then I'm not sure if it would have had such an impact.

\subsection{Developing a more critical understanding of the term "reflective practitioner"}

The final aspect of reflection to be discussed in this chapter is the portfolio's role in shaping the RTLBs' view on the meaning of being a reflective practitioner. While most participants claimed that they have always been reflective in their job, they did acknowledge that compiling the portfolio has added additional layers to their understanding of the term "reflective practitioner." Prior to the portfolio experience, their reflection very often tended to focus on the outcomes of their practice (i.e., whether it had been a good outcome or a bad one). Their aforementioned engagement in different aspects of reflection during the portfolio process thus enabled them to go beyond that and acquire a broader, more holistic understanding of what it meant to be a reflective practitioner. An RTLB explained: 
As a teacher, I guess that was probably more task specific. I was looking at more specific learning outcomes in the class whereas through the training, it's much broader. It's not just about academic achievements; it's more holistic and encompasses the whole ecological process that we work from. Yeah, quite a big mind shift for me, I think.

With a more holistic understanding of the term, most participants became aware that as a reflective practitioner, their reflection had to extend beyond its simplest notion, (i.e., continually looking at what they were doing and how they were doing it, making adjustments through the process if something was not working, or looking back at what could have been better if they had possibly done something differently). The portfolio made them aware of the need to reflect on what they were doing in relation to the principles that ought to be underpinning their practice. In other words, they must also look at the ecology of the learning environment, at the needs of the student, and the capability of the student in relation to the learning environment; then try to understand its dynamic and look toward a problem solving approach to any mismatches, as the following statements demonstrate:

The sorts of things that you're analysing would be, how it would fit best within practice, how the case that I'm working with is fitted ecologically and how the collaborative process went with the people that I was working with. Also, whether I'm consistent in what I'm doing. So with the goals that are set, do I follow the process through?

So if I'm truly reflecting, as I'm working through potential strategies and discussing with the people involved in the case, I think there's always reflective feedback dynamic which hopefully help me keep aligned with the 
principles by which I should be operating.

The above statements also pointed to the collaborative aspect of a reflective practitioner, which was also acknowledged by participants as something they learnt and valued from the portfolio experience. It could be about reflecting back on their colleagues and the collegial support that they gave and received around their work, or the ability to be open-minded when conflict took place in the job, or in the way they facilitated their work. Some participants also emphasized the importance of being proactive in listening to other people who worked with them and seeking feedback on how they were perceived as an RTLB and whether they have met the criteria for the role.

Another frequently mentioned component of being a reflective practitioner was the need for keeping their practice research-based. Some participants pointed out that this was a shift in their beliefs, as this aspect was often overlooked in their previous role as classroom teachers. Engaging in the portfolio process apparently opened up a new world of theories and research for the RTLB, and subsequently added to their notion of being a reflective practitioner. The following statements demonstrate this point:

We've also got to keep the research current because we're only reflecting on the limited knowledge that we have. That's not good enough.

For me it also includes going back and looking at more research and more ideas and highlighting in my thinking where I've got gaps and where I need to find out more information on.

Some participants pointed out that this added value to their understanding of the term 
"reflective practitioner" was partly due to the fact that the portfolio made them reflect more on the theoretical base of things, rather than merely taking a cursory look at what worked and what did not work. In addition, the portfolio provided them with a set of benchmarks that they could set their reflection against, thus enhancing their understanding of the term "reflective practitioner." An RTLB explained:

I think that probably once I've done the portfolio, the guidelines that they gave me for being a reflective practitioner were a bit tighter and I found those very useful, 'cause I probably wouldn't have been so ordered in my reflection before I did the portfolio.

\subsection{Conclusion}

This chapter investigated the participants' perception of their own reflection while compiling the portfolio. It discussed the different aspects of reflection that occurred throughout the portfolio process. The findings indicated that the portfolio process stimulated the RTLB's reflection on practice in a number of aspects, from selecting cases and evidence to writing, reading, and collegial support and professional supervision. It also promoted a more critical understanding of what it meant to be reflective practitioners.

Overall, the portfolio was perceived as a very valuable process, although it was also a "painful" one. It helped synthesize the learning that the RTLB had, and made them deeply reflect on their own practice. By going through this process, the participants found themselves involved in a process that allowed them to consolidate their understanding and personal theories regarding their job as an RTLB. It has also helped them become aware of the need to keep their practice current and researchbased, as well as the role of theoretical literature in their work as an RTLB. Given the time frame and all the energy that was invested in the portfolio, there were many 
things that the RTLB reported had remained with them that they found very valuable.

The reflection stimulated by the portfolio process was the learning tool to trigger some ongoing changes in the RTLB, such as the ability to be challenged about their assumptions. The portfolio was believed to keep them true to the process and the model that they were supposed to work in. In order to explore the ongoing influences of the portfolio process on teachers' reflection on practice, the following chapter will investigate the aspects of reflection that have been maintained since the portfolio experience ended. 


\section{CHAPTER 5: ON-GOING INFLUENCES OF COMPILING THE PORTFOLIO ON TEACHERS' REFLECTION ON PRACTICE}

\subsection{Introduction}

This chapter addresses the second research question, which investigates the ongoing influences of the portfolio on teachers' reflection on practice. In particular, it aims to identify aspects of reflection that were stimulated by compiling the portfolio that have been maintained since the portfolio experience ended.

As discussed in the previous chapter, participants reported that they engaged in reflection during the process of compiling the portfolio. The reflection occurred in a number of aspects including case selection, evidence annotation, data collection and presentation, and awareness of theoretical literature. As this study's main focus was on the ongoing influences of compiling the portfolio on the RTLB's reflection on practice, the participants were asked to identify which of the aforementioned aspects have been maintained since they completed the portfolio. The participants reported that most of those aspects have been maintained in their everyday practice and impacted on the way they do their job, although the reflection has not necessarily been accompanied by the compilation of a portfolio. The following quotations demonstrate:

Even now, as I look back through the portfolio, even though I reflected at the end of every case, now that I'm two years down the track, there's even more reflection which I suppose shows that I've had more learning ever since completing the portfolio. 
All of those [aspects] have been maintained. I actually use those all of the time. I actually feel so strongly about it that I actually don't think you should be an RTLB if you haven't gone through that process.

The following sections will outline the aspects of reflection that have remained with the RTLB since they completed the portfolio.

\subsection{Being better reflective practitioners}

When they were asked about what aspects of reflection have remained with them since the portfolio experience ended, many participants mentioned their better understanding of reflection on practice and its importance to their job as an RTLB. As discussed in the previous chapter, most participants acknowledged the added value that compiling the portfolio has contributed to improving their perception of the term "reflective practitioner". It gave them a more thorough understanding of what it meant to be reflective, and why it was important for them, as an RTLB, to be reflective practitioners. An RTLB explained,

Before, you don't really know about reflection, so the portfolio taught us how to critically analyse stuff so now that we've been given the skill, it's tailoring the skill as you go along. I suppose before, I thought as a classroom teacher I was reflective. But it wasn't until I've done the portfolio and you had to go through it inch by inch, that I really understood.

Such raised awareness has caused the RTLB to become even more reflective on their practice. Participants generally claimed that ever since they completed the training, they have been constantly reflecting on what they are doing in relation to the principles that ought to be underpinning their practice. This can be demonstrated by their considerations for different aspects of the cases that they work with, such as the 
ecology of the learning environment, as well as for other people who are involved in the cases. Participants also reported that since they completed the portfolio, their reflection on current practice has become more structured and ordered, and they have continued to reflect on the guidelines that they were given for being a reflective practitioner during the portfolio. An RTLB stated:

I think I'm learning all the time and I guess you might say the portfolio experience helped to set it off and my current practice is kind of an extrapolation of the principles and processes that the portfolio experience embedded. So I guess while I don't go and read my portfolio every night, I think there are aspects of the process that are still relevant and probably have had some impact on what I currently do.

As discussed in the previous chapter, the reflection process in which the participants were engaged while compiling the portfolio was highly valued in keeping them true to the model of RTLB practice for which they were trained. Most participants asserted that this aspect of reflection has been an ongoing one that prevented them from cutting corners and enabled them to stay true to the process that they were trained to follow in their professional practice programme. The reflection therefore has been maintained throughout their casework and has triggered further reflection as they went along. The following statement demonstrates:

As you think you're getting better at one thing, there's always another area that you become enlightened to and you think, I need to make my shift now. And each case is very different too, like trying to tailor the intervention to the uniqueness of what you're working with, so there's a lot of learning to it, trying to be innovative with what to come up with as well. 
Most participants revealed that they did not continue to compile a portfolio; instead, they have been reflecting in a less structured manner in comparison with what they did with the portfolio. Instead of putting their reflection down on paper, most participants asserted that they now reflect constantly in their heads and via dialogues with colleagues, critical friends, or supervisors. According to participants, reflection has to some extent been naturally incorporated into their own practice and personal beliefs. They now do it automatically and are quicker at reflecting. This can be inferred from the following statements:

I don't think it's something that you can now not do because it's just become a natural thing that you do. You look at what you do so that you can improve on it next time.

I think it [the portfolio process] is a very structured way of doing it that has morphed into a less structured way of doing it. But we still do case closures where we reflect on what we've done and the impact that it's had and what are the next steps that would be useful for the school. Those things are included as part of our work as well, but it's actually a part of what we're meant to do.

There are many different instances in the RTLB's job in which reflection has been maintained. Case summaries, as mentioned in the above quotation, were referred to by several participants as such an instance when most of their reflection on practice takes place. Several claimed that they have continued to write reflective statements at the end of each case, which is influenced by their experience with the portfolio. It is a stage in which the RTLB have the opportunity to really look back at their 
practice and reflect on what they did, how well they did it, and what could have been done better, as the following statement indicates:

Sometimes you can lose sight of where you're heading with a case and I have to be honest and say, sometimes the reflective part of it starts to become more enlightening to me when I write up my full summaries. So I'm sort of dissecting it as I go.

Nevertheless, apart from that, reflection in the form of writing has generally been maintained at a minimal level due to a number of constraints. This will be discussed in more detail in the next chapter. However, it is worth mentioning here the only case in which a participant has compiled a portfolio since completing the PDP. This portfolio has been compiled specifically for her appraisal. The participant described her own experience as follows:

We have an appraisal system and I do a portfolio for it. I don't have to but my appraisal shows all the learning outcomes again. It's pretty much set up as how this [the portfolio for EPSY 564] is but it's about half the size of this. Because I put all those efforts into showing that I'm having these targets and that I was doing the job that I was appointed to do and a lot of it has reflective evaluations in it, so I self-reflect. I put down what I could have done better. I put down what went wrong, what went well, and then I get the teacher, or the main person I was working with in the casework to also comment on how I did the job, and they usually list a part of their evaluation as where do they think I could improve.

This participant did emphasize that as much as this helps her reflect, she does not do it on a regular basis, but only at the end of a term or a year. She also pointed out that 
while she enjoys doing it and finds the experience rewarding, her colleagues do not seem to have the same opinion. Other participants were somewhat skeptical about the possibility of keeping a portfolio in their current practice due to constraints such as time and workload. This issue sets up a basis for further discussion and recommendations that will be addressed in Chapter 7.

\section{3. Ongoing reflection on the learning outcomes of the programme and setting them as standards for practice}

Another prominent aspect of reflection stimulated by the portfolio that has had ongoing impact on participants' reflection on practice was their continued reflection on the LOs. As seen from the previous chapter, the LOs of the professional development programme under study were a crucial component that was embedded in every part of the portfolio. Throughout the process of constructing their portfolios, RTLBs had to present their casework and evidence in relation to the LOs, which have been described in Chapter 1. Because RTLBs had constantly to review those outcomes throughout the whole portfolio process, it could be assumed that they have been somewhat enbedded in the RTLB's mind and in their practice.

Such an assumption appeared to be valid, as most participants acknowledged that they have been reflecting back to the learning outcomes in their work since the portfolio experience ended. The reflection occurs at different points for different participants; some have been constantly reflecting back on those outcomes throughout each case while others only do it when they are doing their end of year appraisals. However, in general, those LOs are characterized by participants as the foundations for their job as RTLBs and thus have been internalised into the participants' practice. As some RTLBs explained, 
I think they're just internalised really because it would be hard work recalling all of them individually but when I look at them, they form the basis of what we do every day.

Most participants applauded the benefits of having such LOs internalised in their practice. For many, they serve as over-arching guidelines that shape what they do and why they do it. They have become the benchmarks against which practice could be measured. Some participants reported that those LOs have formed a set of questions that they regularly ask themselves as they self-assess their own practice. This has helped them to become better reflective practitioners, and at the same time encouraged them to facilitate the same sort of reflection among teachers that they work with. The following statements demonstrate:

I think these are good things for us to have in our heads and when we are listening to what the teachers are saying the problems are, we've got those things in the back of our minds, those questions that we're thinking about, we reflect on those and the way we give reflective questions to the teachers.

The learning outcomes have always been very specific to our job. In order to show that you're a reflective practitioner, that you're doing your job, it's basically like having an overall statement that encapsulates what your job description is.

I think they have [become standards for my practice]. They morphed into what we're doing.

Among these LOs, following an educational/ecological model was generally perceived as one that stood out as a standard for practice. Many participants stated 
that they have been following the ecological model as set forth in the portfolio, in which they are urged to be mindful of different elements of the cases that they are working with. In that sense, instead of just collecting data about the characteristics of particular child, for example, the RTLB go further to find out other things that might be influencing that child in his/her environment. They also involve the teachers in the process in order to establish what they see as the problem, and to help them become aware of other ecological factors that may need to be considered as well. Participants find this particularly helpful as it triggers teachers' reflection on the shifts that they can make within their own programmes. This model therefore appeals to them as something that they need to be more reflective about in order to ensure that they were consistently working within that model, as illustrated by the following statements:

I'm actually working to that model all of the time so that it's not just the teachers or the task but it's the instructions, the homes, the schools, the students, all of that.

I think of the learning objectives that are listed, following an ecological model would be the one that I perhaps have picked up on the most and have probably applied more in my previous work.

Working to a collaborative problem-solving model is another LO that has been set as a standard for practice by most participants. Given their original roles as individual, self-reliant classroom teachers, some participants pointed out that working within a collaborative model was a fairly new concept for them as RTLB practitioners. By going through the portfolio process, they began to gain a much better understanding of the concept; that it is not just the sharing of ideas, but also about all the parties 
being able to each have a part in the process of it right from the outset till the end. Such a shift in awareness urges them to continue to reflect on the concept and everything that is associated with it. An instance of such reflection can be seen in the following statement by an RTLB:

When you walk into a room, you can see that there're children that the teacher may be a bit harder on or they're not working in an equitable fashion for children. Sometimes it's brought to your attention because you've got the luxury of being able to look at things as a whole picture. They're right in the midst of something and they don't necessarily see their behaviour may be influencing the children in the room.

Such an instance of reflection on the teacher's role in facilitating equitable learning opportunities further enhances the RTLB's understanding of collaboration and its contribution to their job. It has encouraged them to stay true to the collaborative model in which a reflective feedback dynamic between the RTLB and all other parties being involved in the case is maintained from the beginning of a case until it is closed.

The other LOs have also become standards for practice by most of the participants, albeit to a lesser extent. For example, working to improve learning and behavioural outcomes for Māori students has not been a frequently revisited one due to the fact that most participants have not had much chance to work with Māori students. However, most participants emphasized that this LO is always on the back of their mind although they do not use it often. In some cases, participants did revisit Māori pedagogy in search for the solution to a non-Māori case, because they believe that what is good for Māori students is good for all students. This demonstrates the internalisation of the LOs in the RTLB's practice and beliefs. To quote a participant: 
They're not even things that you think about. I mean you do keep those more in the forefront of your mind. They've become such strong beliefs in your belief system that you don't even think about.

\subsection{Being research-based practitioners}

As seen in the previous chapter, one of the most prominent aspects of reflection that was stimulated by compiling the portfolio was the RTLB's raised awareness regarding the role of research and theoretical literature in their practice. Most participants commented that the portfolio experience has set up a strong theoretical basis that they have continued to revisit. The exposure to different authors with different ways of thinking through the portfolio in the process of reflecting and writing has impacted participants' views on theory and research-based practice. According to participants, such awareness has remained with them and shaped the way they think and do their job. This can be seen in the following statements:

This legitimized taking the time to actually think about it and taking the time to go back and look at the research rather than just keep on doing the things that you always do. I think that makes quite a difference.

It's crazy really because you can start quoting. And you're able to just recall and I think it's because you've written it so many times in the portfolio. Yeah, it's definitely true. You relate your work back to that.

Most participants asserted that as an ongoing influence of the portfolio, they now understand the value of looking at their work from a research angle. It encourages them to take time to investigate the literature behind everything that they do in their job and, in many cases where they are dealing with particularly challenging tasks, to venture into other resources that could help with their problem. According to 
participants, it puts them in a good position where they know that their practice is research-based, and that they can actually cite different authors' work to support their practice. Participants saw this shift in their beliefs as an important part of being a reflective practitioner. In some RTLBs' words:

It got me to sit down and think about the theories, and heading back to the books rather than doing it for the sake of, you know, gee I did it last time regardless of the problem.

I feel that there's a world of information out there that one needs to be up to date with to really be fresh and functioning appropriately.

When asked about whether they have continued to look into theoretical literature in their current practice, most participants claimed that they have, albeit not to the level that they would desire. Some participants have had more opportunities to do this than others due to their ongoing study and access to university libraries. Most participants acknowledged that they have been revisiting the materials that they got from the training and continued to reflect on those with regard to different casework that they are working on.

I certainly dip into a lot of what we have previously because we had so much in there, so many notes which are really good, relevant notes that are still applicable to what I'm doing.

Some of these readings in particular have had a strong impact on the RTLB's current practice. Many participants mentioned certain readings that they found particularly relevant to their job and professional interests, and emphasized the values that they have brought into their practice. The following statements demonstrate: 
I know in my readings, there was some stuff on student motivation that I come back to from time to time again. In fact I often refer to it with teachers I'm working with.

I think when I look at a class learning environment, those three aspects [from the readings] come back to me a lot. I think they are useful tools for trying to understand the learning environment for kids who may appear to not be coping with it. So that would be a big one for me and one I live with even today.

Some participants also claimed that apart from the readings that they got from the training, they have also ventured into new materials, albeit not as much as they would have liked. In most cases, they have dipped into new materials about topics that they are particularly interested in, and also those that are relevant or can be of some help to the cases that they are working on. An RTLB asserted:

Yes, certainly, not only look back at the old materials but also the new materials. One of the things that I did over the past 3 years while I'm involved with this job is I have gathered new materials and I've done a bit of reading on some areas that I'm interested in and involved in some work around that. Yes, I do go back and hunt the literature from time to time.

Participants have gained access to new materials in a variety of ways. The Ministry of Education library was referred to as one good option for those who do not have access to university libraries through ongoing study, and some participants mentioned the role of professional supervisors in recommending relevant materials. There are also other circumstances in which exposure to new materials has been facilitated, such as in the following example: 
And when we do our community of practice group, we try to bring in some research findings, but certainly not trying to do nearly as much. I did enjoy the new learning that went with it, just to know that sometimes you can be paddling on a part and then you read some research on it and you think, well no wonder it's not working.

Some participants also observed that as an influence of the reflection that was stimulated by the portfolio process, they have become more critical in appraising new materials to which they have access. As mentioned in the previous chapter, during the portfolio experience, not only did the RTLB establish the practice of using research-based evidence to support their work, but they also challenged themselves to look at theoretical literature in a balanced way by asking questions regarding the credibility and validity of the research and how it matched their goals. This kind of reflection has remained with them and has caused quite a shift in their practice. In that sense, instead of accepting new materials at face value, they take time to consider where it comes from and how it fits with the situation that they are trying to apply it to. An RTLB explained:

And even question new stuff that comes out, question the integrity of the person who's suggesting all the research, where I'd say stop, hold on, who is this person who's suggesting this research? What are the other credentials and whether they align with the meta-theory that they believe in.

However, although participants generally acknowledged the raised awareness regarding theoretical literature and their own efforts in keeping their practice research-based, participants generally claimed that they have not managed to do it at a desirable level. In most cases, this was attributed to the RTLB workload, as most participants are currently responsible for quite a large number of cases. Many 
participants saw this as an obstacle that prevented them from maintaining the habit of reading and researching new materials. The following statements explain:

It would be nice to be able to have about five cases which you could really focus on theory, the underpinned behavior or learning or whatever to help your goals. I still do that in cases when something is going on but not all the time.

Yes, it was critical in our learning but I have to be honest and say that as important as it is, I find now, with all the paper work that we're doing, it's the time factor of being able to do all the reading and stuff.

Many participants also pointed out that although they have been venturing into new materials, it is not up to the level that they would have liked. Again, it is the time factor that plays a key role here. Participants generally find it quicker and easier to go back to materials from the training because they know exactly what to look for and where; however, it is not always the case for new literature from other sources. As important as they know it is, it requires more effort and motivation to maintain the practice to a desirable level. To quote a participant:

I can't say I've been taking the initiative in going into a lot of new stuff. I just don't have the time. Holiday time, I'd probably try to pick up one new thing.

\subsection{Ongoing influences on the collection, management and presentation of data}

Participants also identified the collection, management and presentation of data as another aspect of reflection that has been maintained since the portfolio experience ended. As described in the previous chapter, compiling the portfolio had a 
considerable impact on RTLBs' awareness and reflection regarding the type of data they needed to collect and how to collect them. Most participants affirmed that this reflection has been maintained and continued to shape their thinking and practice. The following statement by an RTLB demonstrates this:

Certainly data driven analysis of the situation is important and certainly that is something that the portfolio emphasized and it's something that I attempt to continue with.

Most participants acknowledged the learning and reflection that this process stimulated and affirmed that they have been doing what they learnt from the portfolio. Because they had to follow a very detailed process of collecting and presenting data in the portfolio, their current practice in this regard has also become more structured, as they are more sure about what data they are looking for. This can be exemplified with the observation process in which the behaviours and the environmental settings that they are trying to capture can be known and considered beforehand. The learning from the portfolio has thus been consolidated and sustained, as can be inferred from the following statements:

Yeah, [I'm still doing what I learnt from the portfolio] and still learning to manage, to make it more concise.

It was a huge learning curve at the beginning too. It was one of the areas that grow straight off because you look at things from an ecological perspective and how you can gather the data in that way. I think it really consolidates my learning of what you're observing, becoming a better practitioner.

The most prominent ongoing impact of compiling the portfolio in this aspect was arguably the raised awareness regarding the importance of quality data and proper 
data collection process. Most participants claimed that compiling the portfolio has enhanced their understanding with regard to robust data and its impact on the success of their intervention and its subsequent outcomes. The emphasis on the importance of pre and post data in the portfolio has also been incorporated into their practice and has assisted them when they are working on other cases. This has been affirmed to have an ongoing impact on the data that they collect, as exemplified in the following statements:

Pre and post data was emphasized as being important and I think it got me to be thinking about that when gathering the initial data. Ok, we've got all this, how will we able to see whether we have made the difference with that data later on, can we compare.

I think in our work where we're meant to try to not just go by hunches, we need good data and triangulated data from more than one source. I would certainly try and practice it currently.

Moreover, many participants also emphasized that the reflection that they experienced during the portfolio process has encouraged them to maintain the data collection process that they familiarized themselves with in the training. That is why in their current practice, the RTLB try to gather as much data as possible and to be more thorough throughout the process. By staying true to the model and the process, participants could be assured that they would not overlook crucial insights and details regarding the situation, thus managing to gather data of higher quality. This has caused a shift in their practice, as demonstrated by the following statements:

Before I used to worry about if I had to go back and get more data because sometimes you're sort of mid-way through something and now I don't 
hesitate. Now I just think, we need to go back. We've gone down the wrong path; we need to go back and have another look.

I think just working through that system, we work through the model that we were taught in the training is something that I really keep going with. So I'm quite particular about getting as much data as possible and doing observations and then coming back and just presenting that data and then expecting everybody to play a part in analysing it, so it's not about just what I think about it.

Beside data collection, the management and presentation of data also benefited from the reflection that was stimulated by the portfolio. Some participants reported that thanks to what they learnt from their experience during the portfolio process, they have now become more organized and creative in managing their data, although they generally do not keep them in a nice package like the portfolio. Some also stated that their data has been computerized for easy management, and they make sure that the teachers will get a copy of any data that is collected, as well as the case summary. An RTLB explained:

When it came to this sort of thing, it's easier to be organized, and also organized in my thinking about the job, about what was required. But yeah, you just do your end of it. Everything definitely has happened since I was done with the portfolio.

The same applies for data presentation in which participants praised the portfolio process for inspiring them to continually reflect and try to present their data in such a way that is concise and "user-friendly" for the teachers they work with. Because of the word limit being applied as a restriction in the portfolio, RTLBs had to find other 
ways to convey their messages. The use of charts, graphs and tables was thus seen as the optimal solution, and has continued well into their current practice as they reflect on the best ways to clearly and concisely present the data. Most participants find this particularly helpful for their teachers who are likely to get discouraged by long written texts. Given the RTLB's efforts to follow a cooperative problem-solving model that required active participation from teachers, this certainly helped to facilitate the involvement of the teachers in the casework which most participants find rewarding. The following statement illustrates:

Ifound that the teachers really like to see it in that sort of format. It makes so much sense to them than a whole lot of writing. They seem to be bombarded by that.

When I presented it [data] to the teacher in a graph format, she saw it for herself, like the data spoke for itself. She could say, oh he's actually quite capable. And she said to me, I wonder if he's getting bored, and then I have to put more into my program for him. So I never had to initiate that; she arrived at it. It's very neat when teachers arrive at that, but they don't have the luxury to just sit and watch that child for half an hour.

However, as they continue to reflect on this particular aspect, participants generally claimed that data collection is still their weakest area. Most of their problems lie in the process of collecting pre and post data. Many participants claimed that they have had trouble figuring out what kind of data they need to collect. This issue can be attributed to the difference between their original role as a classroom teacher and their current role as an RTLB. An RTLB explained, 
One of the areas that I needed to hone was data collection. As a classroom teacher, you do observations but not to the intensity that we do as RTLBs, and that for the first couple of years was an area that I really worked hard to focus on, to get good data. But now, I'm better at the data than I was before but I'm still not there with the data, that's still an area I reflect on and I still go to others and say, what would you do for this? What sort of stuff would you collect?

Others found it challenging to balance between gathering data, having evidence, and maximising their time with a case or situation. This is due to the fact that they often have many cases to keep track of simultaneously, which minimises the time they spend on keeping proper written records of each case. Having to deal with this issue, knowing they are expected to do differently, has caused a conflict about doing their job while also needing to demonstrate in an accountable way what is happening and what the data shows. This conflict apparently has not been completely resolved, as an RTLB explained:

I guess if I was to do a portfolio job on every case, I would have to reduce my case load by $50-60-70 \%$, otherwise I'd be locked in the office three days a week doing the write up work.

This is similar to the aspect of researching new materials, in that the participants were aware of the level that they ought to be working to but failed to do so. As previously mentioned, such shortcomings could be attributed to constraints such as time and workload, which are also accountable for the lack of written records in the RTLB's current practice. This issue will be further discussed in chapter 6 . However, the level of dissatisfaction expressed is evidence of ongoing reflection by RTLB of their own practice against what they believe to be the standards of good practice. 


\subsection{Conclusion}

This chapter took the first step into investigating the ongoing influences of compiling the portfolio on the RTLB's reflection practice. In particular, it aimed to answer the question of which aspects of reflection on practice that were stimulated by the portfolio process have been maintained after the portfolio experience ended. The findings revealed that most of those aspects have been maintained in participants' current practice, albeit at different levels.

It can be concluded that compiling the portfolio has influenced RTLBs to become better reflective practitioners. This was highlighted by their raised awareness in what constituted the term "reflective practitioner", as well as by using the LOs from the training as overarching guidelines against which to reflect on their practice. It was also demonstrated by the participants' attempt at keeping their practice researchbased by revisiting materials from the training and, to some extent, by venturing into new research. Also, their efforts in maintaining and improving the data skills that they learnt from the training and the awareness of their own shortcomings proved that the reflection has been ongoing in this aspect as well.

The following chapter will investigate how these aspects of reflection have been maintained after the portfolio experience ended. 


\section{CHAPTER 6: MAINTAINING THE INFLUENCES OF THE PORTFOLIO ON TEACHERS' ONGOING REFLECTION ON PRACTICE}

\subsection{Introduction}

This chapter reports and discusses the way in which teachers' reflection on practice has been maintained since they completed the portfolio. As presented in the previous chapters, the portfolio process stimulated the RTLBs' reflection on practice in a number of aspects, from selecting cases and evidence to writing, reading, collegial support and professional supervision. It was also revealed that since the portfolio experience ended, most of those aspects, to some extent, have been maintained in participants' current practice. This was demonstrated by their enhanced understanding of the term "reflective practitioner"; their use of the LOs from the training as overarching guidelines that their practice could be evaluated against; their attempt at keeping their practice research-based by revisiting materials from the training and also venturing into new research; and, lastly, their awareness and efforts in maintaining and improving the skills that they learnt from the training with regard to the collection, management and presentation of data. This evidence has validated the portfolio's long-term influence on RTLB's reflection on practice. This chapter will examine the conditions under which the reflection has been maintained since the completion of the portfolio.

Overall, participants reported that they have maintained reflection in their current practice. The reflection has naturally been incorporated in their practice, although there has also been help from supervision and collegial support in various forms. However, participants also claimed that there was not much written evidence to 
show that they were reflecting. The following sections will address this issue in more detail to examine the quality of reflection among participants, the reasons why they have not been maintaining reflective writing, and, under such circumstances, how their reflection has been maintained since the portfolio experience ended.

\subsection{Quality of reflection}

Most participants claimed that the portfolio enhanced their reflection, and that reflection has since been occurring daily in their practice, although it has not been maintained at the same depth of reflection as it was while they were compiling the portfolio. Although they have not been keeping a portfolio in their current practice, all of the participants asserted that their reflection has been sustained as they incorporated the good practices that they learnt in the portfolio process into their daily work. This can be seen in the following statements:

When I start an intervention, I always make sure I use something that's evidence-backed, but portfolio-wise, I'd only be looking at that ecological model and working through the whole process. That's what the portfolio could have given me. And the reflection part comes in at each of these stages in the process of it.

For me the benefit derived from the in-depth analysis of one's work especially in relation to the relevant literature and what has been taught over the past 2 years ... I tend to be fairly self critical but it would appear that the practices described in the portfolio have been largely beneficial to me. I believe that that being consistent with the inclusive paradigm fits comfortably with my aspiration. It is something I try and reflect and work on nearly every day. 
Most participants argued that while the portfolio process was very structured and somewhat artificial, the way they are reflecting now has become more practical and sustainable. It now comes out of need, but the RTLB has merged it with the criteria that they learnt from the portfolio and thought more deeply about how they can best do their job based on those criteria. In that sense, reflection has continued to grow as participants gradually self-improved as an RTLB. It has led them to take the time to consider the appropriateness of their actions in practice and hunt down more information in their attempts to problem solve and improve performance. The reflection that has been maintained so far is thus viewed as purposeful and useful, as indicated by the following statements:

The quality of my reflection, I would say, is probably broadened and it continues to grow so it's sort of find other ways in which I can reflect. And how do you keep on that self-improving system.

The fact that we actually had to do it [the portfolio] in a quite detailed way actually helps us to minimize a little bit at other times and then we can still follow ... we're still aware of what we're doing. We don't necessarily have to do it at a greater depth for every case.

One example of the reflection as a growth process was the participants' activeness in seeking professional development opportunities. Some participants described this as something new to them, given their previous role as classroom teachers. The portfolio experience has made them become more aware of their new role as change agents, thus the importance of keeping their practice current. Most participants asserted that they have continued to reflect on this and tried to seek for more professional development opportunities, alongside reading, thinking and researching 
the areas that are of interest to them, as the following statement demonstrates:

The other thing that might show that you're evolving is your interest in what $P D$ you're going to do. So therefore you might be choosing different PD from the interest through your reflection and therefore gain more knowledge.

Some participants also asserted that their reflection has become more specific and thorough, as they developed a more critical eye in evaluating their own practice. Not only did they continue to reflect on things that were happening in their current practice, they also reflected on their own reflection in the past and acknowledged the shortcomings that they once did not notice. This demonstrated their growth as a reflective practitioner, as shown by the following statement:

I think I may have changed since then, just looking at these [reflective statements in the portfolio] is embarrassing. But this has humbled me. I think when you really do reflect on your work, it's a very humbling experience.

\subsection{Form of reflection}

As mentioned above, most participants claimed that their reflection has not been maintained in written forms, such as a portfolio or a reflective journal. Most of them pointed out that as an influence of the portfolio, they have been constantly and automatically reflecting, albeit in their thinking rather than in the form of writing. It has become a natural part of their practice, as an RTLB asserted:

I reflected in my head. It's very hard actually to stop that. I think we just do it all the time.

Without the pressure of being graded, written records have been maintained at a minimal level, much less than when keeping a portfolio. A few participants mentioned that they did keep reflective notes as part of their case summaries or 
appraisals, albeit not as comprehensively as they did with the portfolio. Some participants referred to the case summary in particular as a vehicle to sustain their reflection on the goals that they have or have not achieved after a term or a year, and the reasons behind their choices of practice. A minority of the participants reported that they did this, although most participants asserted that keeping reflective notes would probably be a good way to maintain the reflection on an ongoing basis. An RTLB described her experience regarding reflective notes as follows:

Sometimes I make lists of what I want to look up more than I make journal entries like I did in my portfolio. It's nowhere near comprehensive at all, but I have a very good memory so I do remember a lot of stuff which is quite good. But I do tend to take more bullet point notes that I can hold on and go back to.

The participants provided a number of reasons for the lack of written evidence of their reflection, one of which was the fact that it was not compulsory for them to do so. Even though they had all the evidence and documentation needed for their job, they generally did not have the obligation to keep written records of their own reflection or to provide commentaries on their practice. Participants argued that in the portfolio, the commentaries were meant to demonstrate their understanding to lecturers, whereas in their current practice, they have no one to demonstrate that to. As an RTLB explained:

I suppose because, to be honest, there's no requirement to. The portfolio is the documentation and the commentary, why you did it. I don't have to provide that in my documentation now. I don't even have to provide a reflective statement; however, I always have a reflective statement at the end of a case but that's as far as it goes. 
Another prominent factor that discouraged participants from keeping written records of their reflection was the time factor. Most participants claimed that their job as an RTLB was already too busy with all the paperwork involving different cases to find sufficient motivation to write more than they were obligated to. Some mentioned that they have resorted to sticky notes and bullet-pointed lists to remind them of their goals or the theories that they ought to look into. Keeping a reflective journal or a portfolio therefore did not appeal to the participants, as they were concerned about the time and effort that ought to be invested so as to do it properly. The following statement demonstrates:

Sometimes it's hard enough keeping up with the paperwork requirement as it is without having to put a commentary on every aspect of what you've done. If I could limit it to five cases then it would be good.

The above quotation also pointed to the RTLB's workload as an obstacle to reflective writing. According to participants, within their current practice, they are trying to maintain a high number of cases whereas with the portfolio, they only had to focus on the cases that matched the requirements of the paper. This meant that once they decided on the ones that they were going to do, all of their energy went into those cases and thus other cases did not get as much attention as they could have. An RTLB explained:

It's all good but I'll have to say if I have to write, it would divert me from other stuff that I'll be doing and I don't know if I'll go back to it. But it's not to say that I'm not highly self critical or highly self reflective so I think I do it but not in that way.

Some participants also argued that because the practices have been embedded in 
their thinking as they become more experienced in their job as RTLBs, they should not need to write down every detail as they did in the portfolio. They pointed out that the portfolio process was an important step that established and embedded the good practices in their own thinking. As they completed the training and moved on with their job, those good practices have remained with them in everything that they do, even though the writing has not been as comprehensively maintained. An RTLB asserted:

I would like to think that I can justify everything I do; it may not be all in writing. That's the way it is.

However, participants generally thought that maintaining written evidence of their reflection on practice was a good model to work forward to and was not beyond what they should be expected to do. Some participants suggested that it could be a good idea to keep a reflective journal as part of their end of year appraisal, in which they could provide examples of good practice and justify them with evidence and commentaries. It would give them a chance to reflect on what they do in their job and set goals for the following year.

It would be nice to have something that you can go back over and look at and something that you can talk through at an appraisal. It's a mind-jogger rather than something you have to have.

When asked about maintaining the reflection, most participants mentioned supervision and collegial support as the two main vehicles that helped them sustain their reflection on practice after completing the portfolio. Participants particularly valued formal supervision and collegial support in the form of a community of practice, as they greatly helped them grow as a reflective practitioner. The following 
sections will discuss these two aspects in more details.

\subsection{Maintaining the reflection: Formal supervision}

According to participants, a large part of their reflection has been maintained by their engagement in formal/professional supervision. Having been exposed to the supervision that was offered during the portfolio experience, participants understood its value in stimulating their reflection on practice, and thus the importance of keeping it ongoing. Some have worked with personal supervisors; others have had group supervision in which an outside facilitator helped them reflect on the issues that came out of a group perspective, and how they might deal with it as a group. There were also those who have not had the access to formal supervision but would like to have the opportunity. Overall, participants viewed formal/ professional supervision as a valuable and necessary vehicle in maintaining their reflection. The following statements demonstrate:

It's really helpful in terms of where you're going but also to make sure that your practice is safe. I'm not sure if you can get that entirely from peer supervision, from within your cluster.

It would actually send me back into my practice with new enthusiasm and a definite direction toward which I could act upon. It's something I could take away and do it.

Most participants perceived that formal supervision made them more reflective by giving them the opportunity to discuss their practice with someone with expertise who really understood their job as RTLBs. They could take the cases that they were struggling with or did not think that were going so well, and their supervisors would use probing questions to help them reflect on certain aspects that may not have been 
addressed in the past. They found it particularly helpful that they could be honest with their supervisors and get some direction as to where they might need to improve in their practice. This was something they could only get from a professional supervisor, as an RTLB explained:

Although I could discuss it with colleagues, because they were trained so long ago, I feel like some of their suggestions or direction sent me down a different paradigm.

Participants also pointed out that formal supervision helped them keep the reflective process at the forefront of everything they did. They generally valued the professional conversations that they had as their supervisors kept them focused and asked questions that triggered their own reflection. Participants claimed that they benefited a lot from a process in which they arrived at the solutions themselves instead of having the supervisor tell them exactly what to do. In most cases, participants found added value in the fact that their supervisor was someone they respected and trusted, as the following statements demonstrate:

I got a lot from that. I would take any issues, any concerns and just be able to talk and reflect on it and get a little feedback from her or she might just sort of say what are her thoughts about that. It helps me a lot because she's reflective.

He doesn't say a lot necessarily. I tell him what I'm working and he'll ask me a couple of questions and I'll think, hmm I didn't think of that. They're just questions that I know that are good reflective questions, that are open ended, that I actually need to think about.

The fact that they were given such questions to reflect on challenged the RTLB to 
look at their own practice with a more critical eye and really consider the changes that had to be made in order to improve practice. In that sense, they have learnt to be less egotistical and more open to different options other than those that they have always followed. Some participants acknowledged that they reflected better and learnt more when their supervisors pushed them out of their comfort zone. An RTLB explained:

I like to go and think, yeah I need to look at that or do something else. I think for me having a formal supervisor allows you to have that opportunity just to push a little bit further. You learn a lot of lessons on the way but there's always a lot to learn.

Furthermore, some participants also pointed out that such formal supervision gave them the acknowledgement that they sometimes needed. They could come to their supervisor when they were not too sure about whether their reflection on certain things was going in the right direction or not, and be assured that they had made the right choices. According to some participants, this kind of acknowledgement boosted their confidence, hence sustaining their reflection on practice. An RTLB explained:

Sometimes you just want that, you want someone to say you're doing the right thing and it looks fine even though it might not working, that would be something that I would have done too. I guess sometimes you just need that affirmation. Yes, formal supervision is good.

Another benefit that formal supervision has contributed to the RTLB's ongoing reflection was the guidance on literature and research. Most participants appreciated having a supervisor who was continually researching and could point them to particular journal articles or books that could be relevant to their needs and/or 
situations. This gave them a better sense of direction as they ventured into new materials, which has been identified as one of the weaker areas among the majority of participants. An RTLB asserted:

[Without a formal supervisor] You have to sit at the computer for hours and search for articles and journals whereas I can sit down with him and discuss and he'd say, oh have you read about so and so and his paper, and I'd go, no I haven't. So he'd give me the name of the paper, and so I can have it.

However, as much as participants valued formal supervision as a vehicle to sustain their reflection on practice, they also expressed regret that they have not been receiving supervision to the level that they would have liked. A number of participants reported that their formal supervision had been recently aborted which was a disappointment as they knew they needed it. Others have been doing group supervision but think that individual supervision would be a better option. An RTLB explained:

It's not that I didn't find it valuable, it's just that in a group I don't think it's as specific as it should be.

According to participants, this situation could be blamed on the lack of financial funding for individual supervision. Some participants also expressed concern regarding the quality of supervision, even if sustained, as they mentioned the possibility that their management might be considering cheaper options. An RTLB explained:

And I think it's very important who we have as our supervisor. We can go and get someone who's really cheap but I think the quality that we get out of the discussions with him ... high quality conversations, an hour's worth of 
very valuable stuff. That was good.

As mentioned above, some participants have not had access to formal supervision. However, they all asserted that it was something that ought to be addressed. Although they have never received formal supervision, they were generally aware of the benefits that it could bring and the impacts it could have created on their reflection on practice. The following statement demonstrates:

I think that would hugely [help with the reflection] actually. I really like an idea in psychology that action shapes our belief more than our belief shapes our action, so if we actually put it in there and actually do it, that impacts on your doing much more than you say, yeah I think it's important but you don't ever give it time.

\subsection{Maintaining the reflection: Collegial support}

Beside formal supervision, collegial support was also perceived as having played an important part in maintaining the participants' reflection. As discussed in the previous chapter, the portfolio process made them more open to sharing thoughts and ideas with others, thus stimulating their reflection. Most participants pointed out that this still applies in their current practice, as they find it extremely important to have colleagues whom they can talk to and who can help them reflect. Despite the distinctive features of their job as RTLBs that requires them to work across multiple schools, participants generally reported that they have been trying to maintain this collegial support, as it was essential for sustaining their reflection. The following statements demonstrate this:

It's hugely important. I don't think RTLBs should be working on their own. I would hate to be in an office all on my own because I think on your own, 
you're not reflective enough. But other people pose questions that make you more reflective and that process is really important. Talking about things clarify your thoughts.

I think I'm really lucky because we're a good cluster and we talk to each other and we've got a lot of different strengths and experience and networking in the area at different levels of that in the cluster so personally, I do spend a lot of time talking to other people and colleagues about things and what I'm doing and listening to what they say. I'll look at the research, I'll talk to other people and I'll share cases in our case discussions. I spend time to think and allow time to think about things.

\section{5.1. Collegial support within cluster}

Most participants claimed that a large part of their reflection occurred during conversations with colleagues within their own cluster. These could be informal dialogues that happened everyday in the office. In some cases, they would visit one of the schools in their cluster together and discuss casework as well as reflect on the cases. Sometimes the reflection they have actually undergone was also communicated back to the school, allowing the school to understand what direction they were taking with the casework. It also gave them a chance to receive feedback from the school's leadership as to whether they were satisfied or not, or to justify why something had or had not happened. Most participants found this particularly valuable, as can be seen from the following statements:

I guess we get a better understanding of what we can do better. We share what's working in our schools and what's not. We all share like that, and how we can do things better. 
I think sometimes you have to discuss some of the interplay with the people within your working environment. What you think is safe but may be some other doesn't.

Some participants reported that they have also maintained informal supervision in the form of peer supervision. This provided an opportunity for RTLBs in one cluster to supervise each other through discussions about different issues in their casework. In such events, they each would bring a case and talk through it with the rest of the cluster. They would also have to justify their own choices by answering others' questions about things that were happening in their practice, and reflection was thus sustained. In many cases, peer supervision was included as part of the cluster's appraisal in an effort to compensate for the formal appraisal that has been recently lacking in some clusters. An RTLB explained:

That's very useful and it's also good for us because we're the person who's reflecting back to the person that's telling us about their issues. It's given us an opportunity to think things through.

Participants generally found peer supervision useful, although they admitted that it was not at the same level as formal supervision. One of the drawbacks of peer supervision, as pointed out by some participants, was the gap between the recently trained RTLBs and their other colleagues who had undergone training a long time ago. This could pose itself as an obstacle to the effectiveness of the peer supervision that was going on in that cluster, as the following statement explains:

It's not that great because the others are working in a different model to what I'm working so they tend to be a bit more deficit in the way in which 
they operate [work in the functional paradigm]. I don't feel I get as much learning from that. Some of their ideas don't fit with what we're trying to do.

Some participants mentioned that their reflection has also been sustained by tutoring colleagues who are new to the job and have not gone through the same training. As they pointed out, this was an ongoing influence of the portfolio, because the portfolio experience was such a valuable one for them that they felt the responsibility to share their knowledge. This was a process where their reflection was triggered, and their learning was once again consolidated, as an RTLB described her experience:

What I did, because there's no training this year, I said to her that I could go through the training in my first year. So I got all my folders there, and we've gone through it. And so having taught her what I learnt has been a reminder to me, and it's still very current in my mind, and I've gone through the exact same steps so I actually tutored her exactly the same way as I was tutored, and I got all the readings there so I gave her the readings as we go through one step at a time. By doing that, she and I have actually shared understanding of our work, even though she isn't under training.

This process was perceived as valuable because not only did it help them reflect back on the portfolio and the training, it also allowed them to see what knowledge they could bring and how this impacted on their colleague, as well as the cases that they were working with. This made the experience even more meaningful, as the following statements demonstrate:

Sometimes they're so busy looking at this that they forget the stuff that they're meant to be covering. It's much easier when you're on the outside to see that, so I think that's very useful. 
I found it really, like, awakening. It's something I enjoy doing 'cause I knew what I was doing, I got into a really good flow. It supported how I felt. It gave me meaning and it gave the job purpose.

However, the most prominent benefit of this peer tutoring/supervision in maintaining the participants' reflection was that it was a reciprocal process where the RTLBs learnt from each other. Some participants emphasized the fact that as they went through the process, the colleague that they tutored turned out to be a critical friend who played a key part in stimulating their reflection on practice. The conversations that took place throughout this process were highly valued in stimulating thoughts and reflection in such a way that the RTLB could not get from other colleagues. Participants also found it particularly useful to have someone to reflect with and challenge them to keep the reflection ongoing. An RTLB explained:

I think that's a really important part of reflecting as well, having someone to talk to. So I would regard her as my professional buddy, even though she's not an expert or a trained RTLB. She's got other skills that I regard as really valuable to me, and I've got skills that she regards as valuable to her too, so we bring that together and we do a lot of reflection on that.

\subsubsection{Collegial support across clusters/ Community of practice}

Apart from the collegial support that they received from their own cluster, participants also valued the professional relationship that they have been maintaining with RTLBs from other clusters. This cross-cluster support that they received could be as simple as informal meetings where they discussed aspects of practice. However, it was the establishment of formal communities of practice for RTLBs across clusters that was credited by most participants as an important vehicle in maintaining their reflection. Because all participants included in this sample were 
working in secondary schools, they generally found their work slightly different from primary practitioners. A community of practice specifically initiated for RTLBs in secondary school was therefore seen as a good opportunity to present and share the things that they found useful, discuss the issues that they had in common, and look at better practice and better opportunities, as the following statements demonstrate:

I think that network is a very important source of reflection and guidance and learning. All of those, I guess in a sense have been a substitute for the supervision role that the portfolio was a part of.

That is something that we will definitely continue with and I think we hope to meet a couple of times a year at least.

Participants pointed out that through the community of practice, they were able to work within a collaborative problem-solving model that was deemed important to them as RTLBs. Because the community of practice served as a forum for professionals from different clusters to share data and resources, the issues that needed to be addressed were collectively analyzed from multiple angles, hence producing more holistic solutions. Not only did participants find this collaborative approach helpful in generating better outcomes, they also admitted to having learnt a great deal from the collaboration process with other professionals. An RTLB asserted:

It's where many of the best outcomes occur because it's not one person analysing and delivering a solution. It's about a group of people looking at the data, looking at what might need to be addressed and coming up with a 
collaborative solution. And those are the situations that generally have the best outcomes.

The most prominent feature of a community of practice that made it an important vehicle in maintaining participants' reflection was the opportunity to have their practice challenged and critiqued. Some participants compared this feature of the community of practice to the portfolio in that despite the differences in form (the latter is in formal written form while the former is in a less formal oral form), they both aim at ensuring that the RTLB's practice is of a high standard. Reflection on practice is therefore stimulated and enhanced in both processes, as a participant explained:

If someone says to you why did you do that, you've got to have some sort of theory to base it on or evidence to show that when I collected these data, this is what the data shows me, therefore I think the theory sees it and this is why I did it. It's the portfolio verbalized.

\subsection{Conclusion}

This chapter examined the ways in which the RTLB's reflection on practice has been maintained since the portfolio experience ended. Most participants claimed that the reflection that was stimulated by the portfolio has been maintained daily in their practice, although it has not been maintained to the same depth as it was while they were compiling the portfolio. The overall quality of reflection was generally perceived as more technical as it grew to cater for participants' professional needs. Most participants agreed that there has been a lack of written evidence of their reflection for a number of reasons, such as time constraints, heavy workload, and the fact that it was not compulsory to maintain reflective writing. 
Much emphasis was put on formal supervision and collegial support as important vehicles in maintaining the participants' reflection. In the participants' view, the former was valuable for the professional guidance and the sense of direction that a formal supervisor could offer as he/she triggered the RTLB's reflection, while the latter provided them with opportunities to share with their colleagues the things that they found useful, discuss the issues that they had in common, have their practice challenged and critiqued, and look at better practice. All of these helped participants sustain the reflection that they developed from the portfolio experience and continue to grow as reflective practitioners. The following chapter will discuss the recommendations for sustaining the reflection stimulated by the portfolio. 


\section{CHAPTER 7: DISCUSSION, IMPLICATIONS AND CONCLUSION}

\subsection{Introduction}

As discussed in the early chapters, despite the large body of literature addressing multiple aspects of portfolio assessment, there remained the need for further research to better understand the role of portfolios in promoting professional development (e.g., Borko et al., 1997; Smith \& Tillema, 2003; Jones, 2007, 2009, 2010a, 2010b). In particular, very few studies have been conducted on the long-term influence of portfolios on teachers' reflection on practice. In that context, Jones (2007) emphasizes the need for further research into the sustainability of reflection after the portfolio experience is completed and calls for a follow-up study to verify whether the reflection is maintained on an on-going basis. This thesis has therefore sought to shed light on the area of interest, specifically on the process of compiling the portfolio and its ongoing impact on the RTLB's reflection on practice.

To achieve this aim, this thesis has focused on three main objectives. Firstly, the study has examined RTLB's reflection stimulated by the process of compiling the portfolio. Secondly, it has explored the aspects of reflection that have been maintained in the RTLB's practice since the portfolio experience ended. Thirdly, it has investigated the vehicles that helped sustain the reflection. Relevant literature was reviewed to establish a theoretical background for the study, which highlighted a need for research on the area of interest. A qualitative approach was adopted, and data were collected from a focus group and semi-structured in-depth interviews with RTLBs from different clusters in New Zealand. Content analysis was then employed to analyze this 
information.

This concluding chapter summarizes and synthesises some of the main issues addressed under each of these three objectives. This is followed by a discussion of the implications for practice based on the findings from the study. Limitations of the study and recommendations for future research are then presented. Some concluding remarks summarizing the study's main findings, and its significance and contribution to the area of interest are presented..

\subsection{Discussion of research findings}

\subsubsection{Reflection promoted by the portfolio process}

The first prominent finding from this study is the role of the portfolio as a process, not a product, in promoting reflection. To begin with, it should be noted that this process seems to manifest itself as a laborious and even "painful" one, although its value is generally appreciated. The most obvious reason for this is the time and the amount of work that is required to complete the portfolio. Another reason for the perception of the portfolio process as a "painful" one could be the fact that RTLB are not familiar with this form of self-reliant assessment as they may be more accustomed to assessment being provided by an external agent. It can therefore be difficult for them to understand the entire process and decide on which materials to include in their portfolios. This issue has been recognized by some researchers (Smith \& Tillema, 1998; Wade \& Yarbrough, 1996) who thus emphasize the need for clarity, particularly in the explanation given at the beginning of the process. Furthermore, it can be implied from the findings of this study that teachers initially may not have adequate understanding of reflection as a skill and how they are expected to reflect during the process. This is likely to add more pressure on them from the onset of the portfolio 
experience.

Despite these difficulties, it is apparent from the findings of this study that the portfolio process is highly valued for promoting reflection. It helps synthesize the RTLB's learning and encourages them to deeply reflect on their practice. A deep level of reflection essentially means opening oneself up to more specific feedback (Thornow, 1993). The reflection stimulated by the portfolio process is thus the learning tool to trigger ongoing changes in practitioners' practice, particularly by allowing them to challenge their personal theories in relation to the way they facilitate their jobs. This supports the findings by Jones (2009), who claims that the inclusion of a personal theory statement in the portfolio process helps raise RTLBs' awareness of the content and influence of their personal theories on practice, and consolidates the link between their theories and the literature being presented in the PDP.

In summary, the findings of this study indicate that the portfolio process stimulated the RTLB's reflection on practice in a number of aspects, from selecting cases and evidence to writing, reading, collegial support, and professional supervision. It also promotes a more critical understanding of what it meant to be a reflective practitioner. Among these, the writing involved in the portfolio process appears to be one of the most important factors in promoting reflection. In particular, the writing of reflective and theory statements seems to offer an opportunity for the practitioners to critically think about who they are, what they do and why, thus further consolidating their personal beliefs, theories and values. Furthermore, the reflection appears to be greatly assisted by the faculty support during the portfolio experience, as well as the collegial support within clusters. Each of these aspects plays an important part in promoting teachers' reflection on practice. These findings are closely consistent with Jones' (2007) and support Smith and Tillema's (1998) view 
on the portfolio's main function, (i.e., to provide relevant feedback about one's own performance while offering opportunities for dialogue and reflection about performance).

\subsubsection{Sustained aspects of reflection after the portfolio experience}

The second objective of this study is to investigate the ongoing influences of compiling the portfolio on the RTLB's reflection on practice. In particular, it aims at finding out which aspects of the reflection on practice that were stimulated by the portfolio process have been maintained after the portfolio experience ended. The findings reveal that most of the aforementioned aspects have been maintained in participants' current practice.

Compiling the portfolio has influenced RTLB to become better reflective practitioners in that they continue to reflect on what they are doing in relation to the principles introduced during the portfolio process. This aspect of reflection appears to be an ongoing one that prevents them from cutting corners and enables them to stay true to the process that they were trained to follow in the PDP. However, it should be noted that the reflection has been maintained in a less structured manner than it was during the portfolio experience; it now occurs mostly via dialogues with colleagues, critical friends, or supervisors.

Another sustained aspect of reflection that has been identified in this study is the use of the LOs from the training as overarching guidelines against which teachers reflect on their practice. The findings from this study indicate that those LOs, to some extent, have become standards for the RTLBs' practice. Among those LOs, following an educational/ecological model and working to a collaborative model are most commonly employed as standards for practice. By reflecting on these LOs, RTLB are reminded to be mindful of different elements of the cases that they are 
working with and maintain a reflective feedback dynamic between themselves and all other parties involved in the case from beginning to end.

Other aspects of reflection that have been sustained are the RTLBs' attempts at keeping their practice research-based and maintaining the data skills that they learnt from the portfolio. As the findings suggest, the research aspect of reflection has apparently remained with the RTLB and has caused quite a shift in their practice, in that instead of accepting new materials at face value, they take time to consider their source and how they apply to the situation they are addressing. Also, their efforts in maintaining and improving the data gathering and presentation skills that they learnt from the training and the awareness of their own shortcomings indicate that the reflection has been ongoing in this aspect as well.

However, it should be noted that there is a gap between the RTLBs' ideals of what it means to be a reflective practitioner and their performance in reality, for which the above two aspects of reflection can serve as good examples. For both of these aspects, the practitioners are aware that the reflection has not been maintained at a level that they see as desirable. The findings also reveal that overall, the reflection has not been maintained at the same depth as it was during the portfolio experience, and it apparently does not seem to be at the critical level in which the reflection is linked to the wider ethical or socio-political issues related to the case. Furthermore, as much as writing helped them to reflect during the portfolio experience, it has not been maintained in their current practice. This issue will be further discussed in the following section.

\subsubsection{Vehicles for sustaining reflection}

The final objective of the study is to investigate the way in which teachers' reflection on practice has been maintained since they completed the portfolio. The findings 
suggest that the overall quality of reflection has become more practical as it grows to cater for participants' professional needs; however, the lack of written evidence of the RTLBs' reflection is also apparent. The findings indicate a number of reasons for this issue, such as time constraints, heavy workload and also the fact that it is not compulsory to maintain reflective writing in the participants' job. Despite these reported barriers, the example of one RTLB who has been compiling a portfolio for her appraisal raises some interesting points. Firstly, the issue of maintaining reflective writing may largely depend on the practitioners' attitudes towards its importance and relevance to their reflection on practice. Secondly, the maintenance of the portfolio in the form of an end of year appraisal appears to be feasible, as long as its scope and scale are manageable. If it is properly sustained, reflective writing can be particularly helpful in enhancing reflection. This study therefore supports Walker's (1985) viewpoint that the use of writing can facilitate the integration of existing and new knowledge by creating a dynamic in which one's existing knowledge is held in a more "fluid" state. Walker thus asserts that portfolio writing not only helps practitioners reflect and learn, but also allows them to appreciate the actual process of reflection within learning.

The participants in this study put considerable emphasis on formal/professional supervision and collegial support as important vehicles in maintaining the postportfolio reflection. The former is deemed highly valuable for the professional guidance and the sense of direction that a professional supervisor can offer as he/she triggers the RTLB's reflection, while the latter provides them with opportunities to share with their colleagues the things that they find useful, discuss the issues that they have in common, have their practice challenged and critiqued, and look at better 
practice. These findings support a number of studies (e.g., Boud, 2010; Brookfield, 1995; Klecka et al., 2007) in which contextual elements are emphasized as significant in enhancing reflection. This finding also fits Boud et al.'s (2006) notion of productive reflection which highlights the collective approach to reflection in group settings. Accordingly, reflection has an organizational rather than an individual intent, and a collective rather than individual orientation. Reflection is necessarily contextualized within work; it connects learning and work, involves multiple stakeholders, and connects players (Boud et al., 2006). These key features of productive reflection are to some extent present in the findings of this study, which confirms that reflection can be enhanced by being relocated in the professional practice context that is characterized by contextualization, transdisciplinarity, embodiment, and co-production.

In the same vein, the findings from this study show that the establishment of communities of practice is also an effective vehicle for sustaining reflection. This finding aligns with Klecka et al.'s (2007) study that advocates practitioners' participation in professional communities outside the context of their own institutions. Klecka et al. highlight the importance of "professional, crossinstitutional collaboration to promote reflection that is not confined by institutional norms and policies" (p. 35).

\subsubsection{Summary}

Figure 7.1 illustrates the conceptual framework of the ongoing influences of the portfolio process on teachers' reflection on practice. Firstly, it identifies the aspects of reflection that are stimulated during the portfolio experience: engagement in the 
process, reading and literature, engagement in collegial support and faculty supervision, and raised awareness regarding reflective practice. It then presents the aspects that have been maintained in the post-portfolio stage, including the use of LOs as standards for practice: being research-based, practicing data skills, and always being reflective. The supporting agents as well as the barriers that exist in the process are also presented. 


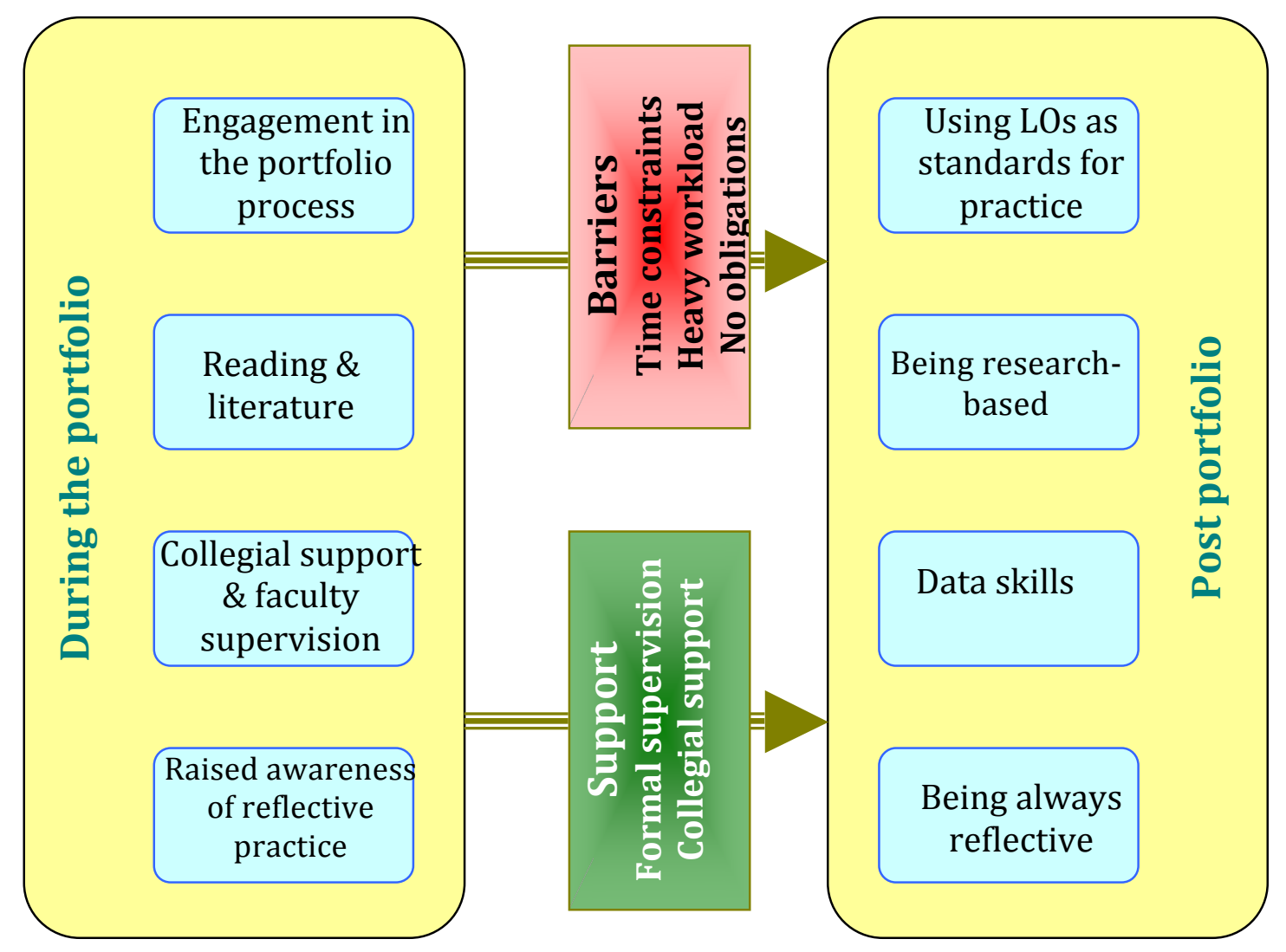

Figure 7.1. Conceptual framework for ongoing influences of the portfolio process on teachers' reflection on practice.

In summary, the findings suggest that the portfolio does fit into teachers' ongoing reflection on practice. It serves as a vehicle for teachers to reflect in a relatively complex and intense manner in a long and laborious process. Because of the efforts that have been put into that process, in which a great deal of writing and rewriting is involved, the RTLB are thus firmly set on a course of good practice. The principles and methods laid down in the portfolio process are embedded and continued well into their current practice, causing them to constantly reflect on what they do and why. Judging from the findings of this study if it were not for the portfolio experience, the practice would presumably not be as good. So while the portfolio 
document may not be maintained, the reflection is ongoing, albeit in a less structured and more practical manner.

\subsection{Implications for practice}

\subsubsection{Maintaining the reflection}

The findings of this study allow the researcher to arrive at several implications for practice. First and foremost, in order to sustain the reflection after the portfolio experience ends, it is crucial for the practitioners themselves to understand the need for reflection and have the desire to make continual improvement. As Dewey (1933) points out, having an attitude which values one's own personal and intellectual growth as well as others' is central to developing reflective practice.

Secondly, it is important to maintain professional supervision. As the findings of this study suggest, supervision is, in a sense, a part of the reflection process and thus manifests itself as an effective way to keep the reflection going. Supervision encourages transformational learning which "creates new mental maps or meaningmaking frameworks that help interpret their experience, learn from it and go back to their work with new insights and new behaviors" (Carroll, 2010, p. 17). Supervisors play an important role in promoting the ability to reflect systematically, (i.e., to look back on an experience in a structured manner, and to draw conclusions for future actions) (Korthagen \& Vasalos, 2005). However, it is important to ensure that the supervision is centred around the practitioner while the supervisor takes on the role of a facilitator for reflection and learning. It means that supervisors should be careful not to focus too much on teaching competencies without taking into account the overall objective of promoting reflection (Carroll, 2010). Supervisors must also have 
confidence in the practitioners' capacity for self-direction and give them sufficient autonomy to apply metacognitive knowledge (Meeus et al., 2008)

Thirdly, building supportive clusters and communities of practice can be crucial to the sustainability of any reflection stimulated by the portfolio. As implied by the findings of this study, a high trust model among colleagues within a cluster can facilitate reflection at a very honest level. Conditions for such a supportive work context include effective leadership, shared decision making, opportunities and rewards for collaboration, adequate time to focus and reflect on the growth process, and follow-up opportunities (Ellsworth, 2002). Additionally, another important finding of this research suggests that critical friends play a significant role in maintaining the reflection. Being able to have a professional conversation with someone, or to share the reflection in a serious manner can help stimulate reflection and learning, as in many cases the "critical friend" is not necessarily someone from the same cluster or has the expertise in the same area. It is therefore a process of cross sharing as well as reciprocal learning.

Finally, it is recommended that a refresher course is held every year in order to help RTLB maintain their reflection and keep them updated with the latest practices. In a sense, it can be argued that the portfolio experience provides RTLB with good theories and ideas, but once they finish the training and move on with practice, very often some of the learning may be lost. A refresher course can therefore be particularly helpful in sustaining RTLBs' reflection after the portfolio experience ends. It can be a one-day session for RTLB to get together, reflect back to the portfolio experience, and see what impacts it is currently having on them. It can also serve as a self check to whether one has strayed from the principles of good practice that were exemplified in the portfolio. 


\subsubsection{Sustained portfolio use}

"Portfolios are not a novelty, but for many - probably the majority - of faculty, creating and maintaining them would be an innovation" (Wright, Knight \& Pomerleau, 1999, p. 100).

The biggest challenge for sustained portfolio use is that it is a time consuming and laborious process. Therefore, when it comes to actually keeping a portfolio, it is crucial to understand its importance, make the time for it, and follow the process through. People who think more favourably of self-directed learning and see the relevance of the portfolio process to their own work tend to use the portfolio as an instrument for personal development more easily and readily (Smith \& Tillema, 1998). In the same vein, one factor to be considered for sustained portfolio use is the balance between the dimensions of purpose and setting of use. According to Smith and Tillema (2001), while voluntary use of the portfolio is better in enhancing professional development, it is more likely to be sustained if it is mandatory. Smith and Tillema also suggest that a balance can be reached by the inclusion of a coach in the assessment context who provides instructions for the compilation of the portfolio and at the same time offers professional and personal support in a non-threatening way.

It can therefore be recommended that a portfolio process is incorporated into the mandatory appraisal process at the end of every year. As discussed earlier, the maintenance of the portfolio in the form of a year-end appraisal appears to be feasible, as long as it is set up with a manageable scope and scale. In that sense, the portfolio can be used as a template to develop a "mini" portfolio that effectively shows the quality of casework without being as detailed as the original portfolio. It may include the dimensions that practitioners need to show or the learning outcomes 
that help demonstrate to their management committee that they are working effectively. It also serves as an opportunity to see that practitioners are following the model that they have been trained to use and that their reflection on practice is ongoing.

Additionally, in order to sustain portfolio use, it is necessary to ensure that the portfolio establishes clear individual needs and aspirations for further development. This means that regular maintenance must be conducted to monitor the progress of changes and growth as demonstrated by the portfolio. In that way, practitioners can gain confidence in their ability levels and become more determined in refining them (Smith \& Tillema, 2001).

\subsubsection{Implications for portfolio use in the Vietnamese education context}

As discussed in the introduction chapter, the Vietnamese higher education system has been receiving much criticism regarding its many shortcomings, especially when it comes to the quality of training and education. Assessment in the Vietnamese education system in general and its higher education system in particular has not been receiving proper attention; the main form of assessment that has been used so far is summative assessment which is deemed subjective and not scientifically reliable (Tran, 2006). This situation has persisted for a number of reasons. One of the very important goals of assessment is to promote learning; however, in the Vietnamese higher education context, assessment often serves only the most basic purposes of assessment, without addressing its wider and deeper intents (Le, 2008). In that sense, it aims at evaluating lecturers' performance rather than encouraging improved practice or the elevation students' achievement. Furthermore, the assessment process is mostly conducted internally, where colleagues openly comment on one another's performance. This tends to create a sense of unease 
among the lecturers themselves and thus manifests itself as a threat to the validity and reliability of the assessment (Tran, 2006).

Another reason for the current situation is that the assessment process fails to address the double targets that are associated with it: personal growth and the university's benefits and responsibilities (Le, 2008). The use of quantitative criteria for assessment such as the number of published articles, or the number of research projects that lecturers participate in can lead to unexpected outcomes in that lecturers only focus on the outcomes of their job rather than how to continuously improve their practice. They do not reflect on their practice as they go along but only after they finish the job. In some cases, student evaluation is conducted at the end of a course in which students are asked to comment on the lecturers' performance; however, it does not address the difficulties and challenges that students have to go through in the process. Therefore, it does not help lecturers self-assess and make appropriate adjustments during the teaching process (Tran, 2006).

In that context, the use of the portfolio as a form of appraisal for lecturers in Vietnamese universities is likely to fill the gaps that have been left open in current practice. It provides formative assessment while promoting professional development and improved practice, thus enhancing the quality of teaching and learning. As asserted by Rijdt et al. (2006), teaching portfolios are very useful for appraisals, and can effectively demonstrate and clarify teachers' efforts. Using portfolios as an assessment tool for learning competencies can therefore allow teachers to be professionally competent and capable of continuing to learn on a lifelong basis.

In addition, the use of portfolios in the Vietnamese higher education context can also be useful for the assessment of pre-service teachers. Similar to the case of in-service 
teachers, the assessment for teachers in training in Vietnam has also been mainly summative, in that pre-service teachers are assessed based on traditional theoretical tests, the development of one (or more) lesson plan, and one (or more) teaching session in a simulated classroom while being observed by a panel of assessors. This form of assessment is heavily theoretical and does not facilitate a holistic judgment of the student teachers' competence. Furthermore, it does not promote learning and professional development. While it is impossible, and by no means necessary, to reform the entire system, the portfolio can be incorporated into a practical component of the teacher-training programme.

In particular, most teacher training programmes in Vietnam include an internship period in which teachers in training spend a few months teaching at schools to gain practical experience. The assessment of their learning and practice in this period is done solely via a formal report to be submitted by the end of the internship. In this context, the portfolio seems more likely to be appropriate and useful. Instead of writing a formal, heavily theoretical report, student teachers could be required to compile a portfolio to demonstrate their competency with regard to what they have been trained to do in the previous components of the training programme. By doing so, student teachers can gain a more holistic and accurate insight into their students' learning and competence, while students can benefit from the formative aspects of this form of assessment.

However, certain issues need to be taken into account when applying this form of assessment into practice for both pre-service and in-service teachers. Firstly, as discussed in the previous section, portfolios are time consuming; therefore appropriate time should be allotted for teachers to work on this assessment task. Preservice teachers, in particular, should have adequate time to practise and become 
comfortable with the process of compiling the portfolio. Secondly, because portfolio assessment is unfamiliar to students and teachers alike, the purpose, requirements and process must be made explicit to both parties. Also, as indicated by the findings of this study, it is particularly important to model what students are expected to do so they have a clear understanding of the requirements and expectations. This issue has been recognized in a number of studies that suggest teachers who are developing portfolios often need a lot of scaffolding during the process (Klecka et al., 2007). In addition, specific strategies for reflection should be taught to both pre-service and inservice teachers (Ellsworth, 2002). As discussed earlier, the findings of this study imply that teachers initially may not have an adequate understanding of reflection as a skill and how they are expected to reflect during the process. This is likely to add more pressure on them from the outset of the portfolio experience. Finally, support from peers, faculty and colleagues is crucial to the successful implementation of portfolio assessment. It is thus important to create a supportive environment in which the necessary conditions for reflection and inquiry are provided. In such an environment, teachers should have the opportunities to be involved in collaborative work, to reflect with peers, and to benefit from faculty support and supervision (Ellsworth, 2002).

In conclusion, with careful attention to the introduction of the portfolio and guided support throughout the portfolio process, the use of portfolio assessment can be particularly valuable in the context of the Vietnamese higher education system. It will not only fulfill the basic purpose of assessment but also enhance teachers' reflective thinking and their enthusiasm for learning about themselves, others, and the process of teaching (Wade \& Yarbrough, 1996). 


\subsection{Limitations of the study}

This study has employed an appropriate methodology that has generated meaningful results. The findings have been presented and discussed based on the research objectives and linked back to the literature review. However, it is necessary to consider the limitations of this study.

Firstly, due to the limited scope of this study, the findings relied solely on the perception and judgment of the participants. Furthermore, the sample of this study did not include RTLB who were less successful with the portfolio (i.e., had lower grades or failed the portfolio paper). The reason for this selection criterion is because this is a small-scale study, hence the need to focus on rich sources of information. However, it could be argued that the study did not address both ends of the spectrum, which may pose certain threats to the generalisability of the research findings. Furthermore, as explained in chapter 1, I was already favourably disposed to the concept of portfolio assessment from the outset of the study. In that sense, although the study has employed triangulation in a variety of forms to enhance its validity and reliability, there is a possibility that personal bias might have played a small part in the study.

Purposeful sampling was used to select participants for this study because it helps develop a deeper understanding of the phenomena being studied by selecting cases that were likely to be "information-rich" with respect to the purposes of the study (Gall et al., 1996). However, this sampling method has certain limitations, one of which is the limited ability to generalize from the sample to a wider population (Johnson \& Christensen, 2008). Also, the sample was rather small despite the range of participants' characteristics within the sample, as described in chapter 3. In particular, the number of participants who took part in the focus group was much 
less than desired. This was due to the participants' conflicted schedules, which made it very difficult for the researcher to arrange a time for the meeting that best suited everyone.

Participation in and attribution of information from the interviews and the focus group require formal consent from participants. While obtaining the consent from the interviewees was not difficult, it did take quite a long time to confirm all the interviewees' participation. Additionally, while all of the participants were extremely helpful and keen to participate, busy schedules meant it took quite a lot of time to confirm an appointment.

Last but not least, the researcher is not a native speaker of English; therefore, to some extent, the language barrier can be an obstacle in gaining in-depth information from the interviews, as well as in reporting the research findings.

\subsection{Recommendations for further research}

Due to the aforementioned limitations, several recommendations for further research can be made. Firstly, future research could expand the scope of this study to include a larger sample and more diversified participants. This will provide a more comprehensive insight into the area of interest and allow for better generalization that can represent a wider population. Besides the research design could be expanded by conducting a comparative analysis on student and faculty portfolios instead of just focusing on the participants' perceptions.

Additionally, empirical studies on the application of portfolio assessment in the Vietnamese higher education context would be particularly valuable. The findings from this study suggest that the use of portfolio assessment has the potential to fit well in the Vietnamese higher education context. It is therefore recommended that 
further research is undertaken to collect empirical evidence that validates these findings. A more thorough investigation into the Vietnamese higher education context and its cultural, social and political features is also recommended in order to generate a more detailed proposal for the application of portfolio assessment in Vietnam.

\subsection{Conclusion}

This study has made a theoretical contribution to educational research, particularly in the field of portfolio assessment, as well as a practical contribution to the understanding of the ongoing influences of the portfolio process on teachers' reflection on practice. Firstly, the study confirms the portfolio's role as a vehicle for teachers to reflect in a relatively complex and intense manner in a long and laborious process. The portfolio thus serves as a conduit for teachers' professional transformation while giving them a safe environment to discuss and reflect (Klecka et al., 2007). Secondly, it has been revealed in the study that compiling the portfolio does have an ongoing influence on RTLB, which encourages them to become better reflective practitioners. This is highlighted by a number of aspects of reflection that has been maintained since the portfolio experience ended, and while none of these aspects has reached a critical level, they do have positive impacts on the RTLBs' practice. Finally, the findings of this study indicate that the ongoing influences of the portfolio can be maintained by regular professional supervision, a supportive environment in which the necessary conditions for reflection and inquiry are provided, and an attitude that values one's own personal and intellectual growth. It is therefore recommended that with careful planning, modelled instructions and guided support throughout the portfolio process, portfolio assessment may potentially 
enhance teachers' reflective thinking and enthusiasm for learning and teaching in the long term. 


\section{REFERENCES}

Antonek, J., McCormick, D., \& Donato, R. (1997). The student teacher portfolio as autobiography: Developing a professional identity. The Modern Language Journal, 81, 15-27.

Argyris, C. and Schön, D. (1974). Theory in practice: Increasing professional effectiveness, San Francisco: Jossey-Bass.

Ashford, A.N., \& Deering, P.D. (2003). Middle level teacher preparation: The impact of the portfolio experience on teachers' professional development. Paper presented at the Annual Meeting of the American Educational Research Association, Chicago, IL.

Atkins, S. \& Murphy, K. (1993). Reflection: A review of the literature. Journal of Advanced Nursing, 18, 1188-1192.

Barton, J. \& Collins, A. (1993). Portfolios in teacher education. Journal of Teacher Education, 44 (3), 200-210.

Baume, D., Yorke, M., \& Coffey, M. (2004). What happens when we assess, and how can we use our understanding of this to improve assessment? Assessment and Evaluation in Higher Education, 29 (4), 451-477.

Bellenger, B., Bernhardt, K., \& Goldstucker, J. (1976). Qualitative research techniques: Focus groups interviews. In T. Hayes \& C. Tathum (Eds.) 1989. Focus group interviews: A reader ( $2^{\text {nd }}$ Ed.) Chicago, Illinois: American Marketing Association.

Biggs, J. (1998). A role for summative assessment. Assessment in Education, 5 (1), 103-110. 
Bloor, M. \& Wood, F. (2006). Keywords in qualitative methods: A vocabulary of research concepts. Sage.

Borko, H., Michalec, P., Timmons, M., \& Siddle, J. (1997). Student teaching portfolios: A tool for promoting reflective practice. Journal of Teacher Education, 48 (5), 345 - 357 .

Boud, D. (2010). Relocating reflection in the context of practice. In H. Bradbury, N. Frost, S. Kilminster, \& M. Zukas (Eds.) Beyond Reflective Practice: New Approaches To Professional Lifelong Learning. UK: Routledge.

Boud, D., Cressey, P., \& Docherty, P., Eds. (2006). Productive reflection at work. New York: Routledge.

Boud, D., Keogh, R., \& Walker, D. (1985). Reflection: Turning experience into learning. New York, NY: Kogan Page/Nichols.

Boud, D. \& Walker, D. (1998). Promoting reflection in professional courses: The challenge of context. Studies in Higher Education, 23 (2), 191-206.

Boyd, E. \& Fales, A. (1983). Reflective learning key to learning from experience. Journal of Humanistic Psychology, 23 (2), 99-117.

Brookfield, S. (1995). Becoming a critically reflective teacher. San Francisco, CA: Jossey-Bass.

Buysse, V., Sparkman, K., \& Wesley, P. (2003). Communities of practice: connecting what we know with what we do. Exceptional Children, 69 (3), 263-277.

Carr, W., \& Kemmis, S. (1988). Becoming critical: Knowing through action research. Waurn Ponds, Victoria: Deakin University Press. 
Carroll, M. (2010). Supervision: Critical reflection for transformational learning (Part 2). The Clinical Supervisor, 29, 1-19.

Clift, R., Houston, W., \& Pugach, M., Eds. (1990). Encouraging reflective practice in education: An analysis of issues and programs. New York: Teachers College Press.

Cochran-Smith, M., \& Zeichner, K.M. (2005). Studying teacher education. Report of the AERA Panel on Research and Teacher Education. Mahwah, NJ: Lawrence Erlbaum.

Cohen, M. \& Engelberg, I. (1989). Focus groups: Procedures and pitfalls. Paper presented at the convention of the Eastern Communication Association, Ocean City, M.D.

Cohen, L. \& Manion, L. (1994). Research methods in education $\left(4^{\text {th }}\right.$ Ed.). London: Routledge.

Cohen, L., Manion, L., \& Morrison, K. (2007). Research methods in education (6 $^{\text {th }}$ Ed.). New York: Routledge.

Danielson, C. (1996). Enhancing professional practice: A framework for teaching. Association for Supervision and Curriculum Development (ASCD), Alexandria, VA.

Daro, P. (1996). Standards and portfolio assessment. In J. Baron \& D. Wolf (Eds.), Performance-based student assessment: Challenges and possibilities (pp. 239- 260). Illinois: The University of Chicago Press. 
Davies, A., \& LeMahieu, P. (2003). Assignment for learning: Reconsidering portfolios and research evidence. In M. Segers, F. Dochy \& E. Cascallar (Eds.), Optimising new modes assessment: in search of qualities and standards. Dordrecht: Kluwer Academic Publishers.

Denzin, N. (1997). Triangulation in educational research. In J. Keeves (Ed.) Educational research, methodology, and measurement: An international handbook ( $2^{\text {nd }}$ Ed., pp. 318-322). Oxford, UK: Pergamon.

Denzin, N. (2009). The research act: A theoretical introduction to sociological methods. Piscataway, NJ: Aldine Transactions Publishers.

Denzin, N.K., \& Lincoln, Y.K. (2000). Handbook of qualitative research $\left(2^{\text {nd }}\right.$ ed.). Thousand Oaks, CA: Sage Publications.

Dewey, J. (1933). How we think. New York: Heath and Co.

Dimova, Y. \& Loughran, J. (2009). Developing a big picture understanding of reflection in pedagogical practice. Reflective Practice, 10 (2), 205-217.

Elliott, J. (1991). Action research for educational change. Buckingham: Open University Press.

Ellsworth, J. (2002). Using student portfolios to increase reflective practice among elementary teachers. Journal of Teacher Education, 53 (4), 342-355.

Ferraro, J. (2000). Reflective practice and professional development. ERIC Clearinghouse on Teaching and Teacher Education Washington DC. 
Flick, U. (1992). Triangulation revisited: Strategy of validation or alternative? Journal for the Theory of Social Behavior, 22 (2), 175-197.

Flick, U. (2009). An introduction to qualitative research. London: Sage Publications.

Flick, U., Kardorff, E., \& Steinke, I. (2004). A companion to qualitative research. London: Sage.

Flores, J. \& Alonso, C. (1995). Using focus groups in educational research: Exploring teachers' perspectives on educational change. Evaluation Review, $19(1), 84-101$.

Fook, J. (2010). Beyond reflective practice: reworking the "critical" in critical reflection. In H. Bradbury, N. Frost, S. Kilminster, M. Zukas (Eds.) Beyond Reflective Practice: New Approaches To Professional Lifelong Learning. UK: Routledge.

Francis, D. (1997). Critical incident analysis: A strategy for developing reflective practice. Teachers and Teaching, 3 (2), 169-88.

Freidus, H. (1998). Mentoring portfolio development. In N. Lyons (Ed.), With portfolio in hand (pp. 51-68). N.Y.: Teachers College Press.

Gall, M., Borg, W., \& Gall, J. (1996). Educational research (6 ${ }^{\text {th }}$ Ed.). White Plains: Longman.

Gore, J. \& Zeichner, K. (1991). Action research and reflective teaching in preservice teacher education: a case study from the United States. Teaching and Teacher Education, 7 (2), 119-136. 
Graves, D. \& Sunstein, B. (1992). Portfolio portraits. Portsmouth: Heinemann Books.

Griffin, P. (1995). Competency assessment: Avoiding the pitfalls of the past. Australian - New Zealand Journal of Vocational Education Research, 3 (2), $34-59$.

Groom, B. \& Maunonen-Eskelinen, I. (2006). The use of portfolios to develop reflective practice in teacher training: a comparative and collaborative approach between two teacher training providers in the UK and Finland. Teaching in Higher Education, 11 (3), 291-300.

Gupta, S., Ecclestone, K., \& Greaves, D. (2001). Portfolio based learning as a tool for insider practitioner research: Developing professional knowledge. Paper presented at the Third International Inter-disciplinary Evidence-based Policies and Indicator Systems Conference.

Hammersley, M. (1992). What's wrong with ethnography: Methodological explorations. London: Routledge.

Hancock, D. \& Algozzine, B. (2006). Doing case study research: A practical guide for beginning researchers. New York: Teachers College Press.

Hargreaves, A. (1994). Changing teachers, changing times: Teachers' work and culture in the postmodern age. London: Cassell.

Hua, V. A. (1998). Truyen thong ton su trong dao (Traditions of revering teachers and scholarship). Vietnam: Nha Xuat Ban Tre. 
Huba, M., \& Freed, J. (2000). Learner-centered assessment on college campuses. Boston: Allyn and Bacon.

Jarvinen, A. \& Kohonen, V. (1995). Promoting professional development in higher education through portfolio assessment. Assessment and Evaluation in Higher Education, 20 (1), 25-37.

Jick, T. (1979), Mixing qualitative and quantitative methods: Triangulation in action. Administrative Science Quarterly, 24 (4), 602-611.

Johnson, B., \& Christensen, L. (2008). Educational research: Quantitative, qualitative, and mixed approaches ( $3^{\text {rd }}$ ed.). Thousand Oaks, CA: Sage Publications.

Jones, E. (2007). A portfolio for assessment of the practice of the special education resource teachers. Unpublished $\mathrm{PhD}$ thesis. Victoria University of Wellington, Wellington.

Jones, E. (2009). Can portfolios promote quality learning? In L.H. Meyer, S. Davidson, H. Anderson, R. Fletcher, P. Johnston \& M. Rees (Eds.), Tertiary Assessment \& Higher Education Student Outcomes: Policy, Practice \& Research. Wellington, New Zealand: Ako Aotearoa.

Jones, E. (2010a). Personal theory and reflection in a professional practice portfolios. Assessment and Evaluation in Higher Education, 35 (6), 699-710.

Jones, E. (2010b). Enhancing professionalism through a professional practice portfolio. Reflective Practice, 11 (5), 593-605. 
Kemmis, S., \& McTaggart, R. (Eds.). (1988). The Action Research Planner (3rd Ed.) Victoria: Deakin University.

Klecka C., Donovan, L., \& Fishee, R. (2007). In their shoes: Teacher educators' reframing portfolio development from the students' perspective. Journal of Computing in Teacher Education, 24 (1), 31-36.

Korthagen, F. (2001). Linking practice and theory: The pedagogy of realistic teacher education. Mahwah, N.J.: Lawrence Erlbaum.

Korthagen, F. \& Vasalos, A. (2005). Levels in reflection: Core reflection as a means to enhance professional development. Teachers and Teaching: Theory and Practice 11(1), 47- 71.

Krause, S. (1996). Portfolios in teacher education: Effects of instruction on preservice teachers' early comprehension of the portfolio process. Journal of Teacher Education, 47 (2), 130- 138.

Kvale, S. (1996). Interviews: An introduction to qualitative research interviewing. Thousand Oaks, Calif:: Sage.

LaBoskey, V. (1993) A conceptual framework for reflection in preservice teacher education. In J. Calderhead \& P. Gates (Eds.), Conceptualizing Reflection in Teacher Development. London: Falmer Press.

Ladbrook, J. \& Middleton, S. (1997). Portfolios: Promoting the role of reflection in the pre-service education of graduate teachers. Paper presented at the NZARE Conference, Auckland. 
Le, D. (2008). Danh gia giang day - Mot nhan to quan trong trong dam bao va nang cao chat luong giao duc dai hoc (Assessing teaching - An important factor in ensuring and improving quality in higher education). Retrieved from http://ussh.edu.vn/danh-gia-giang-day-mot-nhan-to-quan-trong-trong-dambao-va-nang-cao-chat-luong-giao-duc-dai-hoc/711

Lester, S. (1995). Beyond knowledge and competence: towards a framework for professional education. Capability, 1 (3), 44-52.

Loughran, J. (1995). Practising what I preach: Modelling reflective practice to student teachers. Research in Science Education, 25 (4), 431-451.

Loughran, J. (2002). Effective reflective practice: In search of meaning in learning about teaching. Journal of Teacher Education, 53 (1), 33-43.

Loughran, J., \& Corrigan, D. (1995). Teacher portfolios: A strategy for developing learning and teaching in persevere education. Teaching and Teacher Education, 11, 565-577.

Lyons, N. (1998). Portfolios possibilities: Validating a new teacher professionalism. In N. Lyons (Ed.), With Portfolio in Hand (pp. 1-21). New York: Teacher College Press.

May, T. (1997). Social research: Issues, methods and process (2 ${ }^{\text {nd }}$ ed.). Buckingham: Open University Press. 
McIntyre, D. (1993). Theory, theorizing and reflection in initial teacher education. In J. Calderhead \& P. Gates (Eds.), Conceptualizing Reflection in Teacher Development (pp. 1 -9). London: Falmer Press.

Meeus, W., Van Petegem, P., \& Van Looy, L. (2006). Portfolios in higher education: Time for a clarificatory framework. International Journal of Teaching and Learning in Higher Education, 17 (2), 127-135.

Meeus, W., Van Petegem, P., \& Meijer, J. (2008). Portfolios as means of promoting autonomous learning in teacher education: A quasi-experimental study. Educational Research, 50 (4), 361-386.

Meeus, W., Van Petegem, P., \& Engels, N. (2009). Validity and reliability of portfolio assessment in pre-service teacher education. Assessment and Evaluation in Higher Education, 34 (4), 401-413.

Mezirow, J. (1990). Fostering critical reflection in adulthood: A guide to transformative and emancipatory learning. San Francisco, CA: Jossey-Bass.

Mezirow, J. (1991). Transformative dimensions of adult learning. San Fransisco. CA: Jossey-Bass.

Miles, M., \& Huberman, A. (1994). Qualitative data analysis (2nd ed.) Thousand Oaks, CA: Sage.

Mokhtari, K., Yellin, D., Bull, K., \& Mongomery, D. (1996). Portfolio assessment in teacher education: impact or preservice teacher's knowledge and attitudes. Journal of Teacher Education, 47 (4), 245-251. 
Morgan, D. (1988). Focus groups as qualitative research. Sage University Paper series in Qualitative Research Methods 16. Beverly Hills, CA: Sage.

Morrison, M. \& Moir, J. (1998). The role of computer software in the analysis of qualitative data: Efficient clerk, research assistant or Trojan horse? Journal of Advanced Nursing, 28 (1), 106-116.

Nagle, J.F. (2009). Becoming a reflective practitioner in the age of accountability. The Educational Forum, 73, 76-86.

Nguyen, K. D. (2003). International practices in quality assurance for higher education teaching and learning: Prospects and possibilities for Vietnam. The University of Melbourne.

Orland-Barak, L. (2005). Portfolios as evidence of reflective practice: what remains 'untold'. Educational Research, 47 (1), 25-44.

Paulson, F., Paulson, P., \& Meyer, C. (1991). What makes a portfolio a portfolio? Educational Leadership, 48 (5), 60-63.

Pham, T.T.H. (2008). The roles of teachers in implementing educational innovation: The case of implementing cooperative learning in Vietnam. Asian Social Science, 4 (1).

Richards, L. \& Richards, T. (1994). From filing cabinet to computer. In A. Bryman \& R.G. Burgess (Eds.), Analysing Qualitative Data (pp.146-172). London: Routledge. 
Rijdt, C., Tiquet, E., Dochy, F., \& Devolder, M. (2006). Teaching portfolios in higher education and their effects: An explorative study. Teaching and Teacher Education, 22, 1084-1093

Rodgers, C. (2002). Defining reflection: another look at John Dewey and reflective thinking. Teachers College Record, 104 (4), 842 - 866.

Schön, D. (1983). The reflective practitioner: How professionals think in action. New York: Basic Books.

Schön, D. (1987). Educating the reflective practitioner: Toward a new design for teaching and learning in the professions. San Francisco: Jossey-Bass.

Seale, C. F. (1999). The quality of qualitative research. London: Sage.

Seale, C., Gobo, G., Gubrium, J., \& Silverman, D. (2004). Qualitative research practice. London: Sage.

Setteducati, D. (1995). Portfolio self-assessment for teachers: A reflection on the Farmingdale. Journal of Staff Development, 16 (3), 2-5.

Shulman, L. (1998). Teacher portfolios: theoretical activity. In N. Lyons (Ed.), With Portfolio in Hand (pp. 23-49). New York: Teacher College Press.

Sloper, D. \& Le, T. C. (Eds.) (1995). Higher education in Vietnam: Change and response. Singapore: Institute of South East Asian Studies.

Smith, K. (1997). School principals' experiental learning with and about portfolios. Paper presented at the Annual Meeting of the American Educational Research Association, Chicago, 24-28 March. 
Smith, K., \& Tillema, H. (1998). Evaluating portfolio use as a learning tool for professionals. Scandinavian Journal of Educational Research, 42 (2), 193205.

Smith, K., \& Tillema, H. (2001). Long-term influences of portfolios on professional development. Scandinavian Journal of Educational Research, 45 (2), 183203.

Smith, K., \& Tillema, H. (2003). Clarifying different type portfolio use. Assessment and Evaluation in Higher Education, 28 (6), 625-648.

Strijbos, J., Meeus, W., \& Libotton, A. (2007). Portfolio assignments in teacher education: a tool for self-regulating the learning process. International Journal for the Scholarship of Teaching and Learning, 1 (2).

Taylor, I. (1997). Developing learning in professional education: Partnerships for practice. London: Society for Research into Higher Education \& Open University Press.

Thornow, W. (1993) Perception or reality, is multiperspective measurement a means or an end. Human Resource Management, 32, 221-230.

Tillema, H. \& Smith, K. (2000). Learning from portfolios: differential use of feedback in portfolio construction. Studies in Educational Evaluation, 26, 193-210.

Tran, B. X. (2006). Danh gia giang vien - Van de buc thiet trong giai doan hien nay (Assessing lecturers in universities - An urgent issue at present). Tap chi 
Khoa hoc Cong nghe Dai hoc Da Nang (Danang University's Journal of Science and Technology), Vol. 3-4.

Tran, V.T. (2004). Nang cao chat luong giao duc: Khong can nhieu tien (Improving educational quality: not so costly). In the articles series " Chan hung giao duc - Menh lenh tu cuoc song" (Educational reform - The call from life). Tuoi Tre Newspaper, October $23^{\text {rd }}, 2004$.

van Manen, M. (1977). Linking way of knowing with ways of being practical. Curriculum Inquiry, 6 (3), 205-228.

van Manen, M. (1990). Researching lived experience: Human science for an action sensitive pedagogy. Albany, NY: State University of New York Press.

van Manen, M. (1991). The tact of teaching: The meaning of pedagogical thoughtfulness. Albany, NY: State University of New York Press.

Vu, D. B. (2004). Con duong cai cach qua gian kho ... (Educational reform: The long hard road ...) In the articles series “ Chan hung giao duc - Menh lenh tu cuoc song" (Educational reform - The call from life). Tuoi Tre Newspaper, October $26^{\text {th }}, 2004$.

Wade, R., \& Yarbrough, D. (1996). Portfolios: A tool for reflective thinking in teacher education? Teaching and Teacher Education, 12 (1), 63-79.

Walker, D. (1985). Writing and reflection. In Boud D, Keogh R, Walker D. Reflection: Turning Experience Into Learning. New York, NY: Kogan Page/Nichols. 
Webb, E., Cambell, D., Schwartz, R. \& Sechrest, L. (1966). Unobstructive measures: Non-reactive research in the social science. Chicago: Rand McNally.

Wilson, V. (1997). Focus groups: A useful qualitative method for educational research? British Educational Research Journal, 23, (2).

Winsor, P., Butt, R., \& Reeves H. (1999). Portraying professional development in preservice teacher education: Can portfolios do the jobs? Teachers and Teaching: Theory and Practice, 5 (1), 9-31.

Woodward, H. (1998). Reflective journals and portfolios: Learning through assessment. Assessment and Evaluation in Higher Education, 23 (4), 415423.

Woodward, H. (2000). Portfolios: Narratives for learning. Professional Development in Education, 26 (2), 329-349.

Wright, W., Knight, P., \& Pomerleau, N. (1999). Portfolio people: Teaching and learning dossiers and innovation in higher education. Innovative Higher Education, 24 (2), 89-103.

Yin, R.K. (1994). Case study research: Design and methods. Thousand Oaks, CA: Sage Publications.

Yin, R.K. (2003). Case study research (3rd Ed.). London: Sage.

Zeichner, K. (1996). Teachers as reflective practitioners and the democratization of school reform. In K. Zeichner, S. Melnick \& M. Gomx (Eds.), Currents of 
reform in pre-service teacher education ( $1^{\text {st }}$ ed., pp. 199-213). New York: Teachers College Press.

Zeichner, K., \& Wray, S. (2001). The teaching portfolio in US teacher education programs: What we know and what we need to know. Teaching and Teacher Education, 17, 613-621. 


\section{APPENDICES}

\section{Appendix A \\ INFORMATION SHEET (For individual interview) \\ Project title: Perceptions of ongoing influences of compiling a portfolio on teachers' reflection on practice.}

My name is My Binh Nguyen and I am a student at Victoria University of Wellington doing a Master in Education. As part of the requirements of the degree, I am undertaking a thesis on "Perceptions of ongoing influences of compiling a portfolio on teachers' reflection on practice". The main aim of this study is to explore how participants perceive the long-term influences of the portfolio experience on their ongoing reflection. Semi-structured interviews and a focus group will be used in this research. This research has been assessed and approved by Victoria University Faculty of Education Ethics Committee.

I would like to invite you to take part in an individual interview of about one to one and half hours and with your permission, I would like to record the interview. This interview is designed to collect information on: participants' perception of their own reflection during the portfolio experience; aspects of reflection on practice that were stimulated by the portfolio process and have continued after the portfolio experience ended; and the way in which these aspects have been maintained after the portfolio experience ended.

Participation in this project is voluntary. The collected data will be used to write a final thesis. I would like your permission to use the information which you provide in my thesis and/or any other publications that arise from this research. At no time when reporting on the findings of this study will your identity be disclosed. All the information will be kept at a secure location, and will be only available to my supervisor, Dr. Liz Jones, and myself. Participants have the option to review interview transcripts. All interview transcripts will be stored securely and destroyed two years after the completion of the thesis. The final thesis will be deposited in the University Library and a conference paper and journal article may be published using the data.

I can provide you with a summary of my research findings at your request. Please indicate your preference in the consent form.

You can withdraw at any stage before the process of analyzing collected data starts. I will inform you when this process is about to begin.

If you have any questions or would like to receive further information about this study, please do not hesitate to contact me via email: my.nguyen@vuw.ac.nz or my supervisor, Dr. Liz Jones at liz.jones@vuw.ac.nz, or by mail at School of Educational Psychology and Pedagogy, Faculty of Education, Victoria University of Wellington, PO Box 17 - 310, Karori, Wellington 6147. In case you would like to make a complaint, please contact the Chair of Victoria University Human Ethics Committee, Dr. Allison Kirkman at allison.kirkman@vuw.ac.nz or phone 04 4635676.

My Binh Nguyen 


\section{Appendix B}

\section{INFORMATION SHEET (For the focus group) \\ Project title: Perceptions of ongoing influences of compiling a portfolio on teachers' reflection on practice.}

My name is My Binh Nguyen and I am a student at Victoria University of Wellington doing a Master in Education. As part of the requirements of the degree, I am undertaking a thesis on "Perceptions of ongoing influences of compiling a portfolio on teachers' reflection on practice". The main aim of this study is to explore how participants perceive the long-term influences of the portfolio experience on their ongoing reflection. Semi-structured interviews and a focus group will be used in this research. This research has been assessed and approved by Victoria University Faculty of Education Ethics Committee.

I would like to invite you to take part in a focus group that is going to be around one to one and half hours and with your permission I would like to record the session. This focus group is designed to collect information on: participants' perception of their own reflection during the portfolio experience; aspects of reflection on practice that were stimulated by the portfolio process and have continued after the portfolio experience ended; and the way in which these aspects have been maintained after the portfolio experience ended.

Participation in this project is voluntary. The collected data will be used to write a final thesis. I would like your permission to use the information which you provide in my thesis and/or any other publications that arise from this research. At no time when reporting on the findings of this study will your identity be disclosed. All the information will be kept at a secure location, and will be only available to my supervisor, Dr. Liz Jones, and myself. Participants are able to review the focus group's summaries and conclusions at the end of the meeting. All the field notes obtained will be stored securely and destroyed two years after the completion of the thesis. The final thesis will be deposited in the University Library and a conference paper and journal article may be published using the data.

I can provide you with a summary of my research findings at your request. Please indicate your preference in the consent form.

You can withdraw at any stage before the process of analyzing collected data starts. I will inform you when this process is about to begin.

If you have any questions or would like to receive further information about this study, please do not hesitate to contact me via email: mybinh.nguyen@vuw.ac.nz or my supervisor, Dr. Liz Jones at liz.jones@vuw.ac.nz, or by mail at School of Educational Psychology and Pedagogy, Faculty of Education, Victoria University of Wellington, PO Box 17 - 310, Karori, Wellington 6147. In case you would like to make a complaint, please contact the Chair of Victoria University Human Ethics Committee, Dr. Allison Kirkman at allison.kirkman@vuw.ac.nz or phone 04 4635676.

My Binh Nguyen 


\section{Appendix C}

\section{CONSENT TO PARTICIPATION IN RESEARCH (For individual interview)}

Project title: Perceptions of ongoing influences of compiling a portfolio on teachers' reflection on practice

Please tick the boxes if you agree with the following statements:

I have been provided with adequate information relating to the nature and objectives of this research project. I have understood that information and have been given the opportunity to seek further clarification or explanations.

$\square \quad$ I understand that I may withdraw from this study at any time before the process of data analyzing starts without providing reasons, in which case all the information that I have provided will be destroyed.

$\square \quad$ I understand that any information I provide will be kept at a secure location, and will only be available to the researcher and the supervisor. I give permission for the information which I provide to be used in a thesis or any other publications that arise from this research.

$\square \quad$ I allow this interview to be recorded.

$\square \quad$ I agree to take part in this research.

$\square \quad$ I decline to take part in this research.

Please indicate your preferences for the following statements by circling one of the options:

- I would/would not (circle one) like to review the interview transcript and agree to any amendments being returned to the researcher within 2 weeks of receipt.

- I I would/would not (circle one) like to receive a summary of the results of this project when it is completed and therefore I will provide my mailing or e-mail address.

Name:

Mailing or E-mail Address:

Signature:

Date: 


\section{Appendix D \\ CONSENT TO PARTICIPATION IN RESEARCH (For the focus group) \\ Project title: Perceptions of ongoing influences of compiling a portfolio on teachers' reflection on practice}

\section{Please tick the boxes if you agree with the following statements:}

$\square \quad$ I have been provided with adequate information relating to the nature and objectives of this research project. I have understood that information and have been given the opportunity to seek further clarification or explanations.

$\square \quad$ I understand that I may withdraw from this study at any time before the process of data analyzing starts without providing reasons, in which case all the information that I have provided will be destroyed.

$\square \quad$ I understand that any information I provide will be kept at a secure location, and will only be available to the researcher and the supervisor. I give permission for information which I provide to be used in a thesis or any other publications that arise from this research.

$\square \quad$ I allow this focus group session to be recorded.

$\square \quad$ I agree to take part in this research.

$\square \quad$ I decline to take part in this research.

Please indicate your preference for the following statement by circling one of the options:

I would/would not (circle one) like to receive a summary of the results of this project when it is completed and therefore I will provide my mailing or email address.

Name:

Mailing or E-mail Address:

Signature:

Date: 


\section{Appendix E \\ FOCUS GROUP INTERVIEW}

NAME:

Thank you very much for giving me your time today! The purpose of this meeting is to hear from you about how you perceive the ongoing influences of compiling a portfolio on your reflection on practice. I hope you will feel free to be quite frank. I have five questions I would like you to discuss in this session. Before we begin, I would like you to take five minutes to look at the questions and record your immediate response. I would like to collect these sheets in at the end of the session. Please remember that you should feel under no pressure to share with me or others anything with which you are not completely comfortable.

1. What does the term "reflective practitioner" mean to you?

2. Tell me about how you reflected when you were compiling your portfolio?

3. What aspects of reflection on practice that were stimulated by the portfolio process have continued after the portfolio experience ended? 
4. How have these aspects been maintained after the portfolio experience ended?

5. In light of this discussion, what further comments would you like to make about the portfolio process?

Thank you very much for helping me with my research.

Best wishes,

My Binh Nguyen 


\section{Appendix F}

\section{INTERVIEW GUIDE}

Project title: Perceptions of ongoing influences of compiling a portfolio on teachers' reflection on practice.

The following questions are used as a guide of the interviews. Based on the elaboration of the interviewees, further discussion may be raised. The order of the questions is flexible.

1. What does the term "reflective practitioner" means to you?

2. Tell me how you reflected when you were compiling your portfolio? If possible, please use examples from your portfolio to illustrate.

3. What aspects of reflection on practice that were stimulated by the portfolio process have continued after the portfolio experience ended?

4. How have these aspects been maintained after the portfolio experience ended?

5. In light of this discussion, what further comments would you like to make about the portfolio process?

Thank you for your participation in this study! 